HORSES

AND ROADS

BY "FREE LANCE"

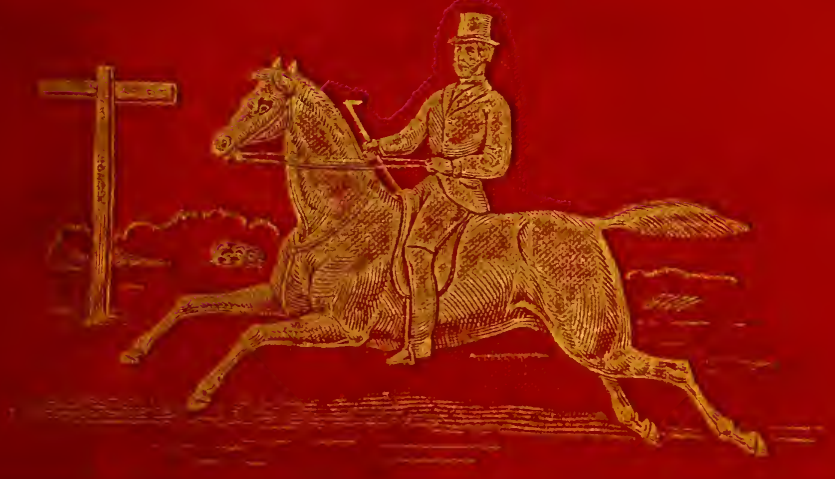




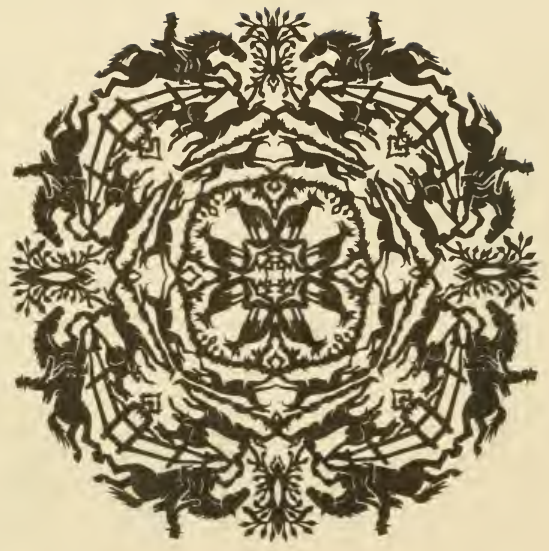

JOHN A.SEAVERNS 
10 


\section{HORSES AND ROADS}

Webster Family Library of Veterinary Medicine Cummings School of Veterinary Medicine at

Tutts University

200 Westouro Road

Norin Grafton, MA 01536 
'The most humane of modern horse-owners is an ignorant tyrant to his graceful bondservant '-MAYHEW

'The history of almost every horse in this kingdom is a struggle to exist, against human endeavours to deprive it of utility'-MAYHEW

'The eye soon gets accustomed to deformity, and then does not perceive it '- BRACY ClARK

'Certainly he who prevents does more than he who cures'-Philip AstLey

'No foot, no horse'- Old Saying 


\section{HORSES AND ROADS}

OR

HOW TO KEEP A HORSE SOUND ON HIS LEGS

BY

FREE-LANCE

BEING A SERIES OF PAPERS REPUBLISHED FROM

'THE FARM JOURYAL'

\section{LONDON}

L O N G A N S, GREEN, A N D C O. 1880 
LONDOS : PRINTED BY STOTTISWOODE AND CO., NEW-STREET SQCARE AND PARLIAMEXT STREET 


\section{PREFACE.}

I'T is a generally acknowledged fact that large numbers of horses are worn out in the feet and legs at a premature age, whilst nearly all are frequently laid off work by lameness; and these two misfortunes for the poor animals appear to be accepted as unavoidable for them. To combat this belief, these papers were written. On their first appearance they excited a certain amount of interest, and several gentlemen put to practical experiment the principles advanced. The results obtained by three of them are given, by their kind permission, in the Appendix.

It is not attempted to palm off any patent upon the public, as the author has nothing to sell, and can be neither benefited nor prejudiced in any way by the adoption or rejection of his principles. He has written from disinterested motives; and he has been rewarded, before the book is published by the knowledge that many horses are already reaping benefit from his efforts in their favour.

London: August 30, 1880. 



\section{CONTENTS.}

CHAPTER I.

Springs and Brakes to Vehicles . . . . . 1

\section{CHAPTER II.}

Douglas on Horse-shoeing-Street Accidents and Brakes —Lord Pembroke and Mayhew on Servants . . 10

\section{CHAPTER III.}

Nostrums-Arsenic and Antimony-Hoof-ointments-

'Stoppings' . . . . . . . .

\section{CHAPTER IV.}

Litter-Xenophon and Lord Pembroke on Bare Paving for Stalls-Physicking and Blistering-the Bearing Rein . . . . . . . . .

\section{CHAPTER V.}

Shoeing-Lord Pembroke on Servants-Lupton on Farriers-Fitting the Foot to the Shoe-Calks-Injurious Effects of fitting Shoes by burning them on -Douglas on Cold Fitting-Shoeing in SpainBrushing . . . . . . . . 
CHAPTER VI.

Youatt on the Weight of Shoes-American Trotting Horse 'St. Julien'-'An Ounce at the Heel tells more than a Pound on the Back'-Lunette Shoe or Tip of Lafosse-Douglas on the Structure of the Crust-Miles on Expansion and Contraction . .

\section{CHAPTER VII.}

Expansion entirely prevented by present Mode of Shoeing, but favoured by 'Tips'-Mayhew and Professor. Percival on 'Tips'-'It is the Shoe, not the Road, that hurts the Horse '- 'Impecuniosus' says there is too much sameness about all existing Writings on the Horse's Foot, and 'Original' Ideas are wanted .

\section{CHAPTER VIII.}

The 'Charlier' Shoe-'Impecuniosus' and 'Kangaroo' on the Charlier System - Sole Pressure - India Rubber Cushions and Pads-Pumice Foot-St. Bell on 'Imitation of Nature' in Shoeing-Nayhew, 'Nature is a strict Economist'-Douglas on the short average Life of our Horses-'One Horse could wear out four pairs of Feet'-Philip Astley, 'He who prevents does more than he who cures' -The Charlier 'Short' Shoe, and the Charlier 'Tip' - Stanley says Navicular Disease is impossible with the Charlier System-Experience of Messrs. Smither with Charlier Shoes-American Experience of Charlier 'Tips'-'Four inches of Iron curled round the Toe' 
Description of Frog and Sole, by Douglas-Russell on Hot Fitting, and 'Clips' on Shoes-Facility of 'Backing' when a Horse stands upon his feet-Strength of the Horse's Toe-Excessive Growth of Horn on Toes of Unshod Donkeys in Ireland-All Shoeing only an Affair of Routine, and is quite unnecessary Mayhew, "Veterinary Surgeons cling to the Practices in which they have been educated'-Retreat of Napoleon from Moscow with Unshod Horses . .

\section{CHAPTER X.}

Unshod Horses in the Indian Mutiny-Unshod Horses in the Zulu War-Farriers in the Army are Tailors, etc. - 'Daily Telegraph' on Frozen Streets-Comparative Inutility of Cogs and Studs-Unshod Horses in Mexico, etc., and their remarkable Freedom from Lameness and Diseases of the Feet and Legs . .

\section{CHAPTER XI.}

Brittle Hoof and the Treatment it gets-The 'Watercure' more effective-Brittle Hoof often leads to Sandcrack, Seedy Toe, and Pumice Foot-Hard Roads are favourable to the Unshod Hoof . .

\section{CHAPTER XII.}

Letter of 'Aberlorna' in 'Farm Journal -Lieut.-Col. Burdett on Hot Shoeing, Greasing, 'Stopping,' and Paring the Hoof-Cold Shoeing-North Metropolitan Tramway Horses are shod cold with the Seeley Shoe -Gradual Breaking in of Horses to go unshodDifferent Characteristics of Countries where Horses are bred-Ancient Writers on bare Stone and Wood for Stalls-Osmer has known Unshod Horses go Sound in England-'Our moist Climate and hard Roads'-Mayhew and Douglas on Opposers of Progress . 


\section{CHAPTER XIII.}

'Aberlorna's' Second Letter in 'Farm Journal'-His second IIorse shod with Tips-Putting on TipsHis Experience in South America of the Exuberance of Growth of Horn and its Toughness, in Unshod Horses - Shod Horses go lame over good roads, whilst the unshod ones go sound over those of the very worst description-Ignorance of People in England of the Nature of a Horse's Foot-'The Lancet' on the Indefensibility, in a Physiological Light, of the Use of Horseshoes-Success of two Gentlemen in working unshod Horses in England-Newspaper Complaints, about the Slipping of Horses, and Stoppage of Traffic on Ludgate Hill-The false Light in which Slipping is looked at . . . .

\section{CHAPTER XIV.}

Ludgate IIill only rises about four feet in every hundred-Societies-The Bearing Rein only required on Cripples .

\section{CHAPTER XV.}

Brittle IIoof-Ignorance of Farriers-'Impecuniosus' says the existing Ideas on the Horse's Foot have sprung from wrong roots altogether-Fearnley says 'The Charlier is the most Common-sense Shoe ever invented'.

\section{CHAPTER XVI.}

Custom of H. Jennings of training Racehorses unshod, and running them in their Races with Tips on their Fore Feet, with the Hind Feet bare-'Evening Standard,' instance of impaired Sight in a Young Lady from wearing high Heels on her Boots - 
Many Diseases of Horses may be attributable to Illtreatment of their Feet-Caries of the Teeth is known to affect a Horse's Action-Veterinary Dentists in America-Crib-biters, Wind-suckers, and WeaversLetter of a Cavalry Officer in 'Daily Telegraph'His farourable Experience of Tips and Unshod IIorses

\section{CILAPTER IVII.}

The Hunter considered-Experience of 'Impecuniosus' with Tips on Hunters-Miles on Cnilateral NaiingCol. Anstruther Thompson's Experience with Guttapercha Soles - Natural Transpiration continually going on in the Horse's Foot . . . . .

\section{CHAPTER IVIII.}

The Lady's Horse-Nust not be exposed to StumblingLight Tips will wear as long as heary Shoes-Horses as Hacks for Elderly Gentlemen-Park HacksCarriage Horses-Abnormal Action and graceful Action-Concussion through the Iron Shoe-Bearing Rein for 'Screws'-It 'pulls them together'Cruelty thereof-'Docking' a IIorse's Tail is Vivisection-'Cutting' caused by Shoeing-Cruel Mode of Cure at present emplojed-Coachmen . . .

\section{CHAPTER XIX.}

The 'Ride and Drive' Horse-Omnibus, Van, Tramway, and Cab Horses-Tramway Mules-Mr. Fearnley on Calks-Unscientific Shoeing of Mules-Mr. Fearnley on the Charlier Shoe-Bracy Clark-Nayhew on the various kinds of Shoes 
Question in the 'Field' as to an unshod Horse working in London - No Roads too hard for an unshod Horse-Xenophon on hard, rough Stable Floors, etc. -Erroneous Idea of 'something nice and soft' to stand upon-Flint Roads of Hertfordshire-' You cannot treat an organic body as if it were an inorganic one'-Bracy Clark, 'the miserable, coerced, shod Foot'-Bracy Clark on Difference of Growth of Horn in the shod and the unshod Horse - Failure of Bracy Clark and Niles to produce a perfect Horseshoe .

\section{CHAPTER XXI.}

Asphalte Paving, and different Opinions concerning it -Dissatisfaction that reigns with regard to the ordinary Method of Shoeing - Transmission by Parents, of Diseases produced by Shoeing-French Statistics as to Diseases of the Feet and Legs of the Horses in the Army-Shoeing, a National Question .

A PPENDices . . . . . . . . 210-224

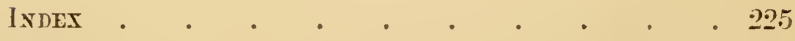




\title{
HORSES AND ROADS;
} or,

\section{HOW TO KEEP A HORSE SOUND ON HIS LEGS.}

\author{
CHAPTER I. \\ SPRINGS AND BRAKES TO VEHICLES.
}

IN the crisis through which agriculturists are at present passing, economical improvements of all kinds are being sought after. Much has been written about the horse; but the field he affords for writing is so extensive and fertile, that much still remains to be said; indeed, he will afford a theme for a very long time to come, to say the least.

To begin with, let us consider the vehicles he is often obliged to draw. Mayhew, an eminent veterinary surgeon, formerly demonstrator at the Royal Veterinary College, states, in one of the various works he has written upon the horse, that ' it is a disgrace to the intelligence of the present age that any cart should be built without springs; the real question being whether living 
thews and sinews should endure the burden, or whether this shall be imposed upon inanimate metal? Reducing the matter to $£ s$. $d$., which is cheaper? Fact pronounces "iron" to be the answer.' Thus much for springs, upon which nothing more is necessary than to give full and hearty assent to Mayhew's opinion.

But there is another subject connected with carts, waggons, and all other vehicles upon which Mayhew has not touched, but which may be here introduced. Those who have been on the Continent may (or may not, according to the use they made of their eyes) have remarked that all vehicles, whether two-wheeled or four-wheeled, are fitted with brakes, which not only serve for down-hill work, but are also applied when horses run away, or when they are left to stand. It will be said that our four-wheeled heavy waggons are fitted with a chain, or a skid. Granted; but these cannot be put to various uses with the same celerity and utility that a proper brake can; in fact, in the case of runaway horses, they are of no use at all. Even in the other cases they are far behind the brake, as they necessitate a stoppage of the team to apply them, and another to remove them. They mostly stop only one wheel; which wheel, in the case of the chain, is exposed to injury by having the tire worn into facets at the corresponding distances from whatever spoke the chain may be put against, while the spoke sometimes breaks; the violent jerk thrown on the next spoke carrying away that one also, as well as 
those that come after, and so on, until the axletree comes down on the ground and is either broken or bent, the shaft horses being generally injured, and sometimes the driver also.

The brakes used on the Continent are always applied to both wheels on the same axle, and they are not screwed up tight enough to effect an entire stoppage of the wheels, as it is found that wheels with smooth tires skidding on a smooth road do not break momentum as much as when the wheel is almost stopped, and biting, by friction, the blocks of the breaks. These brakes vary in form. For horses driven from a box or dickey they are generally worked by means of a screw with a cranked handle, sometimes by a lever and a toothed rack; and for such vehicles as are driven by carters that walk alongside their teams, or even a single horse, they are most commonly a lever which has a ring at the top, to which is attached a rope, the other end of which passes through another ring in the shaft, enabling the driver to pull down the lever. He then makes a fast knot, but a slip one, which he can easily pull loose, and thus throw off the action of the brake without stopping his horses to either put it 'off' or 'on.' As being safer, the lever is sometimes placed behind the vehicle. Two-wheeled vehicles, with half a dozen horses, with one of these horses only in the shafts, are thus safely used.

A horse should not have to work when going down hill; but, on the contrary, it should be so managed for him that at every descent, however gentle, 
he should have some respite from work, as a sort of set-off against the hard labour he endures when drawing a load up hill. There are very many reasons for this besides this most apparent one. Even with our four-wheeled heavy trucks and waggons, the chain or skid is not always put on for every slight descent, as the brake is on the Continent. The approaches to London Bridge, for instance, are bad-in certain weathers especially sobut frequently skids are not applied on account of the necessity for stopping to put them on and offwhich stoppage the traffic does not always admit of - and so the poor horses pay in a direct way, and their careless masters in rather a more indirect one. Unfortunately they only pay out of their pockets, whilst the horse pays with his frame.

It is astonishing that the railway companies, above all others, being such large horse owners as they are, have not paid attention to brakes on their street vans, because, as they employ the best mechanical skill attainable for their other rolling stock, they might have easily appointed an engineer to see what he could do for their horse trucks; but it looks as if no engineer ever went near the horses or trucks, or even noticed them in the streets, where mechanical skill ought to see that there was room for improvement. It appears as if this branch were left entirely to the surveillance of ignorant, prejudiced drivers, horsekeepers, and farriers, who have no emulation, but are quite satisfied to go on like their predecessors. It must be understood that 
railway companies are only cited because they have actually in their employ the men who could see this at a glance, if their attention were directed to it, and almost as soon remedy the evil. But no-they continue in the same old groove, and squander thousands yearly upon horseflesh, at the same time that they are also cruelly working a noble animal, by many considered the most noble and useful ever designed by Nature for man's use.

Besides the mere hard work taken out of horses in holding back a load, it must be apparent to those who know anything about the animals, that they also suffer severely from many diseases brought on thereby. Either slipping and shaking over slippery pavements, or knuckling over on roads which do not allow them to slide, causes a great strain and vibration on the nails with which their shoes are attached, and from them to the hoofs in which the nails are imbedded, thence to the bones and cartilages enclosed in the hoofs, and so on up to the hock and knee, at the very least, besides causing severe strain on all tendons and their sheaths. Hence they are found to be suffering from a great variety of diseases in one, many, or all of these parts, in a short time after they have been first harnessed; let us say in the shape of corns, thrush, quittor, cutting, sandcracks, ring-bone, greasy heels, seedy toe, drop-sole, or pumiced feet, ossified cartilages, which are sometimes called side-bones, splints, spavins, navicular disease, \&c. Horses are often to be seen with a pad confined by a leather strap, or else tarred string, 
applied to keep their hoofs together, and yet they work them, and no one interferes. They manage to steer clear of the law, of which it has been said that ' a coach and four may be driven safely through any Act.' These diseases are the result of reckless treatment, which is very unprofitable to horse owners, let alone the cruelty.

It is pretty well known-or, if it is not, it should be-that any of these diseases, once set up, are extremely difficult to cure; but, on the contrary, mostly go on increasing under the care of ignorant farriers. If an intelligent veterinary should be called in, he will mostly advise a long rest and mild remedies; but this means loss of work, although it means also a prolongation of the useful life of the horse, if the warning be taken on the first appearance of disease. In general, however, violent remedies, such as blistering, \&c., are resorted to, and as soon as possible the horse is put to work again, without having had even the benefit of a rest; for a horse with a blister on cannot be expected to enjoy as a rest the few days he is suffering with a blister.

Railway companies are not referred to in this case, or in any future ones. They were mentioned only as being a power in the land, with a special facility for applying mechanical means to reduce the work of their horses, which are spread over the whole of the kingdom. Improvements on their part would therefore be more extended, general, and useful, than even those adopted by brewers or distillers, who, having, as a rule, no dividends to pay, perhaps work 
their horses under the mark; and they are not losers by that, as their animals last them longer. Still, no one takes this into account; and they are by many considered prodigal in horseflesh. Most likely they know to the contrary; still they may do even better by breaking their trucks down every descent.

Brakes cost infinitely less than forced losses in the shape of rests, and still more in the shape of new acquisitions of horseflesh. It is within the bounds of possibility that the men connected with the care of such horses might be brought to acknowledge that they were none the worse for the brakes; but, ignorant and bigoted as they generally are, it might be difficult to extract from any but an exceptionally intelligent and observing man that they thought much of the change. They know all about horses-in their own opinion. Of course, they should not be led to believe that all existing diseases can thus be entirely cured, especially if in at all an advanced stage. They should, if reasonable, be satisfied on seeing them arrested in the case of old horses, and on having it pointed out to them that young horses were free from them for a longer time, and in a less degree, than formerly under the old system; and they may be brought to confess that the horses generally ' did better,' to use a phrase very common amongst this class of men.

But agriculturists extensively use two-wheeled carts without any means of breaking them down hill; 
and hills in the country roads are constantly to be met with both longer and steeper than those to be found in London, although not always so slippery. In these cases their horses suffer, at least, as much deterioration as any of those hitherto mentioned. They load the carts heavily, as they try to work near, and so make their horses 'earn their living,' as they really should do in their case, which is at present a hard one; but they should consider thoughtfully whether it is profitable to make a horse work hard when going down hill, and so injuring him really more than in drawing a load up hill.

The foregoing remarks have been made to lead up to such cases, although it is open to any other parties to profit by them if they choose. It has been said that 'the work which kills one horse will bring in money enough to buy another;' but this is a great fallacy-in fact, an immense mistake, as it is generally interpreted. Besides, it is evident that no horse can possibly pull over a certain weight up a certain ascent; yet often a single shaft horse is expected, and obliged, to do his best to keep back, without mechanical help, the same weight which has required two, or often three, horses to drag it up the same incline in a two-wheeled cart. Is this rational, or even economical, when well considered? There is another saying, common among horsemen, that ' one horse can wear out four pairs of legs ;' but it is also rational to believe that Nature gave the horse the same requisite number of legs 
that she gave to all other creatures designed for the use of man. It is not in their lawful use that they become so soon worn out, but in the abuse that is made of them.

If Mayhew used such forcible language about springs, it may, with at least equal justice, be said that it is a disgrace to the intelligence of the present age that any vehicle whatever, from the heaviest waggon down to the pony basket of the farmer's daughter, should be built without a brake; the real question being whether living thews and sinews should endure the burthen, or whether this should be imposed upon inanimate metal and wood. Reducing the matter to $£ s$. $d$., which is the cheaper? 


\section{CHAPTER II.}

DOUGLAS ON HORSE-SHOEING-STREET ACCIDENTS AND BRAKESLORD PEMBROKE AND MAYHEW ON SERVANTS.

A veterinary surgeon, Mr. W. Douglas, late 10th Royal Hussars, was so much impressed by the miseries, diseases, and dangers caused to horses by their being pushed down hill by their loads, that it caused him to write a book upon 'Horse-shoeing.' Here is part of his preface:-

- Passing down Ludgate Hill one day [this was whilst it was paved with stone] my attention was directed to the pitiful condition of a horse in the shafts of a large waggon. The poor animal was not drawing the load, but was being driven down the descent by the crushing weight behind; and, utterly unable, from the manner in which it was shod, to withstand the pressure, it had gathered its hind legs well under, and its fore legs well in advance of its body, in a helpless struggle to avert the fall which it too evidently knew was at hand. Never did I witness such a picture of powerless terror as that horse presented, as with eyes starting, body shaking, and limbs stiffened, it was carried down- 
wards against its will, until the fore and hind feet slipping in the same direction, it came down upon its left side with a crash. The thought of what agony that poor beast must have suffered, even before it fell, has haunted me ever since, and knowing if the horse had been able to use the supple elastic cushion nature has provided its feet with to prevent their slipping-namely, the frog-it could easily have controlled the pressure from behind, I resolved if possible to direct public attention to the present cruel and unwarrantable system of shoeing horses.'

His book is full of valuable remarks on the horse's foot and on the evils of shoeing as commonly practised; but he missed the mark in failing to recognise (even supposing that the shoe he proposes might not admit of so much slipping) that the horse would still injure his feet and legs by the immense strain put on them in his violent exertions to hold back the waggon-a work that should be done for him. Perhaps he was not acquainted with the brake, and was labouring under the delusion that all that mechanical skill could effect towards the breaking of momentum by friction had been done by making one wheel skid. Mayhew, in the chapter which he dedicates to 'strain of the flexor tendon,' says that 'this is chiefly present in the shaft horse that has to descend a steep declivity, with a load behind it. The weight would roll down the descent; this the horse has to prevent, and the chief stress is then upon the back tendons.' Elsewhere he states 
that 'the frame of the horse is stronger than machinery; but it cannot resist the wilfulness of human misrule.' Yet, strangely enough, this gentleman, energetically as he speaks, has also failed to seek in mechanics a means of saving the shaft horse excessive and superfluous labour when going down hill, whether over slippery paving, or over rough country roads.

Amongst the societies which we rejoice to possess in England, there is one to prevent dangerous driving. How many of those who form this society have this sensible appendage to any of their own carriages, even those to which they daily trust their own necks? Accidents are not always the faults of drivers. About a year and a half ago, a brougham horse took fright at the engine whistle, and bolted down Ludgate Hill at a gallop. The weather was dry, and the hill not slippery. The coachman suceeeded in turning into Farringdon Street (although it looked as if that was the way the horse wanted to go); yet, up the street, it ran into another carriage, and both were wrecked, and both horses very much hurt. Fortunately, no person was seriously injured on the occasion; but the pecuniary damage was great. If the coachman had had, close to his right hand, the handle of a brake which he could have instantly applied firmly to both wheels, he could have diminished the speed from the outset, and have stopped entirely before he came to the spot where the collision occurred; or, at least, he might have brought the speed down sufficiently to enable himself and the 
other driver between them to avoid it. It was not the slippery shoes (objectionable as they undoubtedly are) that did the harm in this case; but the want of a controlling power more efficient than the man's arms, which only control the mouth of the horse under any circumstances; and, even then, only as long as the horse chooses to submit, or is able to do so. A man cannot 'pull a horse up' with the reins used as a mechanical power, any more than he can get into a basket and raise himself from the ground by lifting at the handles, as the principle is the same; but resistance thrown against the collar will soon tell upon the horse's speed, and the means of throwing it there by the application of friction to both hind wheels (just short of making them 'slicd") would do away with a great deal of the present losses of life, and deterioration of valuable property, put down to ' dangerous driving.'

Conservatism is proverbially strong amongst horse owners, and still more so with grooms and others that surround the horse. In the last century, Lawrence wrote:-'There are some toils to which even the rich must submit. True knowledge is not to be acquired, or the acquisition to be enjoyed, by deputy; and, if gentlemen and large proprietors of horses are desirous to avoid the diffculties, dangers, and cruelties perpetually resulting from prejudice, ignorance, and knavery combined, they must embrace the resolution of making themselves so far master of the subject as to be able to direct those whom they employ.' 
The Earl of Pembroke held very similar sentiments. Mayhew, one of our most modern authorities, says :- 'Of all persons living, grooms generally are the worst informed : here is the curse of horses. No other servant possesses such power, and no domestic more abuses his position. It is impossible to amend the regulation of any modern stable without removing some of this calling, or overthrowing some of the abuses, with a perpetuation of which the stable servant is directly involved.' But, of the master, he says:- 'The most humane of modern proprietors is an ignorant tyrant to his graceful bondservant;' to this he might truthfully have added that the most intelligent amongst masters was but a narrowminded bigot. Tel maître tel valet. Betwixt these two classes stands the helpless horse! - not to mention their natural chosen ally, the farrier.

It is not meant to imply that farmers are guilty of overloading or overworking their horses, in the general acceptation of these terms; but that they neglect taking precautions which would enable the horse to do at least the same amount of work, with comfort to himself, greater freedom from disease, prolongation of life, and economy all round for his owner, besides removing from the latter very frequent anxieties resulting from mismanagement of the animal. The advice or opinion of servants should, therefore, not be asked for. They will immediately object to the brake and all other economical improvements: it is upon principle that they object to everything new. The way to begin all economies, 
therefore, is for owners to escape from the thraldom in which their servants, at present, hold them. Their fetters are self-imposed, and they carry about with them, at all hours, the key to enable them to cast them off; apathy, only, prevents them from doing so. Any man, with determination, could walk into his stable free of them for ever, whenever he chose, and at a moment's notice. It is humiliating for an educated owner to admit tacitly that such a low class should be his superior, which he is really doing when he asks, or acts upon, their advice; or, which comes to the same thing, when he leaves them to do as they like.

At this point, nine out of every ten readers will throw down the paper, remarking that all this may be true as regards their neighbours; but, as to their own 'man,' he does understand horses, and keeps them going without any bother. This is the great mistake. Is it rational to suppose or infer that sweeping dung out of a stable is conducive to the acquirement of even a rudimentary knowledge of anatomy and physiology? Mayhew passed a long career as a veterinary surgeon in continually passing from the stables of one proprietor to those of others; and yet he is unable to cite a redeeming instance of a servant. He appears to have felt this, as he says that he 'deeply regrets those comments which a regard for correctness has compelled him to offer upon the present race of grooms. He can, however, with sincerity deny that the indulgence of . dislike, or the gratification of malice, has induced 
him to travel beyond the limits of his subject.' So, upon his authority, supported by that of so many others, right away back to the last century, every one is safe in coming to the conclusion that his 'man' knows nothing about horses, and that it is high time that he should take the thing into his own hands; for, unless he does so, the prevention of mismanagement is impossible. If he lack confidence in his own knowledge of the animal, which in any case should not be less than that of a carter or horsekeeper, let him read. The subject is replete with interest and entertainment; but he should choose modern works if he wishes to march with the age. 


\section{CHAPTER III.}

\section{NOSTRUMS-ARSENIC AND ANTIMONY-HOOF-OINTMENTS- \\ 'STOPPINGS.'}

IT is well known that all stablemen keep by them 'nostrums' and 'receipts' of their own. First amongst these are generally to be found arsenic and antimony-two active poisons-but they are great favourites with the men; they administer them in secret. These drugs are cheap, and they can afford (or will afford) to buy and pay for them themselves. It is true that occasionally they administer an overdose all round, generally on a Saturday night, and the next morning a stableful of dead horses is found; post-mortems are held, and the poison is discovered, and the horsekeeper finds himself before a magistrate. He sometimes gets imprisonment, it is also true; but this neither brings compensation to the owner, nor seems to act as a warning to others, for cases of drugging are constantly recurring at intervals. But, even if he does not kill the horses at a single dose, he is doing so by degrees. These very active remedies are but seldom employed even by veterinaries, and then only in extreme cases, and in small doses. Nitre is also cheap, and is 
secretly administered to an alarming extent-not sufficiently to kill the horses right off, but sufficiently to undermine their constitutions.

If veterinary authorities should be read, the following dicta will be found having reference to the foregoing remarks:-'Acute gastritis: cause poison;' ' inflamed bladder: cause-abuse of medicine ;' ' diabetes : cause-diuretic drugs ;' ' inflamed kidneys : cause - nitre.' The innocent (?) and phlegmatic owners either are ignorant that their men are making use of these agents, or else indolently satisfy themselves by remarking that their ' man' understands horses very well and that ' if he does not bring them round, no one else can;' until things get serious and the vet. has to be called in. When this gentleman is sent for, he has generally a serious case to deal with, and one that usually lasts a long time, and, consequently, entails a severe loss.

Besides this, many owners knowingly allow their men to order powerful medicines in the shape of ' balls' called ' physic,' 'condition,' ' diuretic,' \&c., and allow their men to give them to the horses, having, at the same time, very little or no control as to when or why they should be given. Now these cost more than arsenic, \&c., and could be more easily accounted for, because the men rarely go so far as to lay out their own money on them, and the owner thinks some medicine must be necessary in a stable; yet even then he is generally guilty of allowing or even asking his man an unmerited 
opinion as to its use, besides being in the dark as to what drugs, secretly given by the said man before, may have caused the disease, which, however, will be attributed to anything but his own act.

There are yet other 'remedies' kept by all stablemen. They are used more openly, and are even highly approved of by some owners. First amongst these rank ' hoof-ointments,' be they either a ' secret' with the stablemen, or a 'patent'-it does not make much difference which, as to their nonutility, or, rather, their positive insalubrity. They almost always consist of admixtures of some or all of the following ingredients:- Tar, bees-wax, train oil, tallow or suet, and honey. Mr. Douglas says that if applications of this kind were made daily instead of occasionally, no horse would have a morsel of sound horn at the end of six months to nail a shoe to: 'for it shuts up the pores in the horn, prevents the natural moisture from reaching the surface outwardly, and the air from circulating inwards-consequences which act upon the horse with ruinous results.' 'If you tell a groom this, he will either refuse to listen to your arguments, or laugh at them as being the height of absurdity.' How many horse owners are on a level with their servants in this matter!

Cowdung, mixed sometimes with some of the above-mentioned abominations, is firmly believed in by servants, and its use condoned by their masters, for 'stopping'-that is to say, stuffing the hoof with - up (or down) to the level of the bottom of the 
shoe. Cowdung is supposed by these ignorant people to be emollient, because it is soft ; but everything that glitters is not necessarily gold, and cowdung instead of being an emollient, is a powerful irritant ; and so between 'ointment' and 'stopping' they are using their utmost endeavours, in surrounding the hoof on all sides with everything that ignorance and stupidity can devise (up to the present time), to render it brittle and otherwise diseased.

As soon as the horse is taken, as a colt, from his natural state into bondage, every one seems to consider that his mother Nature has nothing more to do with his future career. Everything then is carried on by them without once casting a thought on the dominion which she still maintains over him, equally with all her other creatures. Some others of the servants of man are less meddled with than this one, who is, at the same time, the most costly and the most generally useful-here in England, at least. It has been well said that 'the history of almost every horse in this kingdom is a struggle to exist against human endeavours to deprive it of utility.' This is forcible language, but it is the naked truth. Another authority says: 'Strange to say, he frequently suffers as much from ill-advised kindness as he does from cruelty.' This last observation applies to the English farmer, only in so far that, whilst wishing to be excessively kind to his horses, he is often unwittingly laying himself open to censure from want of having duly considered how to treat them. No one can possibly accuse him 
of wanton cruelty - far from it ; but he might avoid inflicting upon them much suffering, with gain to himself, if he would turn part of the attention he bestows upon 'rotation of crops,' \&c., to his teamsand those to whom he entrusts them. 


\section{CHAPTER IV.}

LITTER-XENOPHON AND LORD PEMBROKE ON BARE PAVING FOR STALLS-PHYSICKING AND BLISTERING-THE BEARING REIN.

SERVANTS are apt to be very exacting as to the quantity of straw for litter, and they keep some all day long under the horse's feet, ignorantly believing that it is a comfort and a benefit to the horse. Here, again, they are wrong; and upon both points. Let any proprietor go to his stable, upon returning on a Sunday from morning church service, when the horses will, perhaps, have been left to themselves for three hours, and he will find that his horses have been trying to get rid of it by scraping holes in it, in which to stand in ease and comfort on the bare floor, having pushed as much as they can back into the gangway. It is probable, also, that instinct takes part in their dislike to it, on the score of its being unhealthy, as well as uncomfortable to them.

Xenophon wrote in praise of a bare stone pavement: 'It will cool, harden, and improve a horse's feet merely by standing on it.' Lord Pembroke says: 'The constant use of litter makes the feet tender, and causes swelled legs; moreover, it renders 
the animals delicate. Swelled legs maybe frequently reduced to their proper natural size by taking away the litter only; which, in some stables where ignorant grooms and farriers govern, would be a great saving of bleeding and physic, besides straw. I have seen, by repeated experiments, legs swell and unswell, by leaving litter, or taking it away, like mercury in a weather glass.' It has also been found in the army that the troopers' horses, which are not bedded down during the day, never suffer so much from corns, contractions, thrush, and grease as the officer's chargers do, which have straw to stand upon whenever they are in the stable.

Some owners, with a view to economy, substitute sawdust for the straw, and they leave it for weeks without changing it. This is a still greater mistake; it gets saturated with acids and alkalies, and is most injurious to the feet as well as to the general health of the animals. Veterinary surgeons assign, as one of the causes of cough, ' rank bedding.' It is a frequent source of seedy toe; yet, not many weeks since, a groom to whom this remark was made laughed it to scorn, saying that it was the best possible preventive to the disease, and was, moreover, the very best cure for it in a horse already affected with it; and, he added, the older and more rotten the sawdust the more effective. His horse did have seedy toe shortly after this, and the veterinary had to be called in. He, of course, had all this rotten muck immediately removed. The use of sawdust is no economy at all, when considered from the right 
point of view. The problem to be solved is, how to keep your horse in health and get the most work you reasonably can out of him. Straw, used with judgment, will be found as economical as anything else ; it should only be put under the horse the last thing at night, and it should be removed the first thing in the morning. The horse will dirty it but little in the night; the dirty portion should, of course, be carried out of the stable, and, in this manner, no alarming expense of straw is incurred.

It is well known to many travellers that in countries quite as cold as England straw is so scarce and valuable that horses even sleep by night on the bare floor; and the horses from some of these countries are imported to England with a great reputation for possessing hardiness and sound constitutions. But they do not dwell with us long before we improve them down to a level with our own breeds (in this respect), by hot stabling, foul atmosphere, and many other fanciful crotchets which come under the headings of 'mistaken kindness,' or 'mistaken economy;' and economy well understood is specially in demand, and should be sought, in the present ' hard times.' In the case of straw a double economy is very visibly to be found in using it sparingly, as the outlay upon the article itself is reduced; and the horse, by being freer from ailments, can do more work in the course of the year.

Certain classes of horses get, in the course of the year, a diminution or cessation of labour. This is 
looked forward to by the owner with an inane kind of idea that the horses will receive benefit from their ' rest;' as, indeed, they really ought to do, if they were sanely dealt with during that time. The stableman looks forward to the same period with ferocious satisfaction, as then he will have an opportunity of giving swing to his cruelties. Beforehand he is rejoicing in projects of 'physicking' (i.e. purging) and blistering, and then 'conditioning,' his hapless and helpless horses, and counting on the empire he has over his master-and he is seldom wrong on that head-for carte blanche. Mayhew says 'the prejudices of ignorance are subjects for pity : the slothfulness of the better educated merits reprobation.' 'No slave proprietor possesses the power with which the groom is invested.' In Brazil the slave-owner is not allowed by law to flog his slaves himself; if they are judged to merit flogging they have to be sent to an official specially appointed in each district for that purpose, which official is, of course, free from anger and vindictiveness, and only lays on the regular strokes, which the owner would be likely to exceed both in force and number.

Aloes, as being the most violent and irritating of purges, is the favourite one with the groom. It frequently remains inside the horse a couple of days before it ' sets ; ' it often thus causes inflammation or irritation of the kidneys, and terribly weakens him. Its operation has hardly ceased when the man is applying blisters to the horse's legs; and the most powerful of 'patents' and 'vesicants' are his greatest 
favourites. A horse first weakened by a drastic purge, and then tortured by one of these infernal inventions, is more injured than if he had continued at hard work instead of having his 'rest.' A modern professor of veterinary science says: 'Let all gentlemen discharge the veterinary surgeon who proposes to blister the legs of their horses. The author has beheld hundreds of blisters applied to the legs, but he cannot remember one instance in which such applications were productive of the slightest good.' Youatt said : 'Agriculturists should bring to their stables the common sense which directs them in the usual concerns of life.' Youatt wrote half a century ago, and for farmers; yet it is doubtful whether things have not got worse since then, in spite of his advice. Mayhew says that the administration of three or four bran mashes is in general a sufficient purge; and he further says that, 'during the years he was in active practice, he does not remember to have given a dose of aloes' (presumably only then on an emergency) 'that the symptoms did not afterwards cause him to regret the administration. They are at present chiefly employed in accordance with the dictates of routine.'

Routine seems to be having a long innings in most respects as regards the horse. After long and energetic representations and arguments on the part of Mr. Flower, some of the horse proprietors in London finally discovered, upon trial, that their horses could actually do more work without bearing reins-this was a severe blow to routine-and now 
most, or nearly all omnibus, van, car, cab, and tramway horses are driven without them in London.

Many gentlemen have also done away with them for their horses; even four-in-hand drags are frequently seen without them-but cart horses, say for instance (and only because they happened to turn up first on the surface of memory), those working in the carts belonging to the vestry of St. George's, Hanover Square, are still hampered with them. They are to be seen with their chins drawn up to their breasts, thus having their stride shortened, and thus making many more steps than natural to each mile they travel; and every step, short as it may be, entails a putting in motion of the flexor and extensor muscles and their tendons. But Nature has determined the real economical swing of these muscles and their tendons in each direction; and so it results that, by depriving her of her will, such horses are prevented from exercising their powers to the full, and at great inconvenience to themselves, and prejudice to their lasting power also; for something is bound to suffer undue wear and tear when natural extension and flexion are interfered with-even if it should be only the sheaths of the tendons, to put it in a rery moderate light.

Farmers plead that cart horses, driven by a man on foot, must have something for that man to catch hold of at certain times, and they also parade and make much of the fact that when they have a hill to ascend, the bearing rein is loosened; therefore 
they admit that a horse should have ' the use of his head' at certain times, yet they do not know where to draw the line, although nothing is easier to draw, if common sense were appealed to.

The cart horse should always have the free use of his head at a walk, as it should and does govern his stride; and if a rein of some sort is necessary for carters to lay hold of occasionally, the measure of the length of that rein is easily found. It is just the length that will allow a horse to use his fullest exertion up hill without bearing upon it. To this they object again that a rein of that length would hang unequally on the sides of the horses' necks and be troublesome and unsightly. This only shows them to be short of inventive faculties. They have only to sew on a ring just at the double of the reins, at their determined length, and hitch this ring on the hames, when they would find the reins to hang equally and gracefully, and always ready to be caught hold of; although the best carters lay hold of the cheek strap, above the bit, and thus manage their horses better than those who take their hold below the bit.

We won't quarrel over the last point; but, in the name of common sense, let a horse always have his natural stride-it is essential to his economical work. Yet cart horses are to be seen, in town and country, pegging away with reduced strides, expending on a four-mile journey the same exertion that they would, if allowed, only use on a five-mile one. Their owners handicap them. 


\section{CHAPTER V.}

SHOEIYG-LORD PEMBROKE ON SERTANTS-LUPTON ON FARRIERS -FITTING THE FOOT TO THE SHOE-CALKS-NJURIOUS EFFECTS OF FITTLYG SHOES BY BURNING THEM ON-DOUGLAS ON COLD FITTING-SHOEING IN SPAIN-BRUSHING.

Ax old saying amongst horsemen is, 'No foot, no horse ;' and another, ' Whoever hath care of a horse's feet hath care of his whole body.' From time immemorial it has been recognised that the foot of the horse is the part of him which calls for the utmost care and attention; yet it is actually the one that at the present day receives the least attention, and is subjected to the worst malpractices. To whom is the care of it confided? Why, to the stableman and farrier-two of the most ignorant blockheads, as a class, that could be picked out. Lord Pembroke wrote, more than a century ago, of the first-named: 'It is incredible what tricking knaves most stable people are, and what daring attempts they will make to gain an ascendant over their masters, in order to bave their own foolish projects complied with. In shoeing, for example, I have more than once known that for the sake of establishing their own ridiculous 
and pernicious system, when their masters have differed from them, they have on purpose lamed horses, and imputed the fault to the shoes, after having in vain tried, by every sort of invention and lies, to discredit the use of them.'

Mr. Lupton, M.R.C.V.S., only three years since approved the opinion that 'the master who makes the welfare of his steed subservient to the idle prejudices of his groom, is fitly punished in the lengthened period of his animal's compulsory idleness, appropriately finished by the payment of a long bill to the veterinary surgeon.' And, of farriers, he says : 'Farriers ought to go through a course of instruction previously to being allowed to operate upon structures, the anatomy, physiology, and economic uses of which they have never studied, and, consequently, never understood.' When people have been having this kind of thing continually impressed upon them for such a length of time, it seems strange that they have not long since taken the management of the part of the horse that requires the greatest supervision and intelligence out of the hands of two such ignorant sets of people.

'One horse can wear out four pairs of feet.' That is because the feet are ill treated. Mr. John Bright has discovered, through thirty-four years' experience, and a loss of $300 l$. in the shape of printing, that 'farmers do not buy books!' One would hardly have thought that. We know that they not only buy papers, but that they are also extensive contributors to them. 
What percentage of horse owners accompany their horses to the forge and see them shod? and, what is of great importance, see their feet when the shoes are removed? They would be astonished, for instance, to find amongst many horses that, when the toe had been pared and rasped, they would be able to discover that the outer layer of the wall or crust did not make one body with the inner layer, as it should do if the foot were healthy, but is separated from it by dry fibre. This is the way in which seedy toe begins; and the joint causes of it are, standing on dirty litter, the use of hoof ointments, stopping with cowdung, \&c., burning the seat of the shoe with a hot shoe, slipping down hill, \&c.

If the owner makes a remark thereon to the farrier, he will be told that 'many good horses are naturally like that; but it does not hurt them if they are well shod.' Let them look at the feet of a colt, or of a brood mare, that has been running unshod at grass, and see whether they can find anything like it. They certainly cannot; for no unshod horse was ever known to have such a thing, any more than corns (from which unshod horses are also entirely free). Remarking on this separation of the outer and inner horn of the wall, Mayhew says: 'Pathology has indirectly recognised the intention of their function, by acknowledging that condition to be a state of disease, wherein the two kinds of horn are separated. Such a division is known as seedy toe, and as false quarter; and the foot is recognised as weakened when such a want of union 
is discovered. But in the forge, the application of such facts is by most smiths utterly ignored.' We may add that to most owners its existence is utterly unknown in the beginning, as, when the shoe is on, its first appearance is not to be detected, for of course the iron covers and hides it. It can only be discovered by paring or rasping the bottom of the hoof, when the shoe is off, at the toe or quarter; the toe is where it is most frequently to be found.

Over nearly all country forges it is stated that ' shoeing is done here upon improved principles.' Now, these so-called 'improvements' consist of mistaken theories which were conceived many years ago. They were then considered to be improvements by their authors, and were most likely only received as such because there was a great deal of show about cutting, carving, and paring the under surface of the horse's foot. This was impressive for the vulgar and ignorant, because there was some mystery attached to it; so it became very popular amongst them, and it remains so, to a certain extent, upto the present time, although all modern professional authorities have exerted themselves to explain the immense evils attendant on everything pertaining to the system. The owner, therefore, who should make up his mind to see his horses shod, must not allow himself to be impressed with the idea that the smith is an adept operator, endowed with a knowledge of anatomy and physiology; for he is always giving striking proofs that he knows nothing of either. He can see the outside of the foot; but 
he has not the slightest idea of what corresponds internally to the parts he so mercilessly destroys. There are very few smiths who could tell, off-hand, for instance, how many bones are entirely imbedded in the hoof, and how many only partially imbedded; so they are working in the dark.

Modern authorities tell us that no part of the hoof should, on any account, be cut or pared, except the seat of the shoe-that is to say, the wall or crust only, without touching the sole, frog, or bars; as all of these were placed there by Nature for special purposes, and she has so ordered matters that these parts cannot possibly overgrow themselves. Yet smiths will not let them alone, unless a man goes to look after them, and has sufficient strength of mind to resist their entreaties to be allowed to take off ' just a little bit, here and there,' in order to make what they call 'a clean foot.' Never mind appearances on the bottom of a horse's foot, especially as this kind of neatness is taking his legs from under him. Don't listen to their arguments on any account; have your own way, and see that only the seat of the shoe is pared down on the crust.

Any amount of authorities could be cited here in support of this advice; so many, in fact, that it is uncalled for to quote any of them. The shoer will next cast round in search of a shoe, or even four of them, that will come near fitting the horse. Sometimes he finds that he has to alter the shape to bring it to the hoof ; but, if it comes within a little of that much, he proceeds to rasp and pare the hoof, 
to make it fit the shoe, just as if the hoof were a mere block of horn, instead of every part of it being composed of an outside, or so-called, insensitive covering to an inside corresponding one, which is usually denominated sensitive, because it is more sensitive than the outside one. If he should find that the shoe best suited to his fancy should be too long, he proceeds to shorten it by turning up more calk at the heel.

Now, calks are a great abomination, be they ever so slight. They were conceived by ignorant, unreflecting people, in order to act as brakes; which brakes, we have seen, should be applied to the wheels of the cart, instead of to the horse's foot. Nature has determined the right ' tread ' for a horse; calkins, by raising the heel, interfere seriously with her designs. All the interior parts of the horse's foot are shaped in harmony with the exterior; the coffin bone is wedge-shaped, and, when the foot is tilted up behind, it is forced into the wedge-shaped interior concavity of the toe. This is one of the causes of seedy toe, sandcrack, and laminitis, commonly called 'fever in the feet.' Mr. Douglas happily calls to mind that raising the heels also shortens the stride.

Is it customary to put calkins on the shoes of race horses? From an illustration of the 'plates' they wear, given by Mayhew in his 'Illustrated Horse Management,' it appears that they do not run in calkins = stride counts; and trainers have found out thus much, howerer short they may still be in 
their researches as to the right way of shoeing. Race horses still slip (witness the Derby of 1879) both backwards and forwards, and trainers have not yet arrived at the acme of treatment of the horse's foot. They will not like to be told so, but il n'y a que la vérité qui offense in instances of this kind. Lord Pembroke hated calks, and he lays it down as a rule that 'from the race horse to the cart horse the same system of shoeing, and description of shoes, should be observed; the size, weight, and thickness only of them should differ.'

Nature intended the horse to serve for both draught and saddle, and she designed for him a wonderful foot, equally fitted for both purposes. Man in his perversity is dissatisfied with it, and is vain enough to think that he can alter it to advantage. And to what classes of men has the regulation of such supposed improvements been abandoned, but to the most ignorant? To return to the forge: when the farrier has satisfied himself that he has cut away everything he can possibly get at, without drawing blood-although often on the sole he goes so far as to produce ' dewdrops' of that, which may be seen oozing through the pores he has cut deeply into-and that he has obtained something near a fit by altering both the shape of the shoe and the hoof, he will then again put the shoe in the fire and give a blow up to make it red hot; and, in that red hot state, he will apply it to the foot, in order to burn a seat for it. In so doing it must be evident to every man who will reflect, that he sets all the natural 
secretions of the bottom of the crust into a boiling state, and boiling means simply their entire decomposition; so, therefore, he actually kills the foundation on which a horse is built, and it is only the dead part that he has to cut away again (as regards the crust or wall) on the next occasion that he operates upon him. This burning-in business is, therefore, another cause of seedy-toe, false quarter, and sandcrack.

The opinion of Mr. Douglas is well worth reporting here. He says: 'The fitting of the shoe can always be done better, in my opinion, when the iron is cold, than when hot. Heating the shoe is the quicker way, but it is also the most barbarous one. The mischief done at times, by this custom, was exemplified in the case of Mr. Bevan's trotting-horse Hue and Cry, which lost both its fore-feet through the shoes having been fitted red hot; and many animals, both before and since, have suffered like misfortunes from the same cause.'

In Spain it is the custom to shoe cold, and not one 'herrador' in a hundred has a forge or a pair of bellows on his premises. They even manufacture the shoes without the aid of fire; but it is true that Spanish iron, being primarily manufactured with wood charcoal, is particularly pure, soft, and ductile. The Spanish 'herrador' or shoeing-smith only-for he does nothing else in the shape of iron forging-does not use the drawing knife (although, of course, the veterinary surgeon does), and he never touches or pares anything but the wall, which he pares down 
with the butteris; and he would on no account put a calk on a shoe unless as an orthopœdic resource, and even then only when ordered by a V.S. The natural consequence is that Spanish horses are freer from foot diseases and lameness than are ours in England; and so unaccustomed are Spanish farriers to find foot lameness (as, amongst other things, they shoe short behind, and so let the horse tread on his own heels, thus preventing corns), that they generally suspect, and test for, lameness in the shoulder, when a lame horse is brought to them, before referring to his feet; unless, of course, it is palpable or visible to their experienced eye, from the outset, that the lameness is really in the foot. Most English farriers always suspect the foot first, and even then they cannot always pitch upon the foot on which the horse goes lame: they have even been known to operate first upon the three sound feet in succession, and then to take the lame one!

Amongst the evils of paring away the horn, there is one that appears to have passed unnoticed, or uncommented upon, by the authorities who so strenuously endeavour to point out the evils of shoeing upon the so-called 'improved principles.' Yet it is not one of the least. In trimming away the frog on its sides, the farrier scores deeply with the point of his drawing knife into the sole, and this, added to the paring to which he subjects the sole all over, must necessarily and obviously further weaken the arch of the foot. The letting down of the arch in this way contributes to navicular disease, for between the 
arms of the $Y$ the navicular bone is superposed. But what does a farrier either know or care about that? Must not improved principles be the best, or else why should they be called so? To all your objections he will only remark to your servant, behind your back, that you are only fit to carry food to a bear; and in this the servant will give him reason, and they will go and have a pint together, and laugh at you over drinking it. They are a hard lot to deal with, and that might be one of the reasons that so many owners 'give it up.' When the shoeing of a horse is left entirely in the hands of this brace of worthies, he is generally found to come home 'going tender.' And small wonder! Therefore, many people send their horses to be shod a day or two before sending them on a journey, with a prescience of this ordinary state of things; although the horses are really still going tender then, but only themselves are aware of it.

If a horse wears away his shoe more in one place than in another, the farrier is sure to thicken the next shoe he puts on in that particular place; or, if he considers himself a real artist, and has the time or is not shoeing by contract (contract-shoeing is an additional curse for the horse), he will weld in a piece of steel to prevent the wear on that particular part. If the horse wears calks, he is almost certain to wear down the toe and one calk. This, of course, is only the perverseness of the horse, if you choose to listen to the groom and farrier. They cannot perceive or conceive that the horse is driven or forced, 
by the natural play and action of the muscles and tendons of the legs, to put down his foot in a natural manner in search of a natural 'tread;' and so they continue to oppose his innate desire, until they bring about sprain, and ultimately contraction, of sinews. This is the reason that so many horses are to be seen walking on their toes (in London, cab horses may any day be seen which have to trot upon them), and the back sinews are often divided by veterinary surgeons to enable the horse to go on working at all. If the twist should be on one side it will bring about side-bone (or ossification of the cartilages of the foot), or splints, or something else where undue and unnatural strain or friction is thrown : especially is it the cause of ' cutting.' No unshod horse was ever known to 'cut' or 'brush;' but the shaping of the foot to the shoe is often the cause of this defect. The only alleviation for it, when once produced, is to study the 'tread' of which the horse is in search in order to free himself from it (it is not likely that he is seeking to make things worse for himself), and then humour his instinct, instead of thwarting it, or looking upon it as perversity on his part, and opposing his exertions to get free from it. The ingenuity which some people are capable of displaying, when they have fully made up their minds to oppose nature, is wonderful. They always break down, but, like true Britons, they are always ready to come to the charge again; it is only deferred for them until the next meeting. It is a shocking abuse of pluck, all the same. 
Who is there amongst human beings that does not prefer to wear an old pair of boots to a new pairand why? Because the old pair has accommodated itself, by wear, to the 'tread' of the owner. The heel of a man's foot is round on every side; yet his bootmaker will persist in making the heels of his boots with square edges; the consequence being that they wear more in one part than another. As all men have not the same natural tread, some will wear out the inside of the heel at the same time with the outside of the toe; whilst others will do exactly the contrary, or else wear them away in a different form from either. The time when they require mending is the time when they begin to feel comfortable ; and the human shoemaker, like the equine one, proceeds to reinforce the parts that wear the quickest. The American Indian knows better than this. He fashions the exterior of the heel of the moccasin, as near as he can get it, to the shape of his own heel; and those who have worn moccasins for any length of time (as the writer has), positively ' go lame' when they have to put on a pair of civilised chaussures. 


\section{CHAPTER VI.}

YOUATT ON THE WEIGHT OF SHOES - AMERICAN TROTTING HORSE ' $\mathrm{ST}$. JULIEN'- ${ }^{6} \mathrm{AN}$ OUNCE AT THE HEEL TELLS MORE THAN A POUND ON THE BACK'-LUNETTE SHOE OR TIP OF LAFOSSE-DOUGLAS ON THE STRUCTURE OF THE CRUST-MULES ON EXPANSION AND CONTRACTION.

Fashion has of late led our ladies into the habit of wearing very high heels to their boots; and, to make things worse, they are placed, not under the ball of the heel, but ahead of it-that is to say, in a part which was not intended by nature to take their full weight at every step. Medical men tell us that since this became the fashion, hysteria is largely on the increase, and also that many other illnesses may be traced to the same cause. Fortunately, ladies can take off their boots when they come indoors (and they avail themselves of the chance), to put on others of different construction. From this the horse is debarred.

Medical men, as physiologists, are able to judge to a great extent as to the value or non-value of the foregoing remarks upon the horse's foot and its shoe; they, at least, have no excuse for tacitly admitting that grooms and farriers should have any advantage 
over them. Perhaps some of them may think it worth while to pick up their horses' feet and examine them, and turn things over in their minds. Some of them will admit that they have become 'groovey' to an extent that is inexcusable, especially in men of science. Medical men are all masters of comparative anatomy; and here is a good opportunity for them to bring it profitably into use.

All modern authorities on the matter are of opinion that most horseshoes are made too heavy; and when horses are shod by contract, or by the year, their shoes are made heavier still. Youat, not by any means a modern authority, says that 'an ounce or two in the weight of the shoe will sadly tell before the end of a hard day's work.' The American trotting horse, St. Julien, lately trotted a mile in $2 \mathrm{~min}$. $12 \frac{3}{4}$ sec., being half a second less than the best time of Rarus; and we are told that his shoes only weighed fifteen ounces each on the fore feet, and six ounces on the hind ones. Rarus, as was until lately the custom with American trotters, wore very heavy shoes; is it not possible that Rarus may have been the better horse of the two, but that he was too much assisted with iron by his friends? Besides the weight of an ounce or two 'telling sadly before the end of a day's work,' there remains the evil that it tells permanently upon the horse's legs. There is, perhaps, no modern authority that has not been explicit thereon; yet heavy shoes are still most generally in use, in spite, also, of the old proverb, ' An ounce at the heels tells more than a pound on the 
back.' Mr. Douglas tells us that he found by careful experiment that light shoes will wear longer than heavy ones. The contract farrier, by putting on heavy ones, is thus, as usual, wrong again; and he cheats himself this time-a very fitting judgment upon him. It is unfortunate that the rest of his mistakes do not equally recoil upon him. If this were the only mistake that he makes, it would prove that he takes no warning by experience, and makes no useful observation, when he incontinently, although in an overreaching way, actually mulcts himself! This man will also put in extra nails, and make clips on the shoe to help the nails to keep on the exorbitant weight of iron; and all this means only so much extra mutilation of the hoof.

Horses in England are universally over-shod, as well as over-mutilated in the hoof; although, only last year, the author of the 'Book of the Horse' wrote, in a contemporary, 'The general tendency of the age is to shoe as little as possible.' This 'tendency' is very little apparent when people come to observe every horse they mett (as the writer does); although one notable exception (as there is to every rule) is to be found in the streets of London in the horses belonging to Mr. John Smither, East Smithfield. These horses do not slip about as much upon greasy pavements and asphalt as is the rule with other horses. At the present season, London observers may satisfy themselves on this score. This gentleman is owner of a considerable number of horses, and his cars 
and vans are to be continually met with in the City.

M. La Fosse was deeply impressed with the idea that less iron was required; and he boldly cut off one-half of the shoe-that is to say he maintained that a tip on the front half of the foot was all that was necessary. But, unfortunately, he spoilt a very bright idea in two ways - he recommended the heels of weak-footed horses to be pared (and this, of course, made them weaker), while he fastened on a tip, of about six inches in its entire length of iron, with eight nails. Horse-nails run from about one-eighth up to three-sixteenths of an inch in thickness. So he was inserting wedges amounting, in the aggregate, from one to one and a half inches in thickness, in six inches of horn, thus squeezing it into the space of five, or even four inches, and killing it from the clenches downwards and outwards.

Mr. Douglas says : 'If the crust is closely examined with a microscope, its structure will be found to consist of a number of bristle-like fibres standing on end, but bearing diagonally towards the ground. From the particular longitudinal construction of the fibres, it follows that they will bear a great amount of weight so long as they are kept in their natural state. The crust so viewed resembles a number of small tubes, bound together by a hardened, glue-like substance. Whoever has seen a mitrailleuse gun, with its numerous barrels all soldered together, can form a very good idea of the 
peculiar structure of the crust (or wall), especially if they were likewise to imagine the tubes to be filled with a thick fluid, the use of which is to nourish and preserve them.'

If La Fosse had made a research of this kind, he would have perceived that, by his way of nailing, he was reducing the size of each tube by one-sixth; or, what is more probable, that he was entirely closing those nearest the nails, and compressing those that lie half way between each pair of nails. How, then, could the 'thick fluid which is to nourish and preserve them' circulate when it arrived at the nails? And what, therefore, was to nourish the prismatic-shaped portion that lies in front of the nails? In and around Rome, at the present day, horses are shod with his 'lunette' or tip, and many of them on the front feet only (the hind feet being entirely unshod); but they are generally fastened on with only three, or sometimes four, nails; and these are the only horses that can keep on their legs in the slippery streets of the city. For the benefit of strangers, that come on horseback from a distance, there are posted up notices, at the various points where paving commences, warning them to dismount at such points in case their horses should be fully shod. Those Englishmen who take any notice at all of the Roman horses' feet, mostly ridicule the 'barbarous' way in which they are shod, and boast of the 'splendid English shoeing.' Some even consider it cruelty, and feel so strongly on the subject, that they refuse to hire the vehicles to which 
they are harnessed. If they were a little more observant they would discover that these horses were sounder in their feet and legs than are our London cab horses, which are shod to death, and most of them unsound and lame on all four feet (or legs).

By our ordinary mode of shoeing, in which about seven nails is the average we employ in each hoof, we are still doing, to a certain extent, the mischief of which La Fosse was guilty. We wedge up and compress the horn with the nails to the extent of about one-twelfth instead of one-fourth. How, then, can we wonder if the hoof, deprived of its full supply of nourishment round its edges, becomes brittle and dry? Can 'hoof ointments' or cowdung supply the place of the natural secretions? Mr. Miles, a Devonshire squire, for many years used three nails only on his own horses, and he found them all the better. He had not reflected on the reasons above stated (they are original with the writer, who thought them out for himself, and has never seen them referred to in any work, otherwise he would have acknowledged the source from which he got them, as he always does when he draws upon others); but he was in search of means which might. allow expansion and contraction, and he put only one nail on the inside of the foot, and near the toe, the two remaining nails being on the outside part of the hoof. This gentleman made very clever practical experiments as to the extent of natural expansion and contraction; and in his work, 'Miles on the 
Horse's Foot,' they are illustrated most admirably. The subject of them was a horse nine years old, which had always worn shoes since he was first put to work, and had the shoe removed on purpose for the investigation and experiment. The unshod foot was lifted up, and its contour traced with the greatest precision on a piece of board covered with paper. A similar board was then laid on the ground; the same foot was then placed upon it, and the opposite foot held up whilst it was again traced. The result was that it had expanded one-eighth part of an inch at the heels and quarters; and from the quarters towards the toe this gradually diminished, showing a space of four inches in front, two inches on each side of the centre of the toe, where no expansion whatever had taken place; the tracings proving, at the same time, that expansion was only lateral, and that none took place in the length of the foot from heel to toe. He states that he had other horses which had before shown a still greater expansion than this; but this was only whilst the horse was standing still, and upon three legs. 


\section{CHAPTER VII.}

EXPANSION ENTIRELY PREVENTED BY PRESENT MODE OF SHOEING, BUT FAVOURED BY 'TIPS'- MAYHEW AND PROFESSOR. PERCIVAL ON 'TIPS'- 'IT IS THE SHOE, NOT THE ROAD, THAT HURTS THE HORSE' - 'IMPECUNIOSUS' SAYS THERE IS TOO MUCH SAMENESS ABOUT ALL EXISTING WRITINGS ON THE HORSE'S FOOT, AND 'ORIGINAL' IDEAS ARE WANTED.

ReCEntly, by means of photography, it has been demonstrated that in every gait beyond the walk the horse is, at every extension, bearing all his weight at a certain time on one leg only, and that he comes down with a shock on that one leg. What, therefore, expansion may amount to in an unshod horse at a gallop, or its tendency in a shod one, we have thus far been unable to discover. This expansion has long been admitted by most authorities, and they have studied how to allow for it. In fact this, and the prevention of slipping, have been the motives for many inventions. Most of them have proved failures in both directions; although some of them, after having been buried-like their authors-have been unearthed, pirated, and again presented to the public; but still no progress is made. The full shoe, even in its most perfect form, cannot allow expansion and contraction their natural scope; but, 
as on the front part of the hoof (or the toe) it has been proved that what little there may be is inappreciable, tips will not much interfere with it; that is to say, tips that do not cover more than the front half of the rim of the foot-for many farriers put on shoes that are only an inch short at the heels and with six nails in them, for turning horses out to grass, and call these tips, which they are not. A half-bred horse of $15 \frac{1}{2}$ hands will generally be shod with a piece of iron 14 inches in development when measured round its edge. Six inches would be the measure of a tip, and Mayhew gives an engraving in which a real tip is shown, and it is secured by only four nails.

Mayhew also says: "The late W. Percival, the respected author of "Hippo-pathology," many years ago informed the author that he had long ridden a young horse about town with no greater protection to its fore feet than tips could afford. $\mathrm{He}$ showed the hoofs of the animal to the writer, and more open or better examples of the healthy horse's feet need not be desired.' A gentleman who wrote in the 'Field' some ten years ago, under the nom de plume of 'Impecuniosus,' cites Mayhew to the effect that 'some horses will go sound in tips that cannot endure any further protection;' and he remarks thereon: 'The moral, so to speak, of this is, that it is the shoe, not the road, that hurts the horse ; for if so weak and tender a foot as is described can go sound when all but unshod, why should not the strong sound one do the same? The 
obvious conclusion is that we require a strong sound foot to stand, not our work, but our shoe.' $\mathrm{He}$ is, therefore, a strong advocate for the use of tips, adding that ' $\mathrm{A}$ sportsman, well known some little time ago in the shires, shod all his horses with tipshunters, hacks, and carriage horses ; but, although it was seen that his stud went very well shod in this manner, no one followed his example, the world in general being staunch Conservatives, and diametrically opposed to any innovation in stable matters, whatever their opinion may be upon other subjects.'

Here is another extract from Mayhew: 'When the contents of the foot are compressed by the superimposed weight of the animal, or when the hoof is resting upon the ground, the quarters yield to the downward pressure, and they accordingly expand. When the burden is removed by the hoof being raised, the quarters again fly back to their original situations; the sides, therefore, being in constant motion, are entirely unsuited for the purposes to which the smith compels them. No wonder the clenches are loosened, or the shoes come off, when the nails are driven into parts hardly ever at rest. This action is important to the circulation, for the contraction still allows the arterial blood free ingress, while the expansion permits the full return of the venous current.'

Although Mayhew was formerly demonstrator of anatomy at the Royal Veterinary College, and claims a high respect and admiration for nearly all his observations, the writer is obliged to refrain from 
continuing the present citation, as in what follows therein he differs diametrically from Mayhew, and he declines to follow servilely in the path even of those he most respects; but Mayhew himself could hardly object to his action in this respect when he says: 'Veterinary surgeons display ignorance in nothing more than in being servile copyists.' Not that the writer pretends to be a veterinary surgeon. He is only a practical man who has had a very wide and long experience amongst horses in many countries, and has been a very close observer of everything touching their feet and legs especially, and is now only offering the result of his so-gained experience for what it may be worth. Almost from the beginning of his connection with horses, he declined to consider the legs as a separate part from the body of the horse, and refused to believe that four sets of them were necessary to wear out one body, as, if such were the case, the horse would be an incomplete and niggardly gift made by Nature to man; and from the outset of his religious education, received at his mother's knee, he has always been taught, and in his various wanderings he has never had reason to doubt, that Nature made everything complete, and nothing in vain. Hence he inferred that the horse's body was never made stronger than his legs and feet, and that these, when understood, will be found to be 'fearfully and wonderfully made, and in every respect harmonising with the rest of his structure, and equal to their task.

'Impecuniosus' says truly: 'The prevalent idea 
of the groom and the blacksmith seems to be that they know better what the horse's foot should be than the Creator of the animal does, for they are never satisfied until they have altered the natural foot into a form of their own, which they think the right one; and, though lameness usually attends their efforts, they ascribe it to every cause but the right one, and indeed resign themselves complacently to the presence of many diseases confessedly caused by their treatment-perhaps, because these diseases do not hurt their own sacred persons! It is really curious to observe all that has been written about the horse's foot-the sort of followmy-leader principle, which is more evident here than in writing on any other subject with which I am acquainted. Very, very seldom is an original idea to be found, and still more seldom an original idea that is not marred by some adherence to the old grooves to which preceding authors have confined themselves.' 'Impecuniosus' writes well, and makes many good remarks, as we shall see further on ; but the writer is also obliged to differ from him in some things, as he is, indeed, obliged to differ with all the authorities he quotes. As Baucher said, 'Si je n'avais rien à dire de nouveau, je ne prendrais pas la peine d'écrire;' and it is with the intention of offering some original remarks that he has undertaken the present arduous and responsible task, even in the face of the following words from 'Impecuniosus:' 'Every innovation is not reform, and this remark applies specially to stable practice; but any real 


\section{'REFORM IN SHOEING IS REFORM INDEED.' 53}

reform in shoeing is reform indeed, and the greatest respect and attention are due to it: but how few of these old discoveries, which are from time to time reinvented, are worth even the limited amount of attention which they command?' 


\section{CHAPTER VIII.}

THE 'CHARLIER' SHOE-'IMPECUNIOSUS' AND 'RANGAROO' ON THE CHARLIER SYSTEM-SOLE PRESSURE-INDIA RUBBER CUSHIONS AND PADS-PUMICE FOOT-ST. BELL ON 'IMITATION OF NATURE' IN SHOEING-MAYHEW, 'NATURE IS A STRICT ECONOMIST'-DOUGLAS ON THE SHORT AVERAGE LIFE OF OUR HORSES-' ONE HORSE COULD WEAR OUT FOUR PAIRS OF FEET'-PHILIP ASTLEY, 'HE WHO PREVENTS DOES MORE THAN HE WHO CURES'-THE CHARLIER ' SHORT' SHOE, AND THE CHARLIER 'TIP' - STANLEY SAYS NAVICULAB DISEASE IS IMPOSSIBLE WITH THE CHARLIER SYSTEM EXPERIENCE OF MESERS. SMITHER WITH CHARLIER SHOES - AMEERICAN EXPERTENCE OF CHARLIER 'TIPS' - 'FOUR INCHES OF IRON CURIED ROUND THE TOE.'

ONE of the modern inventions, in the shape of shoes, has been that of M. Charlier ; and 'Impecuniosus,' in his ardent desire to find something that would, or might, be any kind of improvement at all on what he looked upon as the prevalent and barbarous mode of shoeing, gave it a trial in a most enlightened and unprejudiced style, and approved of it. The shoe and the system do not appear generally known; and so it may be well, for those unacquainted with them, to describe both. Charlier started with the assumption that Nature had intended the horse to 
walk barefoot, and that the bottom of his foot was in every way fitted to stand all wear and tear, except the outer rim-that is, the wall or crust. He, therefore, made a shoe of very narrow iron, less than the width of the wall, which he let in, or imbedded, to the crust, without touching the sole, even on the edge; so that, in fact, the horse stood no higher after he was shod than he stood when barefooted. He urged that such a narrow piece of iron would not interfere with the natural expansion and contraction of the foot; and in this he at once went wrong, for malleable iron has no spring in it. Then, in spite of his theory, as he expressed it, he carried his shoe right round the foot into the bars, beyond where the crust ceases to be independent of them. He then got a very narrow, weak shoe, about a foot in circumference (if circumference can be applied to that which is not a complete circle); and, as he ought to have foreseen, the shoe then twisted or broke on violent exertion. Had he restricted himself to tips only, he would have had a great success from the beginning.

'Impecuniosus' says that another correspondent of the 'Field,' writing as 'Kangaroo,' very justly remarks upon ' the impossibility of a horse becoming footsore in the frog, sole, or heel of his foot as a result of his travelling barefoot. It is the toe about half way round that suffers, and this is all that demands protection in the fore feet, whatever the work may be and upon whatever soil.' Hence Charlier made a mess of it when he passed the dimensions of tips, or the mere protection of the 
front half of the crust. If he had stopped at that, his narrow iron would not, in such a short length, have either twisted or fractured, and he would have made an advancement in shoeing which he has failed to bring about.

In spite of 'Kangaroo,' a great majority of horsey men refuse, or decline, to believe that the sole, however liberal they may be in their views towards the frog and bars, is capable of bearing weight; whereas the real fact is that, unless it takes its share of the weight, it becomes unhealthy, and a cause of uneasiness to the horse. What observant and intelligent man, who is in the habit of visiting his stable, has failed to remark that, when a horse is going to dung, he takes a preliminary step forwards, and after having finished dropping, he backs both hind feet on to the top of it? What instinct leads him to do this? The groom will tell you that the horse is in search of something soft and cooling for his feet; but, unfortunately for his theory, it happens that, so far from being soft and cooling, the matter in question is solid and warm; for a horse suffering from diarrhœa will not draw ahead and then back, and of this any one may convince himself by waiting to see. Why, then, does he go through these manœurres? Why, simply to get, what he is otherwise deprived of, sole pressure. Soft cowdung will not afford it to him; and he will knowingly squeeze it out by getting his feet, and his weight, on something more solid.

Again, who has not seen when a horse is at 
grass, that when he is not grazing he will repair to some favourite spot, which is generally stiff, neither hard nor very soft, on which to stand at rest? In dry weather he will even stale upon some place that he can find in the shade, in order to make the ground consistent to his taste and desire-that is to say, 'stiff' - and there he will go when he is satisfied with feeding. And for what reason? Why, in search of sole pressure, which is a relief to him, but which he is generally deprived of. Can people read nothing besides print?

As further evidence upon this point, we will again hear 'Impecuniosus'-not that he seems to have had the slightest idea that sole pressure had anything to do with bringing about the state of things he relates. He clamours for original ideas, free from 'grooviness ;' and here is one for him, as far as the writer knows. As the open-minded, investigating man that he was (and is still, let us hope), he experimented upon all 'new brooms,' as he expresses himself. Among others, he tried elastic ' cushions' and 'pads ;' and he says that they diminish concussion, and prevent stones being picked up by the shoe, and, in so far, are good; but that they cause the shoe to come off, by their elasticity. 'I have personally made a fair trial of them; and this is the history thereof. Some years ago I had a remarkably brilliant hunter, who was also remarkably unsound. He had an inclination to pumice feet, and could hardly get along at all on the road. I shod him with these rubber cushions, or pads, which I may shortly describe as being a piece of 
india-rubber the shape of the foot surface, and the horse went better--in fact, went on the road as if he were on the soft. But I had to leave them off, because the shoes were always coming off. To be sure of their merits, I tried them on another horse; the result was just the same. I should say that the hoof grows very fast when shod with these cushions.' Why did the hoof grow fast with them? Why, because they caused sole pressure continually; there was no possible 'stopping' with cowdung whilst they were worn.

The want of sole pressure, conjointly with the weakening of the crust, when its inner and outer layers (the sensitive and the insensitive) have become diseased through rough and barbarous treatment, and show a tendency to separate, often brings about pumice foot. Pressure on the unpared sole, in imitation of Nature, is the proper treatment to effect its cure. Imitation of Nature should be the universal law of shoeing. St. Bell says: 'No one will venture to deny that, in the affair of shoeing, reason directs us to a close imitation of 'Nature.' The closest imitation of Nature that has ever yet been arrived at is the Charlier tip-' it gives great security for travelling over the most slippery roads, granite, or asphalte pavements; and, in frosty weather, no roughing is necessary.' This is accounted for by the fact that by this system the whole of the bottom of the foot, excepting the groove made for the insertion of the shoe, is left entirely untouched by the knife; and the dense, 
tough horn which the unshod colt possesses is a 'roughing' with which Nature sends him into the world, and which no artificial means can compete with. Why, then, should farriers ignore such an obvious fact, and direct all their perseverance and inventive powers to controvert Nature's designs? 'Because he who is uneducated and unable to comprehend principles can neither profit by his own experience nor abandon the paths of prejudice and custom.'

Mayhew says: 'It is amongst the firmest physiological truths that Nature is a strict economist, and never does anything without. intention' (every one of education ought to know this without having their attention called to it by Mayhew, or in these pages); 'that every enlargement or every depression-however insignificant it may appear to human eyes-is a permanent provision for some appointed purpose, and has its allotted use in the animal system.' How, then, can the ignorant farrier, or anyone else, by carving the hoof to his own fancied artistical shape, be doing otherwise than upsetting Nature's fearful and wonderful designs? 'Man has for ages laboured to disarrange parts thus admirably adjusted. When so employed, he has only followed the example of the savage who destroys the product he is incapable of understanding. No injury, no wrong, no cruelty can be conceived, which barbarity has not inflicted on the most generous of man's many willing slaves.'

Another writer observes that 'appealing to the 
better sentiments of the present age has been proved to be a waste of time; the better plan is to appeal to their pockets.' Now, it is an acknowledged fact that the exercise of these cruelties costs every horse owner considerable sums yearly; and, according to Mr. Douglas, although the natural life of the horse is from thirty-five to forty years, three-fourths of them die under twelve years old, and, in the army, even sooner. Therefore, on an average, every one buys three horses where he might do with one if he were only humane to that one. This ought to be sufficient inducement to men to look to their horses' feet, for it is through the feet that nearly all are thus early rendered useless, and through the feet to the legs. "One horse could wear out four pairs of feet,' is an old proverb, and a true one, amongst horsemen; and Philip Astley justly wrote: 'Certainly he that prevents disease does more than he that cures.' Now diseases of the feet are very rarely cured at all ; but, by the use of brake-power and a sensible system of stable treatment and shoeing they might nearly all be prevented. The Charlier shoe-defective in the beginning because it did not admit of natural expansion and contraction-was improved upon by an observant and reflective man at Melton, who reduced it to a three-quarter shoe; and this was a great stride to the good.

'Impecuniosus,' as he appears to have done with everything that gave any promise of being an improvement, tried it, and found that it really was 
one; but he says: 'My friend, who gave me the pattern of this shoe, remarked that the opposition of the smiths at Melton to it must be seen to be appreciated, and that the same might be said of most of the grooms.' This is the old, old tale. Later on he found that the three-quarter shoe had been with advantage reduced in length until it became simply a tip. Following his usual course, he adopted this improvement, and liked it better still. Nor is this to be wondered at, for expansion and contraction had now got very nearly their own way, frog pressure and sole pressure being similarly favoured, and each horse was left to find and use nearly his own individual natural 'tread,' with which the four inches of iron at the toe did not much interfere, and those that had before 'cut' or ' brushed' gave over doing so. Corns disappeared, as there was no pressure on them; and many of his horses, which had incipient side bones, were entirely cured of them. Of course, when once the cartilage is turned into bone, nothing can reconvert it into cartilage. He says: 'Nothing makes the heels grow so fast as the wearing of tips; with them snow does not ball in the foot; with every other shoe it does so, more or less.' This is very sensible and comprehensible; it arises from nearly copying Nature. Still the 'crowd' refused to believe that the horse's sole could be safely brought down to direct and immediate contact with the ground, even when told by this gentleman that 'one of the most eminent of our veterinary surgeons (Mr. Stanley, of Leamington) 
has stated it to be his conviction that horses shod à la Charlier will never have navicular disease.' Neither could they get pumice foot, or other diseases, attendant on the present popular mode of shoeing. 'Impecuniosus' conferred a favour upon horse owners by communicating the favourable results of his experience; but conservatism, bigotry, shoeing smiths, and stable helpers were too much for him, and the Charlier shoe or tip never got into extensive use, although some people still constantly use it. The difficulty is that, in the country, scarcely any one can be found willing to put it on; but, in London, there are certain forges where it even finds warm approbation. Mr. Stevens, M.R.C.V.S., Park Lane, for one, is a strong advocate for it, and has a forge on his premises where he accommodates all comers with it. If owners in the country choose to have their own way, the country smiths would be obliged to succumb to pressure, although they would grumble and oppose the shoe to their utmost: they want no change, and they resist every innovation.

Messrs. John Smither \& Son, of No. 1, Upper East Smithfield, wrote, in the 'Spectator' of August 3, 1878: 'Some weeks ago you noticed a controversy then going on about horseshoes. Your well known desire to help on the humane treatment of animals leads us to hope that you will give us space to state our experience. Some six or seven years ago we began having our horses shod for the fore feet on the Charlier principle, or a method akin to it. We 
had shoes made of about one-third the usual weight, of half the width, and of rather harder iron. In putting them on, the hoof was not cut or pared, with the exception of a small groove made in what we may call the edge of the hoof ; into this the shoe was inserted. By this system the horse's hoof is on the ground, as if he were unshod; but it is protected from breaking by the thin rim of iron at its edge. We found this shoe answer admirably; but the difficulty in getting it made and put on prevented us using it on more than a few horses until quite lately. We should like to state a few instances in which it has produced wonderfully good effects, but dare not trespass on your space. We have found no horses that it does not suit; and for young horses running on the London stones, for horses with tender feet, or corns, and to prevent slipping, it is of great service. We have lately been able to use it to a larger extent, and have now some forty horses, of all sizes, from the cob to those of seventeen or eighteen hands, at work on the London stones and country roads, shod in this way. These, sir, are facts which your readers can verify. From a business point of view it is also important: the use of these shoes would, in London alone, by preventing the laming and wearing out of horses, save many thousands of pounds every year.'

Here we find men evidently open minded, imbued with the idea that their brains might be at least as good as those of other people who pretend to dictate to them, and possessing the courage to 
persevere for half-a-dozen years, until they were able to establish generally in their stables, under difficulties, a system which their good sense, in the first place, and the experience they gradually gained, in the second, told them was highly economical for them and comfortable for their horses. It is not every farmer that owns forty horses; but in these days of co-operation nothing could be easier than for several farmers to agree among themselves to patronise jointly the first forge in each district, the owner of which would consent to meet their views. Let them, in fact, strike against the farriers, or make a lock-out. It only wants union among themselves, but they must first be converted from their own grooviness in respect to horse shoeing.

The Lincolnshire farmers were obliged, only in November last, to form a society for the suppression of the administration of poisonous drugs by their servants to their horses; one of them stating at the first meeting that, first and last, he had lost over thirty horses through this odious, but almost universal, practice. Perhaps these same gentlemen would excuse the suggestion that at their meetings shoeing might also be profitably discussed.

A remarkable discussion on shoeing, the heads of which may be appropriately introduced here, took place at the meeting of the Massachusetts Board of Agriculture in 1878. Mr. Russell started by stating that the safest way was to let the hind feet be bare, and to shoe the fore feet with tips, or crescents of iron, that only cover the toe Dr. Hunt, curiously 
enough for a medical man, went dead against this opinion, saying that ordinary shoeing did no harm whatever-it was the 'pounding' of the foot on the road which produced disease in the foot. He apparently only owned one horse at a time, as he says ' my horse,' and he was not able to make him last long, for he says that he was continually obliged to be replacing him, because every one of them got laminitis, or what is sometimes called either founder or else fever in the feet-all three terms being used to signify the same disease. When questioned as to how he had his horses shod, he stated, 'I tell my blacksmiths, when they put a shoe on, to heat it red hot:' This, by itself, would quite account for founder ; and it appears strange that a medical man should have been in such a red-hot hurry to expound such views, unless it was that, as a medical man, he thought to carry influence. However, if this was what he counted upon, he was singularly in error; for Mr. Bowditch, a practical farmer, one of those irrepressible Yankees who will persist in thinking for themselves, rose and said that formerly he had had the same trouble as the doctor with his horses, but that he had found out for himself that the only way to avoid founder was 'to shoe the horse properly, that is putting on as little iron as possible; let it cover the toe of the foot, and let the frog come down so that it will take the jar of the foot.' When asked, 'Do you have your shoes put on rerl hot, as the doctor does?' he answered that he made his blacksmith "put the shoe on only as hot 
as he could hold it in his hand;' this is virtually a cold shoe. He did not believe in calks, or paring the horn, but he let in his tips à la Charlier; and, finding that he could not get farriers to shoe as he wanted, he started his own forge, on his own farm, as he says 'for his own protection.' He goes on to say: 'When the mare I drive came to me she had a frog the size of my little finger; now it fills up almost the whole of her foot. Nine hundred and ninety-nine thousandths of all the trouble in horses' feet come from shoeing: in fact, practically all. Even in the case of heavy draught horses, put on as little iron as you can get on: never a heel or a toe calk. I have some heavy horses, and they go with seven or eight ounces on their feet. The whole secret is, if you have a horse whose feet have been abused for a series of years, all that is required is a little piece of iron at the toe. I am afraid I drive very hard down hill. I am in the habit of driving cripples; my friends have a good deal to say about the corpses that I drive; but I take care of their feet, and they manage to do good work. I make my best time in driving down hill. I have no fear of hard roads, and no fear of pavements, if a horse's foot is kept in proper condition. Last winter I rode my saddle mare (and, of course, my neck is more to me than anything else I own) on glare ice, with a small bit of iron'-inlaid, as before explained' four inches long, curled around her toe, and with a very small toe calk. I galloped out on the ice where the men were cutting the ice, and I had no 
fear of her slipping, although the horse that was marking the ice, that had calks on, two inches thick, did slip. There is hardly a person who owns a horse, who, if you put him four inches of iron on the toe, would think he could go more than half a mile from home without the horse breaking down.' Yet so thoroughly was Mr. Bowditch convinced of the value of tips let into the hoof, that he had found it worth while to establish his own forge for preparing them on his own farm. He says that other people will not patronise his forge, because he will not allow shoeing to be done in it on any principle but his own: and so his forge does not bring him in the revenue it otherwise would. He refuses to become a party to propagating mistaken ideas. People come to him, seeing his success, with lame horses; and when he has cured them, he says they go back to their old farrier. Both Mr. Russell and Mr. Bowditch appear to have been convinced, in the first instance, that routine was leading them astray; and, like sensible men, they saw that the only way to escape from it was to throw aside entirely all professional opinion on the matter, and have their own way (as did the Messrs. Smither, here in London), Mr. Bowditch going so far as to start a forge of his own, over which he could be, and was, entirely master. $\mathrm{He}$ says, comically enough, that it was not a commercial success, because his neighbours only patronised him when they were in difficulties, out of which he alone could get them, and then they went their way; but 
he seems to have overlooked the economical facts that, although in this way his horse-shoeing cost him more by the year than formerly, he had less to pay to the veterinary surgeon, that he got more work out of his horses, and that they lived longer, or were likely to live longer (as he had only then had two years' experience). If this be taken into account, his forge was, however indirectly, a great commercial success. If he had not found it to answer, so shrewd a man would not have carried it on, nor would he have ventured to speak on the subject in so independent and authoritative a manner on such a special occasion.

We are sadly in want of a man or two more in England like Messrs. Russell, Bowditch, and the Messrs. Smither, and as outspoken. They need not risk the setting up of their own forge, each man individually. They have only to co-operate, and either arrange that one of them in every district should start one, making an agreement with a certain number of neighbours that they should have all their shoeing done there, or else, by union, bring pressure on the shoeing smiths. A young man, just starting, or having just started, in business would be, perhaps, the best to choose, as he could not point to the universal satisfaction he had hitherto given(although horse owners are quite easily satisfied as long as the shoes will only stick on until they are worn out); and, after a couple of shoeings on the same horses, he might discover for himself that a new era was open to him by lending himself to the 
introduction of an improvement, and that he could thus secure very good and regular custom. There is no secret-or even special tools-required to forge or manufacture a Charlier shoe, but quite the contrary. One man can make it without help, whereas it requires two men to forge the ordinary shoe; and it only requires one special tool for putting it on, viz. Fleming's drawing knife, with movable guide for cutting the groove in the crust, price $7 s, 6 d$. 


\section{CHAPTER IX.}

DESCRIPTION OF FROG AND SOLE, BY DOUGLAS-RUSSELL ON HОT FITTING, AND 'CLIPS' ON SHOES-FACILITY OF ' BACKING' WHEN A HORSE STANDS UPON HIS FEET-STRENGTH OF THE HORSE'S TOE-EXCESSIVE GROWTH OF HORN ON TOES OF UNSHOD DONKEYS IN IRELAND-ALL SHOEING ONLY AN AFFAIR OF ROUTINE, AND IS QUITE UNNECESSARYMAYHEW, 'VETERINARY SURGEONS CLING TO THE PRACTICES IN WHICH THEY HAVE BEEN EDUCATED' - RETREAT OF NAPOLEON FROM MOSCOW WITH UNSHOD HORSES.

WHEN speaking of the importance of leaving the sole free to receive pressure, we by no means mean to imply that it must be under continual pressure. Its arched form indicates that on hard level ground it was not intended to come down. Such ground is often slippery, as in the case of smooth rocks, and the contact of only the frog, heels, and crust is more fitted to prevent slipping than if the hoof were flat. Hence in case of a slip under peculiar circumstances-such as very steep or wet ground, for instance-the concave shape of the bottom of the unshod foot would serve to allow the periphery to catch hold of irregularities which would arrest the slipping. On either softer or more irregular ground the sole is quite capable of taking its proper share of weight, as those who have seen 
unshod horses galloping over the softest or roughest kind of ground in turn (say Dartmoor, for instance) may bear witness to. Such horses only roughly pick their way when at full gallop: they lift their feet high, and let them come down where chance may, in detail, direct them. The weight of the horse is only partially transmitted to the arched sole by the elasticity of other parts of the foot.

The hoof may be described as somewhat resembling a double slanting truncated conic section, with the biggest end on the ground, and semi-cloven behind. To superficial observers this may not be suggestive of great resisting powers to the superimposed weight of the horse; but, if we look inside the hoof, we find that things are all right-how could Nature possibly go wrong? The inside of the crust, instead of being smooth like the outside, is furnished with several hundreds of thin, flexible, horny plates, called laminæ, set edgewise, very like the gills of a mushroom; whilst the coffin bone is covered with an exactly corresponding number of softer plates, which fit with the utmost nicety between, and adhere most closely to, the firstmentioned plates. This beautiful arrangement gives an adhesive surface on both the crust and the coffin bone, many thousands of times greater than the hoof measures in girth; and thus the weight of the horse is attached to, and suspended by, the crust, and only partially coming down on the frog and sole at times, and in irregular amount and force, and always finding delicate compound arrangements 
of elasticity, expansion, and contraction to obviate all danger from concussion.

As regards wear and tear there is nothing to fear; for, as 'Kangaroo' wrote in the 'Field,' ' it is impossible for a horse to become footsore in the frog, sole, or heel of his foot, as a result of travelling barefoot.' The horn of which the frog is formed differs from the horn of the sole in nature; and both of them are unlike the horn of the wall, of which latter the description by Mr. Douglas has already been given. The same authority says of the frog: 'In structure the horn of the frog may be compared to horsehair in the compressed state as used for stuffing sofas; and, if we can imagine this hair to be mixed with a fatty adhesive substance, we shall form a fair idea what the tough elastic frog resembles when under microscopic inspection.' 'The frog is only a continuation of the coronet; and, from its wedge-like form, and nearly total insensibility to feeling, proves that it is meant to take a bearing upon the ground, where it is useful to the animal either in action or repose; in the former it acts as a buffer, preventing concussion, whilst its hold upon the smoothest surfaces prevents slipping.' Of the sole he says: 'Over its surface there is no glazygluey layer to preserve its moisture, as in the crust ; while its fibres, stretched like strings, layer over layer, are as unlike the woolly, oily, substance of the frog as the horn of the crust differs from the bones which it covers. In one respect the sole resembles the frog; which is, that the outer layer of fibres in 
each becomes dead and falls off in flakes, the growth downwards of the new horn pushing off the old in turn.' This being so, all paring of either sole or frog is not only uncalled for but highly detrimental. To such of us as have been in the habit of thinking of the horse's hoof as merely a homogeneous block of horn, without any particular architectural design, the lucid descriptions given by Mr. Douglas must impart a new light. Some amongst us cannot fail to ask themselves whether all these perfectly designed and delicate, although strong, arrangements were so ordered merely to have them thrown out of use by scorching, stiffening, and covering them with rigid iron, and lacerating and compressing with nails the delicate tubes through which flows the fluid on which the crust depends for its health and vitality?

Literary shoeing smiths do not frequently appear amongst us; but America, as usual, has been able to 'supply this long-felt want' in the person of Mr. Russell. He writes, in 1879, a book of 140 pages, containing fifty illustrations, twenty-seven of which are of shoes of different pattern and form. Mr. G. W. Bowler, V.S., writes the introduction, and has 'carefully corrected the anatomical parts of the work.' A man that has invented more than a score of shoes of different principles and shape must have been of an inquiring turn of mind; but the fact that so many different kinds were thought to be necessary seems to argue against the necessity of any of them. A great deal ought to be expected 
from a 'scoop-toed rolling-motion shoe,' if there be anything in a name-which is to be doubted in this case at least. Another, the 'centennial' shoe, is described as follows: 'This shoe is made of steel, and is well concaved on the ground surface. The bars are made so as to fit upon the bars of the foot, and bear weight as the unshod hoof does in a state of nature, preventing bruises in the heels and quarter cracks. I have tested this shoe on horses that were quite sore and lame, the shoe being made of cast steel, the bars being sprung down from the heel to their points on the ground surface about one halfinch; this will soften and mellow the jar. The shoe, being well tempered, will allow the bars to spring with the horse's weight, and will be found one of the best devices possible to soften and relieve the effects of concussion when the horse is tender of foot, as well as to quicken the action in trotting, leaving the frog free and unimpeded to perform its important functions of cushioning the foot and shielding the sensitive parts from injury.'

It is, perhaps, scarcely fair to condemn by theory a shoe which one has not experimented upon; but if a small stone were to get jammed between the spring and the horse's heel, would not the horse be as effectually 'beaned' as if an English coper had done it for him? What a contrast we find between the result of forty years' research (as stated in the preface) of a farrier, and that arrived at by another American, Mr. Bowditch, a practical farmer, who found 'four inches of iron curled round the toe' to 
be better than anything else, 'even in the case of horses that had had their feet abused for a series of years.' This book, however, coming, as it does, from a farrier of forty years' experience, contains noteworthy remarks. Great stress is laid on the importance of paring the crust only, leaving the frog and sole to exfoliate of their own accord, and also taking the greatest care to pare down the crust perfectly level on all sides, so that the foot may stand quite upright. 'If we wish to examine a perfect foot, such as Nature made it, it is generally necessary to find one that has never been shod; for the common mode of shoeing is so frequently destructive, that we seldom meet with a horse whose feet have not lost, in some degree, their original form, and this deviation from their natural shape is generally proportioned to the length of time they have worn shoes. From this circumstance, writers on farriery have been led to form various opinions respecting the most desirable form for a horse's foot; but had an ever provident Nature been consulted, this variety of opinion, it seems to me, would never have existed.'

It is strange that Mr. Russell, after expressing himself thus, should have come to the conclusion that more than a score of different patterns and principles were necessary to help Nature. The fact is that these various kinds of shoes are only so many orthopedic instruments which he considers useful for 'cripples.' So all his inventive powers have been thrown away when 'four inches of iron curled round the toe' are found to answer better 
than all his far-fetched inventions. On the other hand, it is refreshing to find him speak thus: 'The practice of hot fitting and clipping'-that is, raising a clip on the toe, and sometimes also on both quarters-' is very destructive. Burning the sole will, in time, partially destroy the sensitive laminæ, and impair the membranous lining underneath the coffin bone, as well as close the pores of the horn, causing the roof to become hard, dry and brittle. It also impedes, as a necessary consequence, the healthy growth of the hoof.'

'The advocates of hot fitting present many specious reasons for the furtherance of this practice. It is alleged that shoes cannot be fitted so rapidly nor as closely by any means other than that of hot fitting; and this is generally true, for, by this means, the hoof is burned to correspond with the inequalities which occur on the surface of the shoe, until the latter is thoroughly imbedded in the horn. On the other hand, however, this fusing of the horn is in opposition to its right growth and operation, and is the prolific source of many evils and abuses.'

Although a veterinary surgeon certifies to the correctness of the anatomical descriptions contained in the book, we may premise that he does not guarantee everything else; or we should scarcely meet with such a passage as this: 'The shoe should ordinarily be perfectly flat on the ground-wearing part, but is to be worn concave on the surface next the foot, else it will be apt to produce lameness by pressing on the sole. I have shown that, in a sound foot, the 
sole is always concave; and it might be supposed that it cannot possibly receive any pressure from a flat shoe. But when a horse is exerting himself, either in galloping or drawing burdens, the sudden action of the animal's weight causes the laminæ to gradually lengthen, and suffer the coffin bone to press on the sole; its concavity and elasticity allow it to descend and expand, and that gradual yielding must materially endanger the sole by a violent contact with the shoe, were it made otherwise than hollow.'

This theory is untenable. The sole cannot in a sound foot descend round the edge. As to the shoe which he recommends for ordinary use, it was certainly recommended a century ago by Osmer; but Professor Coleman was the first to turn the shoe over, and leave the flat surface against the hoof, and the bevelled, or seated, surface on the ground. And this is the prevailing pattern since then advocated. It is, perhaps, the best of the two ; but neither of them has the claims of the Charlier tip to simplicity, and a near approach to a natural foot. The Charlier shoe, the same as the tip, is only a quarter of an inch in thickness and half an inch in width for a horse of average size, and the full-sized shoe weighs only a third of what an ordinary plain shoe, without calks, will weigh; and this makes eleven or twelve ounces difference on each foot, if the whole shoe be worn, and more in the case of tips. Youatt tells us that ' an ounce or two in the weight of the shoe will sadly tell before the end of a hard day's 
work.' One precaution to be taken when applying the shoe is to pare lightly the bottom of the crust first of all. A whitish line, which marks the inside of the crust, will then be found; and this white line must be preserved intact, with just a little bit to spare, when cutting the groove. Mr. Stevens, M.R.C.V.S., Park Lane, London, sends, for sixpence, a pamphlet, giving instructions; he also keeps ready-made shoes, \&c., concerning all which the pamphlet furnishes information. A correspondent who shoes all his horses à la Charlier, a stranger to myself, writes: 'I live in the country. I have an ardent disciple in the farrier, who shoes beautifully. I really don't think the shoes he puts on my horses weigh more than one quarter those made by his neighbours do. I am glad to say, too, that it has been a fine thing for him in business; many of the neighbouring gentry employ him to shoe on this method. A horse can back a load on any ordinary road without calking, if you let him stand on his FEET.'

Owners, be they farmers or otherwise, who may have read these chapters, and may be induced to give the Charlier shoe a trial-beginning, as is best, with a shoe which, called three-quartered, is short at the heels, not reaching or touching the bars, and, at the next shoeing, having only a half shoe, or rather tip, say six inches roundwould be likely to venture on the four inches, which length has been found already to ' fill the bill.' Having arrived successfully at this point 
(which all would reach, if they tried), they might be led to reflect, and ask themselves whether this was the full extent of improvement they could arrive at. 'Impecuniosus' stopped short here; but the American farmers pushed the thing still further by doing away with even this small protection on the hind feet. At this point they also made a stand, apparently overawed by their presumption or stupefied by their success. They were unaware, or unable fully to appreciate the fact that Nature was smiling benignly upon their efforts in the right direction, even when they were brought face to face with the rewards she was so plainly giving them at each advancing step towards perfection.

It is astounding that the last scales should not have dropped from the eyes of such investigating and liberally-disposed men, and have thus left disclosed to their perfect vision the fact that Nature had not left the toe out of account when she designed the wonderfully perfect and beautiful foot of the horse, defective as it is popularly, but erringly, supposed to be. The toe is even provided in an extra manner with the means of standing all wear and tear; for, if the tips be removed and the horse worked barefoot over the roughest kind of roads, as he is in many countries, the toe will outgrow all calls upon it, which is what no other part of the hoof will ever do, although they all resist wear. The toe alone will require to be restricted in its growth; for it will grow too long, even under hard work on hard roads, and must be kept rasped back occasion- 
ally to a suitable length and shape. In Ireland donkeys are worked unshod in draught and over macadamised roads, even over loose broken stone; and Mayhew gives an illustration showing a donkey's overgrown toe turned upward like a half moon from the want of care in keeping it rasped back.

Only last December a correspondent in a contemporary referred to this same illustration and to these donkeys. He says that lately, when he was in Ireland, he saw the donkeys being worked unshod; and not only had the hoof not been worn away, but, on the contrary, it had outgrown the wear and tear of work, the toe having become turned up, and requiring shortening exactly (as he says) as shown in Mayhew's ilustration. He says: 'Certainly the roads in that part of Ireland are calculated to cause the greatest amount of wear and tear.' In other countries the toe is kept trimmed, and this is necessary for the comfort of the animals. Yet the laziness of the Irish owners in leaving the superfluous horn affords a convincing proof that the toe will outgrow all demands upon it, even on roads that 'are certainly calculated to cause the greatest amount of wear and tear.'

What further proof can be needed that Nature has fully provided for every part of the hoof? A protection of iron, even in its most mitigated form, is only a mistake. Some may say that this is all very well for the donkey, but that it is quite another affair with the horse; and this remark was 
actually made to the writer by an Irish clergyman. Such an argument can only be fished up from the depths of bigotry. Those who urge it would also deny that donkeys could go unshod, but for the fact that they see them doing so, and successfully. Now, in England, donkeys are shod; and why? Only as an affair of routine. One of the chief argumentsin fact, the sheet-anchor - of those who will not allow the equine species to go barefooted is 'our moist climate and hard roads.' Ireland is rather ahead of us in having a moister climate, and the roads, as described, are in no way better than ours; so the point of departure of nearly all sticklers for the necessity of shoes will bear no more investigation than the puerile and futile chain of reasoning with which they follow it up.

To such as are open to conviction, it will be evident, therefore, that our donkeys in England would gain by leaving off shoes, and that their owners would at the same time be richer. Why should this not hold good also in regard to the horse? The statement that he is less fitted for it by nature will stand neither argument nor practical experiment, should the latter be made with intelligence and a desire to succeed.

Can any one really believe that the animal which is endowed with the greater speed and power should have worse feet than his inferior in both respects? Nonsense is no name for such a creed; it is something far worse. Mayhew says: "Nature has in vain laboured to instruct the waywardness of conceit; 
mankind could afford to endure all evils before it could afford to question the perfectibility of mortal invention. There is no accounting for incongruities when men, deserting reason, consent to adopt routine as a guide. Veterinary surgeons attribute to shoeing all the evils with which the hoof is affected. Veterinary surgeons are somewhat slow in adopting new ideas; but seem, with the firmness and tenacity ignorance displays towards a favourite superstition, to love and cling to the practices in which they have been educated.' Some people cling to the superstition that nailing a horseshoe on the door keeps out the witches. The shoe does, certainly, less harm on the door than on the horse's foot; but to nail it on the latter is a superstition utterly unworthy of the civilisation and intelligence of the English nation in the nineteenth century. Future historians will place upon record that an appeal had to be made to us, in the year of grace 1880, to abandon the use of artificial foundations tacked on to a living creation of God; and these historians will not fail to throw further shame on us by pointing out the fact that semi-civilised nations, with whose customs we were conversant, were able to work the horse harder than we did without any protection to his feet.

In the retreat of the French army from Moscow, the horses lost all their shoes before they reached the Vistula. Yet they found their way to France over rough, hard, frozen ground. 


\section{CHAPTER X.}

CNSHOD HORSES IN THE INDIAN MUTINY-UNSEOD HORSES IN THE ZULU WAR-FARRIERS IN THE ARMY ARE TAILORS, ETC. - 'DAILY TELEGRAPH' ON FROZEN STREETS-COMPARATIVE INUTILITY OF COGS AND STUDS-UNSHOD HORSES IN MEXICO, ETC., AND THEIR REMARKABLE FREEDOM FROM I.AMENESS AND DISEASES OF THE FEET AND LEGS.

DURING the mutiny in India many of our cavalry horses went unshod, because they could not get shod, and they never went better in their lives.

In the 'Morning Advertiser' of July 18 last, the special military correspondent at the Cape gives an interesting account of a ride that he made with irregular cavalry on a raid. He says : ' $\mathrm{Few}$ of the men have their horses shod in front; some do not shoe at all ;' and he remarks that, in his excursion, they had to go over 'sheets of polished, wet, slippery stone in the torrent beds, making one wonder how our unshod horses could keep their feet.' It is worthy of remark that this was only a few days before the battle of Ulundi, in which these horses took such an active part. In fact, they saw the whole war through; and, on August 9, we find the special war correspondent of the 'Daily News' reporting of these same animals that 'the 
constant work they have had naturally keeps them devoid of superfluous flesh; but, for all this, they are as hard as nails, and good in the wind.' All through the reports on the war, not a complaint was made as to these horses falling lame. Surely there must be something in this. Sheets of wet, slippery rock, and rolling stones in river beds, would be calculated to try the hoofs to the utmost; yet in the pursuit of the Zulus, when they fled at Ulundi,

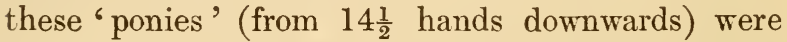
able, we are told, to follow miles further than the shod horses.

Military farriers are no better than others. In fact, it does not appear, even in the army, that any previous knowledge is thought necessary to make a man a farrier, any more than it is generally supposed necessary to get the consent of an eel to his being skinned alive. Mr. Douglas says: ' With facts before me, is it a wonder that I should blame the bad shoeing smiths of the army for much, if not most, of the mischief; the once tailors, haberdashers, colliers, and clodhoppers, but now farriers, who first lame the horses until they are unable to walk, and then are cast and sold for a few pounds? In my own regiment, the 10th Hussars, just before it went out to India, out of fifteen farrier sergeants and shoeing smiths, there were only the farrier-major and two others that had been farriers before they joined the army. One of the remaining twelve had been bred a tailor, and, as a tailor, had worked for the regiment; a second had been a 
collier, a third a groom, and so on throughout the dozen. Hitherto tradition and routine have been permitted to guide farriers in their wondrous ways of horse-shoeing; consequently it is a question whether, in following the manners and customs of their forefathers, they are more to be blamed than the general public.' By 'the general public' it is presumable that Mr. Douglas meant the generality of horse owners. The general public knows nothing about the shoeing of horses.

During this present winter, rate- and tax-payers have clamoured in the daily papers for sand, ashes, salt, \&c., to be sown broadcast, at their own expense, on all the streets of London, and at an hour or two's notice, in order to prevent the slipping of horses, and the destruction of life and property thereby occasioned. In times of frost and snow this sudden and extensive distribution can never be accomplished in time for all; in the case of snow it is almost useless, because it will not prevent snow from balling in the feet of shod horses-except they be shod Charlier fashion. The real remedy lies in the hands of the horse owners, and they could, if they chose, economise for themselves at the same time that they took a heavy charge from the shoulders of the rate- and tax-payers. The unshod horse will not slip upon either asphalte, wood, or granite pavements, or even on glare ice, because the natural healthy hoof is rough enough, and tough enough, to hold on a smooth surface, unless indeed you should ask the horse to keep back a heavy load, when going 
down hill, without a brake on the wheels. Even then he will do better than a shod horse. Here is an extract from the 'Daily Telegraph' of this year, January 28 , in an article on the weather then being experienced: 'As the frost had not given way, the wicked dew turned into glass as it fell in the hard roads, beaten and worn smooth by the slipping hoofs of the pitiable, but not much pitied, horses. Many severe falls were consequent on the slippery state of the carriage-ways and foot-paths; and traffic was much retarded in the busier thoroughfares of the City. Those of the West-end were, comparatively speaking, deserted ; for nobody having horses of any value would willingly have had them out at such a time.' One lady told the writer that she could not use her carriage 'because her horses could not stand roughing, as their hoofs were too tender and delicate to bear the insertion of nails oftener than once a month.' This lady only expressed what hundreds of others felt.

The patentees and advocates of the various systems of cogs, \&c., will say that all this might be avoided if, at the approach of winter, people would have their horses shod with their variously recommended shoes; but even if they were to do so (and they do not, and will not), none of the systems are perfect. Cogs, big or small, get worn smooth in a very short time, and some of them fall out. In either case they are found not to answer; and they are not generally used, or likely to be used, whilst they only hold good for a day or so, and leave one 'stuck' when 
least expected. Even the Charlier shoe, although it will not pick up snow (the facility for doing which is increased by lifting the foot higher from the ground, when cogs and calks are used), is not perfect upon glassy streets. We have seen that Mr. Bowditch condemned the use of both toe and heel calks, as a general rule; yet when he rode his mare upon a frozen lake he turned down ' a small toecalk.' He had no calk behind because the heels were bare, and so there was no danger of slipping on their part; neither would there be any reason to fear that the bare toe would act otherwise.

The writer has seen a valuable light horse, nearly thoroughbred, have on a full set of shoes, in which eight nails, nearly three-sixteenths of an inch in thickness, were driven four in each quarter, and in a space of three inches for each four nails. What an immense amount of laceration and compression the delicate hollow fibres of the crust must have suffered by thus wedging them up within a fourth of their natural dimensions! Besides this, the hoof was carved out on the crust to receive three clips, one on the toe and one on each quarter. A calk, three-quarters of an inch high, was put on one heel of each hind shoe, and, on the other heel, a screw cog of equal height. On each front shoe a cog, also three-quarters of an inch high, was put upon each heel. This wretched victim to fashion was then regarded with the utmost satisfaction by the farriers and his groom; and all this heathenism was perpetrated in the forge of a 
reterinary surgeon. But, perhaps, he was shoeing to order.

It has been well said that 'ladies are not bigger slaves to fashion than are modern horse owners.'

In a paper dedicated to agriculturists it has been maintained that horseshoes are an absolute necessity, but that 'the difficulty in riding or driving through the London streets arises from the variety of pavements in use. From Westminster to the Bank, horses have to travel over macadam, asphalte, wood, and granite. The shoe adapted for traffic on one kind of pavement ill suits another.' But is it so? Ask Mr. Smither. 'If we had a uniform kind of pavement, a shoe for universal (?) use would be quickly invented. The ingenuity of man would devise horseshoes to travel over glass, were glass the only pavement in use.' This is an insult to the common sense of its readers. It has been widely, and for a long time, proved that the naked foot of the horse is as much at home on one kind of hard road as on another, and can pass over all of them alternately without wearing out, or inconveniencing the horse, and that on none of them will he slip, or on wet grass either.

In Mexico, Yucatan, Honduras (both British and Spanish), Guatemala, San Salvador, Nicaragua, Costa Rica, the United States of Colombia, Venezuela, Ecuador, Bolivia, Peru, and Brazil, horses, mules, and donkeys are worked over every description of hard roads, most of them exceedingly rough, carrying very heavy packs from the back country 
down to the seaboard, and in some cases making a journey of several hundreds of miles, and they load back again; yet they never wear out their hoofs. The writer speaks from experience; for it has been his lot to own and work hundreds of animals at a time in more than one of these countries; and if shoeing could have helped him in the slightest he would most certainly have resorted to it. No man could see four or five hundred animals incapacitated from work without seeking such a simple remedy; but it was never wanted, and many years of experience of this kind have naturally convinced him that horses work better, and can travel further, without shoes than with them.

Nor is this all. Unshod horses enjoy almost a total immunity from diseases of the feet and legs. Side-bones, sanderack, seedy toe, ringbone, thrush, and quittor were never seen in the writer's stables. Spavins, curbs, splints, and windgalls were very rare. Thrush is effectually cured by removing the shoe from any horse that suffers from it. Professor Coleman said that 'the frog must have pressure, or become diseased ;' and Mr. Douglas says that 'contraction prevents a supply of blood from reaching the sensitive frog that produces the insensible frog; and so, becoming useless for the purpose nature intended it, instead of coming to horn it oozes out a noxious-smelling fluid.' The unshod horse has frog pressure; so, unless he should stand upon rotten litter, thrush he cannot get. Quittor is caused by pricking with a nail, or by the 
horse resting with the toe of one foot, and bearing with the heel of the shoe of that foot (especially should the shoe be calked) upon the coronet of the opposite one. Hence unshod horses can with difficulty get quittor, neither do they. An unshod horse ' feels his feet,' and knows what he is doing with them; so he scarcely knows what it is to overreach himself; and even if he does such a thing, no evil consequences are ever noticed, because the horn cannot inflict injury like iron. For sandcrack and seedy toe there are no names in the above-cited countries, and no one can bring the natives to understand that such diseases exist. If you suggest corns to them they laugh in your face, and no wonder.

Mr. Dalziel says: 'Corns on the human foot are practically known to most people, being one of the unpleasant and unnecessary attendants on civilisation, for they came into fashion with boots and shoes. So with corns on the foot of the horse.' Mayhew says: 'Spavin, splint, or ringbone are no more the legitimate consequences of equine existence than noads and anchylosis are the natural inheritance of human beings.' By illegitimate treatment ninetynine hundredths of the diseases of the feet and legs are caused-shoeing being the most to blame. 


\section{CHAPTER XI.}

BRITTLE HOOF AND THE TREATMENT IT GETS-THE ' WATERCURE' MORE EFFECTIVE-BRITTLE HOOF OFTEN LEADS TO SANDCRACK, SEEDY TOE, AND PUMICE FOOT-HARD ROADS ARE FAVOURABLE TO THE UNSHOD HOOF.

BRITTLE hoof is so common that all perhaps are alive to some of the vexations it causes. But only when it gets very advanced is it taken in hand, and it is then treated by some kind of 'hoof ointment,' joined to 'stoppings' of various kinds, with a blister, mercurial ointment, or a stimulating liniment applied over the coronet. The first two only aggravate the disease.

Mr. Douglas says : 'The rules for keeping a horse's feet healthy, and preserving the horn, are to use nothing but water to the hoofs-either as a cleanser or an ornamenter; and never allow horses to stand upon litter during the day. Grease or tar, by shutting up the pores in the horn, prevent the natural moisture from reaching the surface outwardly, and the air from circulating inwards-consequences which act upon the horn with ruinous results.' Lieutenant-Colonel Burdett has, within the last few weeks, expressed his opinion of grease 
in somewhat similar terms. Another equally baneful habit is 'stopping' the hoofs with hot greasy mixtures or cowdung, under the idea of softening them or cooling them. This idea works wrong end first; for stopping and greasing heat the horn, whilst soft horn is not desirable; tough, dense, springy horn is the right kind of thing, just. such as Nature supplies when she is not interfered with. As to the blister, mercurial ointment, or stimulating embrocations (which latter the stableman will call ' oils' - a name that has always carried great weight with it amongst his class), in the words of Mr. Fearnley, 'all they can do is to cause a splutter of vitality in the part.' What is the use of a mere splutter of vitality? That which is wanted is a renewal of vigorous and lasting vitality, not dependent on the irritation caused by the continual application of drugs.

There is another way of treating brittle hoof, called the 'water cure.' The horse's shoes are removed, and he is put to stand on the bare stones or bricks. Folded flannel is then fastened round the pastern, but allowed to fall over and cover the coronet and hoof; the flannel is kept well soaked with cold water by day. As it cannot be kept wet and cool by night it is best to remove it the last thing, or otherwise it will heat the foot instead of cooling it. The horse must be walked out twice a day (removing the flannel for the time) over a smooth hard road. In a few days the top of the hoof will begin to lose the harsh, dry, shrivelled, 
scurfy appearance it had hitherto presented, to assume one of plumpness, roundness, fulness, and glossiness, which appearance shows that some important change is taking place. It (the coronary band) is now becoming restored to a healthy condition, and fit and able to secrete healthy horn, which it will straightway set about doing. The exercise on hard roads should now be daily increased-the application of the wet flannel still be continued.

The groom will not like the look of the coronary band, as he is so unaccustomed to look upon a healthy one. But he will be still more disgusted when he sees, a few days later on, that the shiny appearance which he so much distrusts is extending itself down the hoof, and then he will be 'sure as them feet is a rottin' off.' Grooms have been heard to say so, with the addition of a few words not exactly complimentary to their masters.

The coronary band has been restored to health, and the proper secreting power has been recovered, the removal of the shoe having permitted freedom of circulation, which has been further encouraged and stimulated by exercise, whilst heat has been kept down by the cold water. This plentiful supply of healthy blood is assimilated by the coronary band, in its passage through which it is by 'the wonderful chemistry of Nature' converted into plasma, which afterwards becomes hard horn. The treatment must be continued until the shiny horn reaches the ground.

Brittle horn cannot be satisfactorily repaired; 
it must grow out, and be replaced by horn of an opposite character, and this is the way it is done. The disease may again be produced by the same course of action that first brought it on. When this is resumed, and the horse again begins to suffer, they say that he has never been cured.

Mayhew says: 'Nothing can be practical if there be wanting the desire to embody particular directions.' It is found that nearly every one who tries this course of treatment is inclined to have his horse exercised either in a field or on the grassy sides of the roads, instead of on the hard. This is a mistaken theory. On the grass the hoof receives too little friction or attrition. Mr. Douglas says: ' From the moment a horse is foaled, we either keep him in grass fields soft to tread upon, or in warm stables standing upon soft straw, and then we are surprised that his hoofs should become dry and brittle, instead of keeping moist, tough, and hard. In the Orkneys, in the mountains of Wales, the wilds of Exmoor and Dartmoor, many parts of the continent of Europe, and in a considerable portion of the rest of the globe, horses run about over rocks, through ravines, and up precipitous ridges, unshod; yet all this is done without difficulty, and to the evident advantage of their hoofs, for these animals never suffer from contracted feet, or from corns, sandcracks, \&c., until they become civilised and have been shod.' Another writer, a Devonian, says : 'Dartmoor is not a great wild flat, as many suppose; but, on the contrary, it is for the most part a continual 
succession of very steep rough hills or "tors," and rugged "combes," strewed with granite rock and stones. Yet in spite of all, besides the bogs and chronic state of rain, the herds of ponies gallop fearlessly along the rough steep sides of the combes, or down and up. It is a pretty sight to see them, especially in the spring, with the foals by their sides.'

Mayhew says of the shod horse: 'As the shoe alone rests upon the earth, of course the hoof lacks needful attrition.' The attrition or friction caused by exercising the unshod animal on hard roads is salutary to the whole foot, because it acts as a natural stimulant to circulation and secretion, not causing a 'mere splutter of vitality' that is of no lasting worth, but making the horn ' to thicken and accommodate itself to its task, like the skin of a blacksmith's hand.' Youatt says: 'The horn answers to the skin of the human foot.' Magistrates examine the hands of vagrants: and, by their hardness or softness, judge whether they have bon $\hat{a}$ fide 'frozen-out gardeners' before them, or professional beggars. Gardeners and navvies neither wear gloves nor pad their spade handles, although the bottom or forward hand comes down and slides on a roughly riveted iron strap. The hoof of the horse cannot be looked upon as being of a more delicate nature than a man's hand.

Besides the advantage of attrition being gained by the removal of the shoes, expansion and contraction which play so prominent a part in the general 
economy of the whole foot, and its maintenance in health, also lend their aid in producing sound horn. Without the removal of shoes the "water cure' cannot be a complete success. Mayhew says: 'The heels of the horse may become rigid and wired in by the fixing powers exercised by the nails of the shoe. But remove these nails, allow the foot that motion which is needful to the health, and its internal structures may recover their lost functions. The veterinary mind was, however, slow to recognise so plain a rule. Like all Nature's laws, the truth necessitated not that show of mastery in which the ignorant especially delight.'

The writer has already confessed his inability to agree with Mayhew in everything he says; and he thinks that here he is unjust to veterinary surgeons. There is, perhaps, not one among them who would not order the removal of shoes oftener than he now does, if he could be sure that his order would be attended to. Owners rebel, up to the last point, against what will evidently throw the horse out of work for some considerable length of time. They prefer ' patching up.'

It is not sufficiently acknowledged, or understood, that veterinary surgeons have to deal with people who generally want their 'say' in all cases of lameness. In other matters they are more tractable; but every one thinks he knows something about. lameness, and almost every one tries to shirk what every practitioner would recommend, if he conveniently could-REST. But, knowing, as they do, 
what I have attempted to explain, these gentlemen (in practice) find it expedient to order 'mild' or 'sweating' blisters to be applied, with, perhaps, an intimation that they will have to be repeated; and, during the interims, they give the groom a bottle of ' oils,' because they know that this keeps him contented and in subjection; and thus they, justifiably, obtain rest for the horse. This rest is what they are after; but it won't, by itself, cure brittle hoof. When Mayhew speaks of the ' show of mastery in which the ignorant especially delight,' the 'ignorant' is plainly meant to be applied to the owner-or rather to the groom, for he is mostly master. It may be advisable to keep these kinds of things 'straight,' and not make oneself misunderstood on both sides.

Brittle hoof, when neglected, or improperly treated, often causes still more serious diseases. Sandcrack be it either in the shape of 'toe' or ' quarter' crack, is a frequent result ; and so is seedy toe, and also pumice foot. They will all succumb to the water cure if the toe at the same time be kept well shortened, or rounded off. Mayhew says that "seedy toe has been much thought about, and fancy has been somewhat racked to account for its origin.' The origin was not far off, and so it got passed over by hasty searchers for some distant cause: it is radically-shoeing. The same cause, as Mr. Douglas states, produces sandcrack. Pumice foot is often to be accounted for through 
the brittle crust being unable to retain its hold of the sole, which then becomes depressed; and, as at the same time the laminæ, partaking of the general disorder of the crust, of which they form the interior, are unable to maintain the coffin bone in due suspension, and are forced to allow it to follow the descent of the sole, the horse becomes past cure, and should be destroyed-or, rather, finish being murdered.

The fact that hard roads are beneficial to the naked hoof is again substantiated by Mr. Douglas in the following passage: 'When the frog is permitted to remain sound and whole, the more it comes in contact with gravel, stones, or even sharp flints, the firmer, tougher, and more healthy it becomes; while on the contrary, when cut with a sharp instrument, allowing the moisture, which is its life, to escape, it dries up, hardens'-the frog, unlike the crust, should not harden-' cracks, and becomes highly susceptible to every impression, as well as diseased.' The same remarks hold good with regard to the sole; but Mr. Douglas withholds them when speaking of the sole-perhaps he was not convinced of that fact. Experience proves that the crust also holds in contempt sharp flints, \&c., when it is fairly treated and inured to them. By fair treatment it is meant that it should be let aloneas a man's hands would be if he were a labourer on a farm. In the colliery districts, where so many women work with the shovel, their hands become horny, as the doctors find out when they have to cut 
down upon a whitlow. Friction against a hard substance brings about this extra thickness and hardness; the young ladies who handle silk, woollen or cotton textures all day long in shops have soft hands. Like begets like; and hard roads make hard feet for horses, in spite of all superstition to the contrary. The writer has more than a quarter of a century of experience and practice with unshod horses in large numbers. He has, therefore, no theory about the matter, constructed, as may perhaps be imagined, upon the quotations he has so freely used from the writings of scientific, professional, and practical authorities. 


\section{CHAPTER XII.}

LETTER OF 'ABERLORNA' IN 'FARM JOURNAL'-LIEUT.-COL. BURDETT ON HOT SHOEING, GREASING, 'stOPPING,' AND PARING THE HOOF-COLD SHOEING-NORTH METROPOLITAN TRAMWAY HORSES ARE SHOD COLD WITH THE SEELEY SHOE-GRADUAL BREAKING IN OF HORSES TO GO UNSHODDIFFERENT CHARACTERISTICS OF COUNTRIES WHERE HORSES ARE BRED-ANCTENT WRITERS ON BARE STONE AND WOOD FOR STALLS - OSMER HAS KNOWN UNSHOD HORSES GO SOUND IN ENGLAND-6 OUR MOIST CLIMATE AND HARD ROADS' - MAYHEW AND DOUGLAS ON OPPOSERS OF PROGRESS.

THE letter of 'Aberlorna'" seems to render it advisable to introduce here some remarks, which were only intended to be made later on, as to the amount of work to be first given to a horse who has had the full shoe replaced either by a tip or by nothing at all, and also as to small precautions useful to take when making the change.

It is prudent to allow the shoes then on to wear themselves out, as this gives the frog, sole, and bars a chance of somewhat recovering from their last mutilation, which mutilation may have been greater or lesser; as, fortunately, now-a-days some of the smiths do not cut away as much horn as was pre-

1 See Appendix A. 
viously the universal rule. On this account some horses are better prepared than others for the change. Some, again, have naturally stronger and better formed hoofs than others; and all these circumstances weigh. What work one horse would be able easily to perform might be quite too much for another. At any rate, to ride a horse, on the second day after putting on tips, twenty miles 'over a road covered with new metal, in a simply abominable state,' is, without doubt, a hazardous proceeding, and one courting a failure for the trial (not intentionally so, of course). Twenty miles at the present season over the road described is, in fact, a day's work for any horse.

It is not easy, having regard to the various possible existing combinations of the aforesaid circumstances, to lay down any rule. Discretion and intelligence here come into play; it is astonishing what a wide difference there is between people in this respect. Some will carry things to the opposite extreme, and go poking about only a mile or two daily, for weeks, on the grass by the side of the road-or even in a field: something between the two is the correct thing-moderate distances, on hard smooth roads, for a few days.

In the case of 'Aberlorna' all we know is that his horse had ' naturally rather flat and tender feet;' and that, after this rough trip, ' he went tender; but this appears to be wearing away in a great degree, and it is surprising how hard and firm the soles of his feet have got.' 
As this gentleman owns a number of horses, the question must be of considerable pecuniary importance to him ; and if, by an indiscreet step, he had injured his horse, he would have been likely to become disgusted, and have desisted, and so have thrown away a chance of benefiting his whole stable; and, besides, the farrier would have turned the laugh, which he got up at the mere idea of such a thing, unpleasantly against him. It is to be hoped that he will do a little less at the next trial, and then he will not find his horse ' going tender.'

A gentleman writes privately: 'I once rode a hack for six weeks, in comparatively dry weather, with only tips, the heels being quite bare. The heels grew and expanded as you describe, and nothing could be pleasanter to horse and rider; but no sooner did a wet time set in than I was obliged to revert to the full shoe-at least, I thought so.' (!) The naïveté herein apparent could hardly be surpassed. This gentleman received the highest education that England affords, and took his degree. No one can 'spot' him, so there is no breach of confidence in divulging the fact that he is a clergyman of the Church of England. Yet even a man of this calibre was not proof aguinst a popular delusion.

To come back again on the question of shoeing ' hot' or 'cold,' which 'Aberlorna' has revived. It is well known that thereon veterinary surgeons differ. In these articles one veterinary surgeon has been cited who was intensely opposed to hot shoeing; as also an American 'practical horse-shoer,' the author 
COLONEL BURDETT ON THE HORSE'S FOOT. 103

of a work on 'Scientific Horse-shoeing,' professing forty years' experience; and an American farmer who had felt obliged to shoe his own horses ' for his own protection'-three differently interested classes of men who were, as such, purposely quoted.

A prize essay does not necessarily carry everything before it merely because it is a prize essay. Such essays are sometimes written with a view only of obtaining a prize; and 'coaches' tell us that, in order to do so, they must coincide with the views of the examiners. It is not pretended, however, that the essay in question was engineered on this principle: it is much more likely that it was a thoroughly conscientious production; but doctors differ.

An independent, practical essay on the horse, written by Lieutenant-Colonel Burdett, is appearing. since January last, in the 'Richmond and Twickenham 'Times.' Here are some extracts from the gallant colonel's writings: 'One of the first considerations of an owner or driver of a horse should be the feet and legs of his horse; for, should anything be the matter with either, the animal should not be put to any description of work; for, if he is, he is sure to suffer, and in many cases most acutely.' . . . ' 'The foot of the horse is a most complex and elaborate piece of machinery, and perfectly adapted to the work it is intended to perform; but our artificial assistance, so far from preserving, often cripples, and frequently totally ruins it.' . . ' 'The natural sole of a horse's 
foot is almost impenetrable, and so hard and strong that it protects the inner or sensible sole from all harm. In many instances (though I am glad to say not so much in the present time as formerly) farriers were in the habit of paring away the natural sole, and making what they called "a clean foot," and cut so thin that the thumb could almost leave an impression. Consequently, when the horse was required to go over a new made road, either gravel or macadam, he would naturally go "tender;" whereas if the sole had been left intact, and the loose, rough parts taken off with the drawing knife, the sole of the horse's foot would have been protected.' It is disagreeable, and will be thought presumptuous, for the writer to feel himself obliged to differ from the colonel, and to state that experience has taught him that even these loose, rough flakes, of either frog or sole, should never be touched: they are going through the natural process of exfoliation, and should be left to complete that process spontaneously, and without any help from the knife.

We must again cite this estimable writer: "The crust of the hoof is pared to a certain level, and then a hot shoe is placed upon it to burn away the hoof until the two surfaces correspond, thereby heating the outer (?) crust of the hoof and rendering it brittle, and liable to break away, when the nails are introduced for the purpose of holding on the shoe. There is another thing most injurious to the foot, and that is blacking the outside of the hoof. Generally speaking, grease and lampblack are 
used to give the hoof a smart and clean appearance. Instead of that, as soon as the horse is brought out, if broken straws from the stall are not adhering to it (generally the case), in less than ten minutes it is covered with dust, which adheres to it, and stops all chance of circulation of air, which is so necessary to the well-being of the foot. The hoof is naturally porous; and if coated with grease the circulation of air is stopped, and the foot naturally injured, and there is a great probability of engendering disease.' These quotations are taken from the paper mentioned, in its issues of January 17 and 31, 1880.

Some months since a contemporary stated: 'We hear that a new horseshoe has been adopted by the North Metropolitan Tramways Company since they commenced to keep their own horses. The stud of the company numbers over 2,000 animals ; and, with the view of easing the laborious travelling of the horses over stony roads, the new patent horseshoe of Mr. A. Seeley, of the United States, has been tried. This shoe weighs $1 \frac{1}{4}$ lb., or less than half the usual weight' (The Charlier three-quarter shoe weighs five ounces). "It is fastened on when cold, and, being without "clips" or calks, the frog, or centre of the horse's foot, is allowed to rest firmly on the ground. The cost of shoeing under the new system is about ninepence, instead of one shilling, a week per horse.'

The Seeley Company now refer in their prospectus to tramway and other companies in the chief towns in England as to their success in working 
horses with a cold-fitted shoe. It is not to be lost sight of that nearly a score of these companies employ each thousands of horses; and yet leading authorities have pronounced opinions utterly at variance with each other on the use of the shoe. But doctors always have differed. The statement that fifty cold-fitted shoes are lost to every hot one, certainly could not be substantiated; they stand at no disadvantage at all in this respect; the nails hold better in horn that has not been rendered brittle by scorching. The tramways have now been using them for nearly two years, and that looks as if they kept in their places pretty well. In Spain, where cold shoeing is universal, and forges very wide apart, shoes keep on until they wear out.

Cold fitting by no means entails any necessity for 'fitting the foot to the shoe.' The shoe, whilst hot, is forged to the correct size and shape of the foot. The paring of the crust to fit the flat surface of the cold iron takes longer than burning it down with a hot shoe, and the paring of the surface on the bottom is the only 'fitting the foot to the shoe' that has to be done when the latter is of the correct pattern. When it is not, hot and cold fitting stand just equal.

Another objection to the fancied advantage of gaining such very close apposition by burning in, is that the horse thus often gets shod too tightly, and every one knows that this is injurious to the animal; although it is not every one that is fully alive to the great amount of misery and disorder it entails. 
'Aberlorna' says that, 'he believes no ill effects ever result from hot shoeing, except when done by ignorant men, who should be anywhere but in a shoeing forge.' In such a forge, ten miles from his own residence, there is a man so ignorant of the nature of a horse's foot, that he laughed at the idea of his being able to go on the roads with only tips, and was, afterwards, "quite surprised that he had not broken down on the way home after he was shod.'

Cold shoeing is gradually gaining in favour with practical men in spite of prize essays which condemn it. There is one passage in the said extract that the writer is unable to comment upon, because he fails to see any meaning in the assertion that ' two surfaces are caused to correspond, friction is set up between them, and their separation not so easy.' There may, perhaps, be some argument concealed under this verbosity. We are told that " language was given to man to enable him to disguise his thoughts.'

The extract given from the essay is of a very ' groovey' character otherwise.

The Seeley shoe, of which mention has been made, is a plain, light, machine-made shoe, without calks or clips, seated or bevelled on the ground surface, as Professor Coleman was the first to advocate. The chief advantage it possesses is that of being made of iron so ductile that the shoe can be altered in shape whilst cold. It is, in fact, meant to be always applied cold; and this is the only difference there is between it and any ordinary light 
shoe made on professor Coleman's principle. It is not a 'patent' shoe.

At the beginning of March, as 'Will Watch' 1 says, farming operations are too backward to allow of reducing the work of farm horses sufficiently to do away at once with all iron on their feet; neither did the writer intend, for many reasons, to incite the owners of such hard-worked animals to make such an abrupt change. A gradual mode of proceeding will allow the horses to keep on at their work ; and it will not cause so much apprehension to the owner nor so much opposition and eternal grumbling, or ' kicking over the traces' on the part of the carter, especially when he has such a handsome inducement held out to him, in case of success, as ' half the saving in the blacksmith's bill,' which this gentleman so spiritedly offers him.

Unfortunately, as he remarks in his letter, farriers do not, as a rule, 'care to know much about the Charlier shoe,' and this has already been pointed out in these articles. Yet one gentleman has written that he has made of one 'an ardent disciple,' and that 'he shoes beautifully' on this system; also that he finds it to bring grist to his mill. In some places where farmers could carry out by union what has been before suggested, a man might be found who would be willing to go into the thing. However, where the difficulty about the Charlier system is insurmountable, there is another road out of the wood, which 'Aberlorna' appears to have already hit upon,

1 See Appendix B. 
although it was intended, in due course, to have been demonstrated.

On farms or other large establishments where numbers of horses are kept, and no spare ones, for the especial purpose of earning their living and that of their owners, an ordinary tip (the lunette of La Fosse), covering only the front half of the foot, may be used with good success. Any blacksmith can put this on, although ' Aberlorna' tells us that they laugh at theidea. This tip should be light, and narrow in the web, as the sole does not want to be covered, and a light tip will wear as long as is necessary before it wants renewal, for we must recollect that the feet grow faster with tips than with full shoes. The nails should also be light and fine, and only four of them used. There is no danger in driving them into the toe, as many farriers imagine. Mayhew is very explicit thereon; and if farriers only had a slight knowledge of a hoof they would be aware that the horn is thicker and stouter at the toe, and that it also grows faster there than elsewhere.

What we may call the heels of thetip(although they do not reach the heels of the horse) should be eased off on the ground surface in thickness, with the file, at their extremities, so that they may not press unduly at their points upon the crust. The heels of the horse must not have even the slightest paring taken off them; but the seat of the tip must be pared down in the usual manner, because if the toe should be raised at the same time that the heel is lowered, too much work would be given to the back sinews. 
'Impecuniosus,' a thoroughly practical man, begs us to observe that all horses will ' go short' for a day or two the first time that they wear tips. This is because they feel strange on first having their heels let out of a vice.

It is well to go 'slow and sure;' therefore it would be advisable for a man to experiment upon one or two of his horses, say one with flat, weak, tender, shelly, brittle hoofs, and the other with what he considers as the stoutest in his stable. The possibility is that he would find at the end of a month that the weak-footed horse would apparently have derived the most benefit from the treatment, although theory might lead him to suppose that the contrary would be the case.

The tips should, of course, be applied cold. They can be made whilst hot to the exact shape and size. To facilitate and expedite this (and so to avoid lifting up the foot and cooling the iron two or three times), after the crust on the toe has been pared and rasped into proper form, the outline can be easily scratched with a fine, sharp nail, either on the floor, if it should be smooth enough, or else on a piece of board on which the horse is made to stand whilst one of his fore-feet is held up by a groom. When it is the outline of a hind foot that has to be traced, the fore foot on the same side should be held up, because the horse cannot so easily shift about the foot that is being traced if he is obliged to bear his weight on two legs on the same side to do so; not that there is much difficulty, or time required, in 
running a nail round the front half of a well-trimmed hoof, except with fidgety horses, and some horses are inclined to be fidgety in a forge, which is not much to be wondered at. These are minutiæ, but they are worth while being insisted upon by the owner in person. There is no necessity to inform a farrier that there is an intention of endeavouring to dispense with his services at some future date; if things go well he will discover that in time, and you will have spared his feelings for some weeks.

Should the horse or two thus experimented upon be found to do well, another couple or so could be put through the same treatment, and the first tried might leave off the tips on the hind feet on the second shoeing; on the third the front tips might be discarded. In this manner some people might be six months in getting through their whole stable, but they would never have any great amount of anxiety on their minds, especially as they can always revert, at any moment they please (as the clergyman cited did, although without the slightest cause, except ' funk', for so doing), to the full shoe. No one is incited to hurry or flurry himself over it, but, on the contrary, every one is advised not to rush at things. By so doing he will lose little or no work of his animals, at the same time that all those who surround them will take the change in a kindlier manner.

There is one observation to be made, which attentive readers will have already thought out for themselves. Although the foot will have greatly 
benefited all round by the use of tips, the toe will not have received as much benefit as the other parts, both on account of want of attrition and from having been pierced by nails; still it will be found to have made an improvement through the freer circulation of blood, \&c. The toe, as will be seen, has its fibres in a more slanting position than the remainder of the crust, and a leverage is brought to bear upon it every time the horse lifts his foot, which leverage the other parts have not to bear. Nature therefore has made it the thickest, strongest, and fastest growing of all.

On first discarding the tips the horn on the toe may be found to chip away until the nail holes grow out. This may in great measure be avoided by not driving the nails far and straight up into the horn. It is not necessary so to do to hold on a light tip. The points of the nails can generally be brought out low down, and when the iron is thrown aside, the edge of the hoof must be well rounded off with a rasp, which will do away with nearly all chipping. It is best always to keep the hoofs of unshod horses slightly rounded off on their edges. When this is done, once a week or so, no further trimming is necessary.

The shod horse has to dig his toes into the ground to start a load; but it will be found that as he gradually gets unshod he will also gradually lose this habit, because, as he goes on 'feeling his feet,' he will find out by instinct the natural way of using them, which is on the flat, and then the leverage and strain on the toe will be lessened, and the chipping 
away will thereby be also greatly reduced. These facts, although they may not be found mentioned in any one of those prize essays that are written in the ' follow-my-leader style' which 'Impecuniosus' so much deprecates, may be found useful for nervous men to know and keep in mind. Some people conjure up fancied difficulties. Fancy and theory have helped to bring our horses' feet and legs to their present state, which the generality of people find to be a very unsatisfactory one.

There are countries possessing vast tracts of grasscovered plains, on which horses are extensively bred, which from their great abundance are there of low value. The steppes of Russia, the grass runs of Australia, the prairies of some of the Anglo-American States, the savannahs of Uruguay and of the Argentine Republic are instances of such. In the lastmentioned, 'fine colts, from three to five years old, can be bought at from $1 l$. to $4 l$., and mares at from 4s. to 20s.' These horses, which are unshod, are those upon whose backs the ' Gauchos' perform their well-known skilful feats of 'lassoing,' \&c., when cattle-driving - the unshod horse being endowed with an activity and sureness of foot that renders him highly valuable for their purposes.

A gentleman writing in a contemporary, on the subject of cattle-driving, says: 'In Australia, in wet weather, an unshod horse is both a pleasant and a safe mount. Many a roll over I have had after cattle on a shod horse, when the country was soft above and hard below' - as some English race-courses 
and hunting countries often are-6 which would not have occurred with a barefooted animal.'

These almost immeasurable, soft, smooth plains, on which the horses perpetually stand, are not intersected by hard, rough, stony roads; neither are the horses, which are grass fed, worked continuously, although it is well known that they are often barbarously forced to cover long distances, when they are doubly exposed to become footsore from the facts of having to work at intervals only, and then over soft, smooth grass that does not afford what Mayhew calls 'the needful attrition' to keep the horn up to its work. Mr. Miles tells us-what we all ought to know, although even he was unable to grasp it fully-'it is an invariable law of animal economy not to continue to unemployed structures the same measure of efficient reparation that is extended to parts constantly engaged in performing their allotted tasks.' Herein is explained the reason why these horses do not acquire the hardness of hoof that horses elsewhere, and under different circumstances, with harder work, not only acquire but also maintain.

In the North, Central, and South American countries which have been formerly mentioned in these chapters, pastures and breeding grounds are not to be found in such large tracts, as in those that have just now been spoken of. Besides, such grounds being widely separated from each other, the consequence is that horses are scarcer and of far higher value. The geological character 
of these countries is also such that hard, rough, stony ground very largely predominates outside these breeding grounds; although in some parts, where the stone is small and loose, the roads become excessively heavy and trying during the rainy season. In some parts of these countries it rains every day in the year, and in other parts they get dry roads during six months, and wet ones during the other six. The horses have to travel orer either, and over naked sheets of rock, as they in turn present themselves; and, as Mr. Douglas says, "without difficulty, and to the evident advantage of their hoofs, they never suffer from contracted feet, or from corns, sandcracks, \&c.' Yet their work is of the hardest. Many of them bring down from the interior, many hundreds of miles, two bales of cotton, which weigh with pack-saddle, \&c., over $3 \mathrm{cwt}$, and in fording rivers have to carry the driver across also. This is the way in which all the commerce of the country is carried on. There is not a horseshoe or a nail to be obtained over the whole route, and on some roads at crop times nearly a thousand horses will pass daily, descending, and a similar quantity returning, inland, loaded with imports, sometimes of the same cotton that they brought down the year before, but which has been to Europe or the States to get manufactured.

In these countries the natives, when they 'corral' or 'pen' their horses, always look out for a hard site for the purpose. Where stabling exists it is paved with stone if obtainable, and where timber 
is more available this is used instead; where neither can be procured the stable is known far and wide as a bad one.

Xenophon, who wrote the most complete work on horsemanship of his day, makes no mention of horseshoes; while, on the other hand, he is particularly explicit as to the means to be taken to harden and toughen horses' hoofs. He recommends specially for this purpose bare stone pavement, which, he says, 'will cool, harden, and improve a horse's feet merely by his standing upon it, while the same benefit will result to his hoofs as if he were made to travel on stony roads every day.'

Another writer, Vegetius, says: 'The floor of the stable should not be made of soft wood, but of solid hard oak, which will make the horse's feet as hard as rock.'

The untutored natives of the interior of the American countries in question, without having heard of either of these authorities or their writings, have found out for themselves that both of these floorings act in precisely the manner described; whilst we, acknowledging that it should be hard, have nailed the standing place of a horse on to his feet, and have made him carry it about with him. The theory was ingenious, but it was wanting in logic ; and the practice is found to be expensive and unsatisfactory from the outset all through.

Osmer, writing more than a century ago, says : ' In many parts of the world to this day, even on the most rocky ground, horses are accustomed to carry 
their riders unshod; and in this kingdom I have known several horses ridden for a considerable time unshod on the turnpike roads about London without any injury done to their feet. And I believe there are many horses that might travel their whole lifetime unshod, on any road, if they were rasped round and short at the toe; because all feet exposed. to hard objects become thereby more obdurate if the sole be never pared.' In shoeing à la Charlier the sole never is pared, and it is always in direct contact with the ground, without any shield whatever to protect it from even sharp stones.

The hackneyed objection to 'our moist, variable climate, and hard roads,' so continually opposed to the practice of leaving horses to go unshod (even by some of the advocates for shoeing à la Charlier), is a mere empirical assertion, not founded upon experience, but an effect of imagination and prejudice which has become willingly accepted, without a challenge, whilst it is really the reverse of fact.

Mayhew says: 'Truly the stable mind must quit the scene of its present labours before it will submit to be enlightened. It is now so protected by a wall of selfishness, ignorance, and prejudice that it is open to no assault ;' and elsewhere: 'Nature sends the horse into the world with ready-made and stoutmade shoes.' Mr. Douglas says of horse-shoers: 'They think they can stand, as it were, with their backs against the door of the world, in order to prevent novelties which might interfere with their opinions from coming in. But the world's walls are 
wondrous ones, and its side doors numerous; so, whilst these opposers of progress manage to keep the main gate closed, the truth contrives to scale the walls, or slide in by side doors.'

The writer is of opinion that these defenders of the main gate keep a sharp look out over both the side doors and the wall's summit, and allow nothing to pass by either if they can help it. They contradict every statement that is likely to interfere with their gains. Prince Bismarck is credited with saying that ' he never believed anything until it was officially contradicted.'

Those who derive, either directly or indirectly, gain from shoeing cannot be expected to help to make any breach in this wall, but, on the contrary, to defend it to their utmost every time any assault is attempted upon it. 


\section{CHAPTER XIII.}

'ABERLORNA'S' SECOND LETTER IN 'FARM JOURNAL' - HIS SECOND HORSE SHOD WITH TIPS-PUTTING ON TIPS-HIS EXPERIENCE IN SOCTH AMERICA OF THE EXUBERANCE OF GROWTH OF HORN AND ITS TOUGHNESS, IN UNSHOD HORSES - SHOD HORSES GO LAME OVER GOOD ROADS, WHILST THE UNSHOD ONES GO SOUND OVER THOSE OF THE VERY WORST DESCRIPTION-IGXORANCE OF PEOPLE IN ENGLAND OF THE NATURE OF A HORSE'S FOOT- 'THE LANCET' ON THE INDEFENSIBILITY, IN A PHYSIOLOGICAL LIGHT, OF THE USE OF HORSESHOES-SUCCESS OF TWO GENTLEMEN IN WORKING UNSHOD HORSES IN ENGLAND-NEWSPAPER COMPLATNTS ABOCT THE SLIPPING OF HORSES, AND STOPPAGE OF TRAFFIC ON LUDGATE HILL-THE FALSE LIGHT IN WHICH SLIPPING IS LOOKED AT.

THE second letter of 'Aberlorna' is most interesting. ${ }^{1} \quad$ This gentleman is evidently thinking things out for himself faster than these chapters can carry him. In the common interest it may be well to go over his letter somewhat in detail. His successful, although rather severe, trial must 'set a good many people thinking,' especially when they see that within the fortnight he has been so encouraged by the result obtained that he has subjected another horse to similar treatment, only using this time a three-quarter shoe, with the intention of reducing

1 See Appendix C. 
it to a tip later on. Most likely he will bring it to that at the second shoeing; but he is able to take care of himself and his horse, and stands in no need of advice.

'Hot shoeing will become unnecessary by the use of tips, which any person ought to be able to put on with very little practice, and thus save the time and trouble' (and, in his case, a twenty mile journey) ' of having to send their horse away to be shod.' The writer is under great obligation to 'Aberlorna' for having made this remark: he would have already made it himself had he not feared to see it scouted. If owners would interest themselves so far as to accompany their horses to the forge, and carefully watch the process of shoeing, they would see distinctly that the nailing on of a shoe has no great mystery attached to it, and that any carter or groom could do it as well as a farrier, if he tried in earnest. The pointing of the nails is the chief thing. Nails as they come from the manufactory have, of course, a certain kind of point; but it will be seen that farriers always give it a modification by hammering it on one side only, which is on what is intended for the inside, with a view of giving the nail an inclination to drive, in a slight degree, outwards, and so avoid pricking the inner crust. Whilst driving a nail, the operator will be remarked to be feeling, with a finger over the place, where he wishes the point to come out; and, should the slight bulging out, which the nail carries before it, not appear to him.to be in the right place, he will 
draw the nail and point another, and frequently this will be done on the face of the shoe which is partially fixed. Nails that have scales upon them should be rejected, because the scale will weaken the nail at the part where it exists, and may cause it to bulge in, or bend and press upon the sensitive inner parts, although the point may, at the moment when the weak part of the shank gets introduced, be going all right; also, the scale may open out in the course of driving, and cause much injury. The machine-made nails of the Seeley Company are to be recommended for their general good quality and freedom from scaliness. From Belgium also come nails superior to the English-made ones, which seem to be among the poorest.

When once these minutiæ are seized, the fancied difficulty is practically vanquished; and why should not a groom or a carter learn them as easily as a farrier? They generally spring from the same class, and Mr. Douglas tells us that tailors throw down the needle to nail on horseshoes in the army.

We next discover that 'Aberlorna' has travelled in South America, and has ridden hundreds of miles on unshod horses, whose feet ' grew fast.' He states that 'he had often to cut the toes'- the toes only; mark-' which was done with some difficulty with a chisel and mallet.' To people who have not had his experience it might be interesting to learn from him whether he means that the only difficulty consisted in the density and toughness of the horn being so great as to render a heavy mallet necessary to drive 
the chisel through it, or whether there was any other annoyance or difficulty attached to the operation; because some people may say that if the annoyance in cutting the toe is as great as that of shoeing, they prefer rather 'to bear those ills they have, than fly to others they know not of.' By rasping the toe once or twice a week it may always be kept in good form, and then no cutting would be required.

'Aberlorna' has happily known how to compress a large amount of useful observation into the twentyfive lines which his letter occupies; some people cannot say more to the real point in as many columns.

The next statement of this gentleman, who went about the world with his eyes open, is that ' he does not remember seeing any lame horses except in the towns, and these were generally, if not always, $I$ observed, shod. The (country?) roads were for the most part sand, full of rough stones, and in some places causewayed for miles. Anyhow they were pretty rough going.' So, then, it really is a fact that in the towns, where horseshoes would have been brought into fashion by Europeans, and where the road surface would be smoother, shod horses went lame, whilst the unshod ones went sound on long journeys over worse roads. 'Truth is stranger than fiction.'

Another thing which many readers would probably be glad to hear from this gentleman is, whether by 'causeways' are to be understood roads 
that are 'pitched,' or paved with stone, somewhat like London streets, only more roughly, in parts where they would in the rainy season become otherwise impassable; as, in certain places, such roads do exist to the writer's personal knowledge.

'People in this country seem to have no idea what a horse's foot is. They have always seen horses shod, and think they always must be shod, and never will alter the method if they are let alone.' Thanks, 'Aberlorna,' for putting the thing so plainly ; it comes so much better from you. Some who think of a horse's foot only as a lump of horn stuck on to the end of his leg for the purpose of nailing a shoe on to, will be led by you to investigate the nature of the foot of the horse.

'As to farriers, it is useless talking to them. Take your horses to them, and make them follow out your directions through thick and thin; it is the only way.' Exactly so; no one could give better advice.

In November, 1878, a correspondent wrote in a contemporary:- - The argument against horseshoes seemed to me so strong, and the convenience of doing without them so great, that I resolved to try the experiment. Accordingly, when my pony's shoes were worn out, I had them removed, and gave him a month's rest at grass, with an occasional drive of a mile or two on the high road while his hoofs were hardening. The result, at first, seemed doubtful. The hoof was a thin shell, and kept chipping away, until it had worn down below the holes of the 
nails by which the shoes had been fastened. After this, the hoof grew thick and hard, quite unlike what it had been before. I now put the pony to full work, and he stands it well. He is more surefooted; his tread is almost noiseless; and his hoofs are in no danger from the rough hands of the farrier; and the change altogether has been a clear gain, without anything to set off against it. The pony was between four and five years old, and had been regularly shod up to the present year. $\mathrm{He}$ now goes better without shoes than he ever did with them; and without shoes he will continue to go as long as he remains in my possession.'

That eight months after-in August, 1879-this gentleman should send a copy of this same article to a provincial paper, is proof that he had never had any difficulties after the first month, the time needed for the 'thick,' 'hard' horn to reach the ground. There is one thing that he does not tell us, but which would have been interesting to know; and it is, whether any of his neighbours found heart and brains enough to profit by his example. His silence leaves room for the conjecture that 'they had eyes, but saw not.' It is even possible they still look upon his proceeding as an eccentricity. Such is life; the world might stand still for all that some people care to the contrary.

At the same time that this was passing, a wellknown farmer and breeder of shorthorns in Cumberland wrote:-'I had a brood mare which had been running barefooted for several years, when, 
ceasing to breed, I took her up and used her as a shepherd's hack, where she had constant work for two years; and, in travelling from farm to farm, she had a considerable distance of hard road to traverse daily, yet she never required shoeing. In the summer of 1877 I purchased a farm horse which had had the misfortune to get a nail into its foot, and he had been under the farrier's treatment for several months; but had made so little progress towards recovery, that I determined to try what Nature would do for him. I had his shoes taken off and turned him to pasture. In the spring of 1878 , being still rather lame, I put him to work on the land; and he is now doing all sorts of farm work, including drawing manure from the town, and drags his load as well over hard pavement as any shod horse that I have. Whether he could stand constant work on hard roads I am unable to say; but he does all that I require of him, and the experiment is so satisfactory that I intend to put another horse through the same training.'

The 'Lancet' says :- 'As a matter of physiological fitness, nothing more indefensible than the use of shoes can be imagined. Not only is the mode of attaching them by nails injurious to the hoof; it is the probable, if not evident, cause of many affections of the foot and leg, which impair the usefulness, and must affect the comfort, of the animal.' There is no dearth of complaints about horseshoes; but people still 'cling so tenaciously to the favourite superstition ' of regarding them as 'necessary evils,' 
that the idea of fully examining the other side of the question never seems to occur to them; although, when it is brought to their notice, some are found willing to listen to argument and profit by it.

A weekly, having the date of March 7, has the following paragraph :-- Whilst on the subject of animals, I should like once more to draw attention to the terrible suffering which greasy wood pavements entail upon the poor horses. The scene on Ludgate Hill is often heartrending. The poor beasts, struggling madly to gain a foothold on the slippery surface, strain and tremble and sweat, and often seriously injure themselves. It is no uncommon thing for the whole traffic to be stopped by a heavily-laden waggon, which the horse, with the ground slipping from under him, vainly endeavours to drag up the hill. Oaths, kicks, and brutal beatings the poor beast gets; but it never seems to strike any one that a little sand or fine gravel thrown in the morning over these wood pavements would conquer the difficulty. Asphalte and wood require keeping clean where there is much traffic. The present object of the authorities seems to be to keep them filthy. One would imagine they were big shareholders in a joint stock horse-slaughtering company.'

For some days preceding the appearance of this paragraph the weather had been finer than usual, and the watering carts had been at work. If, then, under the best of circumstances things were thus, what must they be on some of the days for which London is so famous? 
Ludgate Hill is neither very steep nor long, yet we have so often heard these stereotyped complaints about it, that we have come to regard it as a veritable mountain. If this mountain refuses to advance to Mahomet, and there is an urgent necessity for their meeting, why should not Mahomet advance towards the mountain? Sand is, at the best, an incomplete remedy, at the same time that it is a costly one for the ratepayers; and its use, instead of inducing to cleanliness, does the very reverse. Every time the road was swept or scraped, the sand would go with the rest, and then we should be ' as we were,' until more was put down. A better measure would be to keep the roadway clean by the use of revolving brushes worked on the end of a cart, into which the dirt should be carried by the brushes. Such sweeping carts were formerly to be seen, but have vanished. But what really wants most looking at is the revers de la médaille. On it would be seen bright, smooth, iron shoes far more slippery than the pavement. Unfortunately for the horse, this face of the coin is downwards, and people will not allow themselves to be persuaded to turn it up and examine it. If they would do so, and efface those slippery shoes, they would find under them a material, placed there by the Almighty to prevent the horse from slipping on smooth surfaces, even on ice. The horses would then give over struggling on the points of their toes, because they would find that a large, tough surface would afford them better holding and a better point d'appui, than would the 
fractional part of an inch of a bright, smooth, slippery iron shoe. Then the shouting, swearing, kicking, thrashing, stoppage of traffic, and other outrages to the feelings of humane people, would disappear; and all this would not only not have cost anyone a penny, but both ratepayers and horse owners would have positively economised, even if we say nothing of the diminished liability to street accidents. It is true that horse slaughterers would find business slacker: it must be a good wind that blows no one any harm.

Ludgate Hill, being a principal thoroughfare, falls more under notice than other streets; but let anyone visit the small streets running up from the river. These are paved with stone more slippery than wood, and the slipping upon it, from its not being level, shakes and injures the horses more than when they slip upon wood. These streets, not being in the road of the generality of journalists, remain unnoticed. Horses must be the meekest of animals when they allow themselves to be induced to enter them a second time. Chien échaudé craint l'eau froide; the horse is even more docile and tractable, meeker, and less easily scared than the dog. 


\section{CHAPTER XIV.}

LUDGATE HLLL ONLY RISES ABOUT FOUR FEET IN EVERY HUNDRED-SOCHETIES-THE BEARING REIY ONLY REQUIRED ON CRIPPLES.

Ludgate Hill is not Moirosi's Mountain, but, after all, is only a gentle ascent of about half an inch in the foot, over a length of about two hundred yards, up which unshod omnibus horses would trot with a full load in any weather. Yet there it must remain, a chief thoroughfare in the heart of London, a perennial cause of complaint, and of fear, disgust, and injury to man and horse. It is of no use to keep eternally grumbling at it, or proposing inefficient remedies; it must be tackled in a rational manner by not irrationally opposing two slippery surfaces to each other, and then the difficulty would be vanquished.

Humane and well meaning, but it is to be feared not eminently practical, people have formed themselves into various corporate bodies, either with the view of protecting the horse from injury by man, or else man from injury by the horse, when in the legitimate exercise of his daily toil. Philanthropic and philozoic individuals have taken the donkey 
under their protection, yet in England he continues to labour under the curse of the iron shoes from which his Irish brethren are exempt. Here is a fitting opportunity for his patrons to widen out the sphere of their humane intervention in his favour. They must not say that the climate of England is so different from that of Ireland that they could not do what Irish donkeys can, for the climate of England is no moister than that of Ireland, and we have testimony that its roads are no worse. In Porto Rico, a Spanish island, horses go barefooted; whilst in Jamaica, in the same latitude and with the same climate, English civilisation (?) demands that they should be shod. Evidently these last could as well go without shoes as the former, and, evidently also, the English donkeys no more need shoeing than do the Irish ones. Climate has nothing to do with the question.

In the invasion of America, Hernan Cortes could not carry about (in a country destitute of roads) anvils, forges, and iron. Without the few dozen horses, which overawed the Aztecs so much that they took them for gods, and carved idols in their resemblance, which they worshipped, he would have been unable to penetrate many miles from the coast. On the performance of those few horses depended the subjugation of Mexico. They did their work and survived it, and from them descends the mustang, which still goes unshod. Horses are not indigenous to America-this was their first introduction; and here is a further proof that climate 
and locality have not that influence over the hoof which they are vulgarly supposed to have.

It is being continually argued that the horse, as we have him, must not be looked upon as being in his natural state, but in an artificial one. Surely a little reflection should lead educated people to perceive that it is we ourselves who have, by continually striving against Nature, unnecessarily and insanely nursed him into an artificial state. People lose sight of the undeniable fact that he was created expressly as a servant for man, and as such was destined to become a captive and a domesticated animal. Simple domestication would not render him artificial; but pampering, continual doctoring, and adding to, or subtracting from, his frame will do so.

The Great Architect of the Universe neither made too little, nor too much, nor did he assign to the horse any inadequate members. Other quadrupeds possess both collar-bones and a gall-bladder, the horse has neither; but no one, however sapient, can detect that this inscrutable economy of construction has rendered him the less powerful, the less fleet, or the less enduring. It was needful that his head should be of a certain size to lodge the many organs which it contains, to provide leverage for the jaw with its powerful muscles, \&c.; and Mr. Fearnley, formerly Principal of and Lecturer on Veterinary Surgery at the Edinburgh Veterinary College, writing, in March last year, a treatise on the structure of the horse, tells us that the head is 
a model of lightness and strength, that the bones contain cavities, which 'are only there to allow of the bone being as light as possible, and as cavities are otherwise quite worthless. The upper jaw forms an arch, having substantial buttresses in the molar teeth and their bony sockets, and the span is of gigantic strength and extremely light, from its hollow construction.'

The tail, amongst other purposes, serves as a rudder with which the horse helps to steer himself when at speed, and the racer gets the benefit of it as such; but we have amongst us barbarians who amputate the end of the spinal column, and fancy that, when they have thus mutilated the animal, they have rendered it more beautiful than the Creator had been able to do!

A crusade is, at this moment, being preached against the cruelty of vivisection by people who condone the practice of vivisection of the horse, when they purchase and drive those who have been thus wantonly mutilated; and they go further against their professed creed when they pay another barbarian to subject his feet periodically to vivisection and vivicremation. These people are straining at a gnat and swallowing a camel with a vengeance. They have the choice of three things-either to abandon their practice, withdraw their theory, or appear as imbeciles before the world. Which road will they choose? There is no compromise.

The description of the hoof already given can scarcely fail to show that as much eare has been 
bestowed upon it as upon the head or any other part. It is small, light, and strong, and so adapted for both power and speed. Is it possible that it can be otherwise than fully adequate to the task of carrying, not only the weight of the horse, but also that of his rider? Religion forbids the bare conception of such an idea, which has not occurred to semi-civilised tribes and nations, who find by practice that the foot really is able to support successfully the very severe toils to which they subject the horse.

Not long ago, the writer heard a luminary of the pulpit read from the Scripture:- ' But they know not the thoughts of the Lord, neither understand they his counsels. Arise and thresh, $\mathrm{O}$ daughter of Zion, and I will make thy horn iron, and thy hoofs brass.' In the sermon of that day, the necessity of faith was much insisted upon; yet the preacher was seen shortly after being drawn by a horse suffering so badly from brittle hoof that parts of the shanks of nails were visible in places where the horn had chipped away. Where was his great faith when he feared to trust the feet of his slave to the hands of its Creator, who had entrusted him with the care of it?

The writer is no respecter of persons or titles when on this subject, which does not allow him to be so even if he felt inclined. Mr. Flower had to appeal to all classes, and Mrs. Flower aided him by addressing herself to the ladies, in his laudable efforts to do away with the abuse of the bearingrein. In the 'Book of the Horse' we find it said of 
him: 'Mr. E. Flower, of Hyde Park Gardens, has agitated this question for some time with that exaggerated enthusiasm which is essential if any deepseated grievance is to be reformed. No great reform from the time of Martin Luther to Clarkson and Wilberforce has ever been effected by cautious advocates and soft suggestions.' Mr. Flower has happily succeeded in convincing many that he was right. Even some 'fashionable' sporting men threw away the bearing-rein in their teams, rightly judging that, whilst their horses thus went better, they also looked better. Managers of heavy traffic, and owners of the hardest-worked slaves, find that they have been gainers by abandoning it. They will soon make the same discovery in the matter of shoes.

Mayhew says: 'That cannot be right the results of which are purely evil.'

The use of horseshoes is a sin; they are unnecessary, and 'their results are purely evil:' they torture the animal and shorten his life; and the sin carries along with it the curse of being a continual source of worry and expense to his owner.

'Fashion' cannot plead effectually in their favour, as they detract from action, activity, smartness, and speed. But then, perhaps, 'fashion' demands clatter; there is no accounting for taste.

The bearing-rein would be still less needed for a horse which, having no pains in his feet, would not be shifting them about, and putting himself into slouching postures at every moment in order to relieve them. 


\section{CHAPTER XV.}

BRITTLE-HOOF - IGNORANCE OF FARRIERS - 'IMPECUNIOSUS'

SAYS THE EXISTING IDEAS ON THE HORSE'S FOOT HAVE SPRUYG FROM WROYG ROOTS ALTOGETHER - 'FEARNLEY' SAYS THE CHARLIER 'IS THE MIOST COMMON-SENSE SHOE EVER INVENTED.'

$\mathrm{Br}$ paying a visit to various camps of the righteous, we have again come round to that touchstone 'brittle hoof.'

All shod horses suffer more or less from brittle hoof; it is only a question as to the extent of the disease in any given instance. Heavily shod horses that have to keep back heavy loads, by either slipping or knuckling-over when going down hill, and have to make that other unnatural exertion of digging in their toes to start a load, or draw it up hill, are the worst sufferers. On looking at their feet, it will be found that the farrier has had a call made upon his ingenuity to get nails into places where they would hold in the horn, by driving them either askant, or else far up into it, or both. By so doing, he is only heightening the difficulty he will have to encounter when the next shoeing comes round.

At the risk of appearing tiresome, we will repeat 
the description which Mr. Douglas gives of the constituency of the crust. He is well worth hearing twice:-

'If the crust is closely examined with a microscope, its structure will be found to consist of a number of bristle-like fibres standing on end, but bearing diagonally towards the ground. From the particular longitudinal construction of the fibres, it follows that they will bear a great amount of weight, so long as theyare kept in their natural state. The crust so viewed resembles a number of small tubes, bound together by a hardened glue-like substance. Whoever has seen a mitrailleuse gun, with its numerous barrels all soldered together, ean form a very good idea of the crust, especially if they were likewise to imagine the tubes to be filled with a thick fluid the use of which is to nourish and preserve them.'

We have already seen that the driving of nails, in any form, must both lacerate and close up, either totally or partially, these delicate tubular fibres containing the fluid which gives life; but when we come to consider that in driving them askant from right to left the farrier is causing a double amount of laceration, we shall easily comprehend that the further the disease spreads, the more he helps it to do so. Well may Mr. Lupton say:- ' Farriers ought to go through a course of instruction previously to being allowed to operate upon structures the anatomy, physiology, and economic uses of which they have never studied, and, consequently, never understood.' 
But how about the hardened glue-like substance which binds the fibres together? It is not difficult to imagine that this, also, must get smashed up, compressed, and its natural secretion and divinely correct distribution impaired if not ruined, by traversing it with nails, which push it on either side, and reduce the space which it was intended to occupy; and this cannot fail to destroy the general adhesion of the whole, even if the whole of the prismatic-shaped portion in front of the nails (from their heads to their clinches) were not already dead -which it generally is. Thus we find that we get a loose, shaky, uncemented bundle of dead fibres (like a rotten broom), easily destructible; and the crust is deprived of its essential property of deadening the shock which it must receive at each step, and of warding it off from the interior of the foot, and from the leg, aided by such important adjuncts as a soft, tough cushion (made further expansible by being cloven) in the frog, and a strong, arched sole, so made as to follow the expansion of the frog by allowing its lateral buttresses to spring out at the quarters, carrying with it, as a necessity, the crust at the quarters to which it is attached. Mr. Lupton has demonstrated that the heel and frog first reach the ground. Hence these parts were made soft and expansible (although strong in the bars) to receive the bulk of the shock, when, immediately afterwards, down comes the crust, proceeding from the quarters gradually to the toe, to complete the action devised by that Omniscience which we fail to acknowledge, 
raising up in lieu thereof a hideous false deity to whom we bow down, whose behests we blindly obey, and to whose high priest, the knacker, we daily give over as sacrifice animals that are just arrived at, what ought to be, the prime of their lives.

'Impecuniosus' remarks:-'It is, after all, no affair of mine what becomes of my neighbour's horses, but in no way is our ingratitude and hardheartedness so apparent as in our treatment of dumb animals, and horses especially. A dog cries out if you hit him, and probably sulks; a horse suffers in silence, and exerts himself the more.' 'We ought to be ready to hail any inventions or ideas which promise to amend the treatment of that essential part of the horse's frame.' 'No foot no horse' has been long a stable proverb; but how little the comfort of the foot has hitherto been consulted! The ideas on the subject have sprung from wrong roots, so to say, altogether; or rather let us say they have been built on fanciful and insecure foundations.' 'Owners of horses too often act as if their intention was to wear out their property as soon as possible. We should think but little of the common sense of the man who, having bought an expensive watch, knocked it about in every conceivable unfair way; but we think nothing of such a course of action pursued towards a horse-and why? Because every one does it, I suppose ; at least, I can think of no better reason.' 'Any one, by stating his experience, at the expense of but little trouble and the wear and tear of pen and ink, hardly enough 
to alarm even Mr. Greg, will assist in throwing light on a subject now confessedly veiled in obscurity, viz. the horse's foot; and, in these days of reduction, reducing our bills, and checking the deterioration of horses.'

If it were only for the invitation thus given by 'Impecuniosus,' how could the writer, knowing what he knows by experience, refrain from standing up for the 'rights of an animal'? And such an animal -not a wild beast, but one 'that was created to be the friend and companion of man,' if we are to believe 'Lavengro;' whilst another writer has said that "had not custom dignified the lion with the title of "king of beasts," reason could nowhere confer that honour more deservedly than on the HORSE.' Virgil describes him as having a hoof 'that turns up the ground, and sounds deep with solid horn.' To be sure Virgil had not seen or heard of horseshoes, or he would perhaps have sung of the clatter of iron. Brittle hoof will not sound deep, like solid horn, but more like a cracked saucer, or a 'shuffy' brickit is flawed all over.

It is all very well for some people to say that they do let the frog and bars alone, and thus comply with everything. They do not comply with more than a fraction. The thickness of a shoe, without calks, is not less than three-eighths of an inch. Hence the frog, to be of any use at all (and it can only be of partial use in an iron-bound foot), must make an abnormal growth to this extent; and abnormal growths are always weak. That it will 
thus grow, only proves still more clearly that Nature is extending her help to the animal, in so far as she is allowed to do so. Here comes in the superiority of the Charlier shoe over all others. As it is let into the crust, the frog has no forced growth to make, but remains (in this respect only) as if the horse were unshod. So does the sole; but the crust, even with this best of shoes, still gets mutilated with nails. ' Of evils choose the least.' The Charlier tip offers the least destruction to the foot, at the same time that it gives greater holding powers to the horse than anything yet invented in the shape of shoes. In his 'Lectures on the Examination of Horses as to Soundness,' published in 1878-Modern Horsey Literature-Mr. Fearnley tells his pupils: - The day will come, but perhaps it will not be in our lifetime, when the streets of our large towns will be paved rationally (with wood pavement), and then, $O$ happy day! we shall have horses wearing on their forefeet at once the most scientific as it is the most common-sense shoe-the Charlier. The stone pavior will cost the country many millions of pounds in horseflesh before the revolution comes about, but no doubt it will one day become a State question.'

Think of this, ye societies who have misunderstood your self-imposed tasks, and ye vestrymen who have squandered public funds, and ye horseowners who have squandered your own, and ye journalists who keep upon the old track and offer questionable advice! Remember that it comes from 
a veterinary surgeon and a professor of high degree and repute.

But how is it that so many people recommend the Charlier shoe for the fore feet only? The fore feet appear to have to carry more weight than the hind ones, as part of the shoulders and the neck and head are in front of them; but certainly they were so constructed by the Almighty as to admit of this. In the case of a saddle horse or pack horse, the hind feet are called upon to share the extra weight. In the case of draught horses, the hind ones do nearly all the propulsion at the same time that (in shod horses) they take nearly all the weight, at the time of starting, which is the heaviest pull. In countries where shoeing is only partially practised the horses are shod in front, and their hind feet left bare. This is the case in Rome, as it is at the Cape, and the American farmers before cited acted thus, and so do many others; but nowhere are horses to be seen which are shod behind whilst their fore feet go bare. There is a striking anomaly of theory about this. Of course the theory of shoeing is wrong $a b$ initio, and perhaps this accounts for the various views taken of it. 'Impecuniosus' was not the man to do things by halves. He began by using the Charlier shoes only in front, and he relates of a mare, which had twice fallen as a hack, that she was benefited by them. He then shod her behind also, à la Charlier, and he says, "after the first few days she never made a "peck" on the road, and felt quite different under me-so 
much more springy. The fact is, I don't think we attend enough to the hind feet. They don't show the effect of bad shoeing like the forefeet, and so they don't get attention; but what is bad in front can't be good behind. The mare's heels became much more open, and no man need desire a better hack on the road.' Not long ago a correspondent wrote that his horses were shod all round $\grave{a} l a$ Charlier, yet they were quite capable of 'backing' a load on any ordinary road, because they stood upon their feet (although they did not quite do so). Now, 'backing' is the most severe work a horse can be called upon to perform; and, therefore, it seems strange that every facility should not be allowed him for its performance. No valid reason has been adduced to deter us from 'going the whole quadruped'-that is to say, if you persist in shoeing him at all. If you do, you should go in for Charlier tips 'all round.' Nothing in the shape of shoeing can touch that form; unless it is to let the hind feet go bare altogether, as they do in Massachusetts. When you reach this point you will soon throw away those in front also. 


\section{CHAPTER XVI.}

CUSTOM OF H. JENNINGS OF TRATNING RACEHORSES UNSHOD, AND RUNNING THEM IN THEIR RACES WITH TIPS ON THEIR FORE FEET, WITH THE HIND FEET BARE - 'EVENING STANDARD', INSTANCE OF IMPATRED SIGHT IN A YOUNG LADY FROM WEARING HIGH HEELS ON HER BOOTS-MANY DISEASES OF HORSES MAY BE ATTRIBUTABLE TO ILL-TREATMENT OF THEIR FEET-CARIES OF THE TEETH IS KNOWN TO AFFECT A HORSE'S ACTION - VETERINARY DENTISTS IN AMERICA - CRIB-BITERS, WIND-SOCKERS, AND WEAVERSLETTER OF A CAVALRY OFFICER IN 'DAILY TELEGRAPH' HIS FAVOURABLE EXPERTENCE OF TIPS AND UNSHOD HORSES.

As a proof of the great diversity of ideas and opinions on the difference between the fore feet and the hind ones, as to which of the pairs should be most protected, or whether either of them should be protected at all, we will give an extract from 'Twenty Years on the Turf,' in the 'Sportsman,' in which a description of the establishment of Mr. H. Jennings, the well-known trainer of racehorses, at Bac de la Croix, Compiègne, is given :-

'Mr. Jennings has as many horses under his care as any other trainer in either France or England. One peculiarity about the horses in the La Croix stable is that the majority of them are unshod, while in training. Mr. Jennings is enabled to adopt this 
capital plan for the reason that the thoroughbreds have not to travel over any hard roads on their way to and from their gallops. They are ridden from their stables over the very short distance that intervenes between there and the loamy soil and leaves over which they gallop on the rides in the forest, and this gives the yearlings and two-year-olds a fine opportunity to expand their heels and their feet generally, instead of contracting the natural growth by "binding" them, as it were, with iron. In fact, very few indeed of the horses trained by Henry Jennings run even in their races with plates on their hind feet, and only wear "tips" on their fore toes. The feet of all the horses in this large establishment are well cared for, and the yearlings especially derive immense benefit from the "barefoot" system of training, as their feet are altogether broader in both the hind and fore quarters of their structure, and their frogs firmer and more healthy than the young things that are shod even before breaking.'

Of course, the remark that the horses are enabled to go unshod because they have not to travel over any hard ground is only due to a popular delusion, the real fact being that it would be much better for them if they took all their walking exercise over good hard roads. Their feet would then become sufficiently toughened to enable them to dispense with the last remnant of iron, which Mr. Jennings employs in the shape of 'tips' on the fore feet only, leaving the hind ones in their natural state. 
But how is it that Mr. Jennings stands alone amongst trainers in his 'peculiarity'? It would appear as if he had thought the thing out for himself, and then had pluck enough to try it by experiment; he was evidently not a slave to routine and fashion. Will he take this 'straight tip' and lay out a piece of hard road, and let some of his unshod youngsters try their walking exercise upon it? This would just make his system complete and his horses' feet perfect.

The foot that is inured to hard roads can but be perfected thereby, and a perfect foot can but stand upon better terms with a racecourse, or a trainingground, hard or soft as they may be at times. Qui peut le plus peut le moins.

In the Evening Standard of March 17, 1880, we find the following paragraph:-

'It is a pity that nature and art should be so often, as they are, in opposition to each other, and that a theory of beauty which satisfies the demands of one should outrage the demands of the other. It was not natural that a girl's waist should be immediately under her arms, yet in former times that was considered indispensable to true grace. In later years it was equally unnatural that waists should be compressed to a painfully-small circumference, but this again became a habit; and there exist others equally false and mischievous. Now and then, however, nature asserts herself, and gives a salutary hint that she is not to be maltreated with impunity. This, it appears, was lately the case at 
Boston. A young lady living there found that her eyesight gradually became worse and worse, and, after a time, she adopted the sensible course of consulting the best oculist in the neighbourhood. To him she told her sad story. She had always enjoyed good health until lately; but now she could neither read, nor work, nor play. Riding and driving were out of the question, and she was in terror of becoming blind. The oculist asked her about several things, and suddenly said, "Put out your foot." The request, strange as it was, did not seem altogether disagreeable to her, for her feet were small, and were incased in a delicious little pair of French boots with, as a matter of course, heels like little stilts. The doctor looked at it stolidly, and then said, "Yes. Go home and take off those heels, and then come to me in a month's time, and we'll see how your eyes are." She did as she was toldwith a slight pang, it may be, but without hesitation; and gradually the eyesight became stronger and stronger. At the end of the month she visited the doctor to report improvement, and he explained to her how certain nerves and tendons communicated with other nerves and tendons, and how injuring some injured the rest; all of which she did not understand, but gathered enough information to comprehend that high heels develope unexpected dangers. In this girl's case Nature was having her revenge.'

Here is food for reflection for us. Ill-treatment of the foot will cause disarrangement in an organ so 
remote from it as the eye; ergo, it will do the same to other organs that are nearer to the foot, or even farther from it.

Mr. Fearnley says: 'Next to the eye the larynx is the most delicate organ of the body.' ' Roaring' is supposed to be due to the abuse of the bearingrein, which, in some cases, is most likely to be true; but then we have horses, such as racers and hunters, that have never become acquainted with the bearingrein, and yet are 'roarers.' ' Whistling,' ' wheezing,' thick wind and broken wind, 'have been much thought about, and have had the fancy considerably racked to account for their existence.' It is a singular fact, that unshod horses are very rarely indeed to be met with suffering from blindness, or any of these other infirmities. Why should they be so free from them? They work harder and fare worse than ours do. So we see that apart from the acknowledged, and most apparent, diseases caused by the falsely so-called 'necessary evil' of shoeing, there are others more subtle which may be attributed to it; and it needs no great stretch of the imagination, when we are let into secrets like these, to suppose that some cases even of glanders may be some day traced to ill-treatment of the foot.

Mr. Fearnley deplores that the spirit of specialism should be wanting amongst veterinary surgeons. In America, however, they have veterinary dentists, as we may learn from a treatise already quoted from in these chapters. Mr. Russell, 'practical horseshoer,' in his 'Scientific Horseshoeing,' says : 'There 
are cases, frequently occurring, where an imperfect action cannot be remedied by any kind of shoeing; but, if we closely investigate the matter, we shall find that it originates from some other cause. This is sometimes the case when caries of the teeth is present, and the animal suffering from a continued toothache inclines to lug on the bit on one side, and in such a manner that he becomes tangled in his gait and bad in his action. If he pulls his head and neck out of line with his body, either to the right or to the left, the hind foot on that side is forced to land between the front feet and legs. The teeth must, therefore, be properly treated to obviate these difficulties. I have had Dr. R. E. Clark, the celebrated veterinary dentist of New York, operate for me on many occasions, and with wonderful success.'

The man who reads us this lesson styles himself a 'practical horseshoer.' But after all, might it not have been the shoeing that had in the first place caused the caries of the teeth, and that this had reacted in its turn upon the feet or other organs of locomotion?

At any rate, Mr. Russell's experience proves that there is sympathy between the teeth and the heels of a horse, and these are the parts of him that are the most remotely separated. Therefore it cannot be considered an exaggeration to conclude that the respiratory organs may be affected in a somewhat similar manner; especially since they are nearer to the seat from which evil may fairly be supposed to 
proceed. By joining his evidence to that of the Boston oculist, whose special study, reflection, and acumen had enabled him to detect a cause concealed under a lady's flounces, it may be assumed that many puzzling infirmities in the horse may have their source in shoeing. The experiment which would prove this would be interesting, humane, inexpensive, and devoid of all risk. There is nothing in the shape of vivisection in anywise involved in it, and, indeed, there is no valid reason why it should not be made, as, in fact, it has been made, and, if we say nothing of the help which it may give us in accounting for occult infirmities, it has been found to succeed; and it will be so found again.

Mayhew says: ' The various aspects which disease can assume, of course, are multiform, and unfortunately these, when exhibited by the horse, are all exposed to the arbitrary conclusions of prejudice.' 'The diseases of the horse are not yet thoroughly understood.' Although an advocate of the use of tips, he did not go to the length of advising the entire abolition of iron, which he regarded as a 'necessary evil.' After saying that 'seedy toe had been much thought about, and the fancy somewhat racked to account for its origin,' he theorised on the subject until he persuaded himself that it was caused by a debilitated and diseased state of the constitution, and prescribed entire rest in the stable (not in the field), with a liberal diet, until a cure was effected. How could he possibly have left out of account the true cause, which was staring him in 
the face in every instance-the shoe? It is true that continual suffering, which would cause nervous irritability, would in most cases have told upon the constitution, but he confounded effect with cause. $\mathrm{He}$ states also that navicular disease is caused by pressure on the frog-a diseased frog, of courserendered incapable by the farrier of performing its functions; and afterwards says that, as far as his knowledge extends, it is unknown in the unbroken animal. Of course it is. The unbroken animal is also unshod, yet he can gallop about amongst loose granite or over solid rocks with impunity. Mr. Douglas says that goats never suffer from navicular disease, but that he believes they would do so if they were shod.

Perhaps some of those correspondents who have so kindly come forward to give their experience of unshod horses will still further favour us by saying whether or not they had found amongst them many 'crib-biters,' 'wind-suckers,' or ' weavers.' The writer has never met with a single case of either of these three; therefore he is forced into the conclusion that shoeing cannot be considered entirely blameless as to their cause. Some day a pathologist will arise who will give an account of influences now 'veiled in obscurity.' In the meantime practical experiment will convince some that by giving up shoeing they have struck at the root of a host of diseases and vices.

Sight could not, of course, be restored to the blind, nor an anchylosis be loosened, and so forth; 
but failing sight might be improved, and incipient ossifications be dispersed in some instances.

The writer knows of one stable which contains only three horses-valuable ones when purchasedof which one suffers from false quarter and very brittle hoofs; the second is a windsucker, and has overshot fetlocks; and the third cuts himself behind so badly that he has no nails on the inside of the hoofs, except one just inside the centre of each toe, whilst on the outside half he has six nails; his action is bad, as he has always a tendency to 'lift up' behind. He knows of another stable, also containing three horses, which would be valuable if they were sound. One suffers from corns that have to be pared out fortnightly; the second has hoofs that scarcely grow, and seedy toe, and has a confirmed habit of gnawing everything within his reach; he has not as yet, being quite young, become a crib-biter, but he will most likely come to that; the third has splints, for which he is periodically tortured with blisters, and after each blistering he is found to be worse. The number of such stables is legion.

Veterinary surgeons, when they examine a horse as to soundness, as it is defined by law, continually find themselves obliged to add riders to their certificates as to existing circumstances which may lead to unsoundness at some future date. If they could only get rid of their prejudice in favour of the shoe, how much trouble and responsibility they might save themselves, and what disgusting operationsfor instance in the case of quittor-they might free 
themselves from performing. Mayhew says:-'It obviously is folly for mortal pride to contend against those organisations which govern the universe. However, in the case of exercising power over the horse, centuries of defeat and ages of loss seem incapable of causing mankind to relinquish a hopeless struggle. The strife has been going forward almost from the commencement of time; nevertheless, human beings, though always beaten, press onward to perpetuate the contest. They scorn to retreat, and will suffer rather than own a victor; they will not, to make an advantageous peace, desert a silly custom or discard an ancient usage. They can sustain punishment; they can endure chastisement; but, like land crabs, when once upon the march, they cannot deviate from the line which they have adopted. They can abuse the master, but they cannot listen to the instructor. "Nature," men exclaim in chorus, " is very stubborn." "Horse property," respond another gang of culpables, "is particularly hazardous!" All this noise, however, might at any moment be avoided, if the human race would only stoop to employ a little reflection. If man would not fight quite so obstinately, but merely think over the cause of combat, he might possibly be a gainer in happiness, as well as in pocket.'

Thus speaks Mayhew; but, unfortunately, he does not appear to have even tried the simple and inexpensive experiment of seeing what a horse might do without shoes. He had always been told that shoes of some sort were a necessity, and he took it 
for granted that such was the case. He strongly condemns 'routine' and 'prejudice,' yet he had a leaven of both still clinging to him.

Fortunately we are not obliged to wait whilst scientists work out the intricacies of the problems. In thirty days people have been able to satisfy themselves thoroughly of the error of their former ways as regards shoeing. Others will do the same; and some of them will not even care to hear at a future date how pathologists may have succeeded in interpreting things which are now to us virtually what cuneiform inscriptions would be to Zulus.

As has been remarked by 'Santa Fé,'1 people will still shirk the trial of doing away with shoes as long as they can, by making all sorts of trivial excuses to themselves. 'Santa Fe' already divines five such probable excuses, of which the one that is perhaps the most frequently urged is, that 'they think there may be something in it, but they will wait until someone else tries it.' But there is one unmentioned by him (although he foresees that there will be others) which is scarcely less used; and it is that many say they believe that it would answer well with most classes of horses, but that the particular kind of horse they possess - it matters not of what breed he may be, or what he may have to do - could not do without shoes, although all the others might do so. Mr. H. Jennings was not so narrowminded as this. He had to do with the racer, and he found out that shoes were a nuisance, both to 1 See Appendix E. 
animal and master, and so he tried to do without them. He succeeded in cutting them down to their smallest size ; and only his fear of hard roads - that bete noire of the multitude-hindered him from arriving at the point of his ambition.

The following extract is taken from a letter signed 'A Cavalry Officer,' which appeared in the 'Daily Telegraph,' of December 28, 1878. 'If people tear off shoes, and put horses to work, or else turn them to grass, they will fail. In such experiments it is not the theory that has failed, but that it has not been put to a practical test. I know a pony over twenty years of age that has never been shod, and has all its life been accustomed to be galloped about by children on the hard roads. I have, myself, kept my horses shod with tips only, for eight and ten months together, using them on hard roads and paved streets, and keeping them, when in the stable, standing on granite-paved stalls, without litter under them, except by night. I found the horn tougher, weak heels grow stronger, brittleness of hoof disappear, and I never had a foot-lame horse during the time named. I am satisfied that the way to improve horses' feet is not by turning them out in boggy meadows, but by removing their shoes, and standing them on paved flooring. That a diversity of opinion exists upon such matters amongst veterinary surgeons I am well aware; but I know some who have served both at home, in India, and elsewhere with their regiments, and who approve my suggestions. I have heard another gravely insist 
that the feet of every horse in his regiment should be stopped twice a week during the summer to keep their feet soft, because the roads are so hard.'

It is refreshing when we find cavalry officers not bound by red tape. But as regards that twentyyear-old unshod pony, unbelievers will immediately say that he only had to carry children (from one to three probably), and so he stands for nothing as a proof. But let some of these unbelievers be asked for the loan of a pony for children's use, and then we should find them refusing it, because, as they would say (inwardly), "they know how children knock ponies about,' which is really true. The remainder of the letter coincides strikingly with a great deal that has been insisted upon in these chapters; still, for the generality of people, this letter may almost as well have remained unwrittenit is so hard to make horse-owners believe that there remains anything for them yet to learn! 


\section{CHAPTER XVII.}

THE HUNTER CONSIDERED-EXPERIENCE OF 'IMPECUNIOSUS' WITH TIPS ON HUNTERS-MILES ON UNILATERAL NAILINGCOL. ANSTRUTHER THOMPSON'S EXPERIENCE WITH GUTTAPERCHA SOLES - NATURAL TRANSPIRATION CONTINOALLT GOING ON IN THE HORSE'S FOOT.

Next to the racer comes the hunter-if, indeed, he may not be considered before him, as a 'general utility' horse. Mr. Fearnley says of him:-_'There is nothing in the world a horse can do which we do not find the hunter capable of.' This is a character calculated to get him a situation, and accordingly we find him drawing a cab years before the natural decay of his strength, fire, and emulation would unfit him from carrying his master into a good place at the finish. If he went unshod, instead of being at such an early age the mass of diseases he now is, he would, when aged, still be fit for slower work, a long way ahead of the cab-rank. In fact, he might in many instances remain a useful servant in his old stable until extreme old age.

'Impecuniosus' hunted in an economical manner. He describes five 'screws' that he had in his stables just ten years ago, which could hardly have cost collectively the price of one sound horse. They 
all had infirmities, which consisted in knuckling over and falling when trotted on hard roads, incipient side bones, brittle hoof, cutting, legs that were always swollen, chronic laminitis, corns, and inability to keep up a gallop through ploughed lands. He shod them on all fours with either short Charlier shoes or tips, and they were all either greatly benefited or else cured of these unsoundnesses. One of these horses he sold to a gentleman, who immediately had him full shod in the ordinary manner. The horse again became as unsound as ever. People read the Field, and neighbours looked on at it all, but it taught no one any lesson. 'Impecuniosus' wrote in the sand for the 'ruck; ' but not so, however, for the present writer, who had the thing quite as closely at heart as had that estimable gentleman himself, and followed him up (although then abroad) with the greatest interest, with the vain idea that he was going to bring about a reform. A decade has since passed away, and nothing has resulted from his efforts. It appears as if he was then ahead of the age-so, possibly, may his imitator be now; but ten years make a difference in enlightenment; and everything should march with the age. If the present appeal should still prove abortive, at all events the subject will have been kept upon the surface, and thus it will again be taken up by someone else in due time; and whenever this happens the intervals will be found to be shortened by the onward march of intellect and science, if not of common sense. 
It has been well said in a work entitled 'The Rights of an Animal :' 'In the history of thought, that which is to-day's laughing-stock becomes tomorrow's doubt, the wisdom of the third day, and the child's lesson of the fourth.'

To return to the hunter : his foot is constructed upon a principle which prevents it from picking up and retaining dirt; but shoeing does away with its architecture and mechanism. Unshod hunters would be free of the drawback of carrying about the weight of iron and dirt. When they put their feet down in ploughed land, expansion would cause them to make a big opening, and as, on withdrawal, the foot would become smaller by contraction, it would slip out without 'sucking,' whilst there would be nothing on the bottom of it that could pull out dirt with it, as the shoe does-always excepting the Charlier.

Youatt says : 'An ounce or two in the weight of the shoe will tell sadly before the end of a hard day's work;' and an old proverb says: 'An ounce on the heel tells more than a pound on the back.' If people would reflect that this extra weight has to be swung at the end of a lever which is not of the first order, they would understand how ounces represent pounds. The leverages in the horse's leg are largely of the second and third orders. Therefore, the shod hunter is more heavily handicapped than any other horse, except the steeplechaser. Add to this, the absence of disease and pain which must detract from weight-carrying power, and we should find the thirteen stone hunter of the present day 
well up to fifteen stone, and ready and eager for his feed when he got home, as his attention would not be distraught from the cravings of his stomach by agony in his feet and legs.

Then, again, we have been told that unshod horses, when used in cattle-driving, do not slip about on wet grass, and roll over as shod ones do. This fact alone is valuable, but we may note further that in certain weathers the feet of shod horses will clog even in grass; and when the clods fly out, with the force they do, the effects of leverage must become, upon reflection, more apparent to the educated. Further still, when we come to consider that horses have so often to take off on slippery grass (and land upon it also) at leaps, we may easily comprehend that refusals, baulks, and falls would be diminished. Then, again, in taking a drop-jump from a field, over a fence, into a road or lane. Mr. Miles says:- 'No horse experiences the full extent of the benefit of one-sided nailing with few nails like the hunter; it is a great boon to every horse, but to him it is a blessing of the highest order, and one in which his rider participates more largely than some persons appear to imagine. When a hunter is shod in the usual manner, with seven or eight nails, some are always, for the sake of security, placed in the inner quarter, which is the most expansive portion of the hoof (?). Let a horse with his feet so circumstanced be called upon to leap from a high bank into a hard road-and what happens? The weight of the horse and his rider is thrown with an impetus, 
which greatly increases that of both, upon the bones of the foot ; these are jammed with immense violence into the hoof, both sides of which are so fettered that neither can yield to make room for them, and they consequently squeeze the exquisitely sensitive lining of the hoof between their own hard substance, the unyielding horn, and the shanks of one, two, or three nails, as the case may be, in a merciless manner.'

Mr. Miles had, as we have already seen, proved by clever experiments that expansion and contraction positively do exist to a very marked extent in the horse's foot ; and it is now universally recognised, in England, at least, that such is the case. To allow them scope, he inserted nails in the shoe on the outside only of the hoof, and used but few nails even at that. The shoe was found to remain on, and the foot to be benefited, and he thus made an improvement; but no one followed it up, although veterinary surgeons said he was right. How is this to be accounted for, any more than the failure of 'Impecuniosus' to make an impression? because people cannot be induced to care for, or think of, their horses any longer than whilst they are on their backs. Both of these gentlemen, although without being aware of it, were precursors of the non-shoeing system, as may be seen by their gradual, although only partial and tardy, reduction of iron, in the number of nails and the size, form, and weight of shoe. Iron was still their stumbling-block, as it will continue to be that of all who uphold its use. It cannot, in any shape, be used to full advantage. 
In the 'Daily Telegraph' of last Christmas Day's issue, we read as follows:-'A strange innovation has just been introduced into fox-hunting records in Fifeshire. According to the "Sporting Gazette," Colonel Anstruther-Thompson, finding that the winter promised to be a long and sharp one, made up his mind that neither frost nor snow should stop him from his favourite sport, and trained men and horses accordingly. A few days since the result was seen. With the thermometer at eight degrees below freezing-point, and the ground covered with snow, he and a number of his neighbours met, amongst them being one lady, their horses having previously had the soles of their feet covered with guttapercha. For a while, Balcorm wood was drawn without success, but presently a fox rushed out and a sharp run followed. The scent in the snow proved amazingly good; and despite all the circumstances, which until now in foxhunting have been regarded as disadvantageous, the going was of the very best. At length, however, the fox managed to escape, and, as the sun was by this time at rest, it was too late for further sport that day. But the experiment Colonel Thompson has thus successfully made has created such an impression in Scotland, that it is likely to be followed everywhere this season; so that the owners of hunters who trembled at the prospects of the early winter, may take heart, and, by the aid of guttapercha soles and a little training, yet chase the fox over snow-covered ground.'

In Colonel Anstruther-Thompson we have another 
unconscious precursor of the non-shoeing system; and this at a late date. The snow would have 'balled' in the hoofs of iron-shod horses, and the eight degrees of frost would have rendered the ground too hard for them to alight upon it after each leap. Guttapercha staved off these difficulties, but the naked hoof would have done better still if it had had a month's judicious care previously bestowed upon it; and for many obvious reasons, one of which is that guttapercha applied over the whole sole would obstruct natural transpiration, and so cause an unhealthy state of the whole hoof, if its application were kept up continually.

All these ideas lead up to the main point, which is that the freer the hoof is from iron the better it does.

Should anyone doubt that transpiration is continually going on in the foot of a horse, let him put an unshod one to stand for five minutes on dry flagstones, and then he will see the imprint of each foot marked in damp upon them; or, as Mayhew puts it, let him hold a wineglass with its mouth reversed upon the sole, and then he will find that the inside of the glass becomes shortly covered with dew. This frightens the grooms into the belief that it is an unnatural phenomenon, because it cannot be seen in a shod horse. The current of air which the raising up of the foot by the shoe admits underneath the foot carries off the vapour, and so does not permit of its condensation upon a dry floor. This, forbids the constant employment of gutta- 
percha. All kinds of diseases of the foot and leg would be found to arise from it; hence that door is closed, except on an emergency, and for a very short time. The Charlier tip is better than this device.

The unshod hunter that is stabled on a bare floor, and that goes to cover and returns at night over hard roads, will have a perfect hoof and foot, and would fear nothing that he could ever encounter in the rest of his day's work; and then, he could hunt another day a week.

Instructions are repeatedly being asked for as to how to make and apply the Charlier shoe. Mr. W. H. Stevens, M.R.C.V.S., of 9, Park Lane, W., sends, post free, for sixpence, a pamphlet, wherein the whole thing is elucidated. This pamphlet is well illustrated, and should make details clear to the most obtuse. If shoes are required, or the necessary drawing-knife (which is the only extra tool required), Mr. Stevens also supplies them, as will be seen on perusal of the pamphlet. Messrs. Arnold \& Sons, 36, West Smithfield, also supply the knife. When ordering shoes, a tracing of one fore and one hind foot should be sent. It is not likely that 'tips' are kept, but the latest information gives the valuable and significant fact that the 'full' shoe is no longer made, but only a 'short' shoe (a three-quarter one, in fact) which stops a good bit short of the bars. This is worth knowing. Those who wish for 'tips' can easily get on after knowing this much, without any further hints on the subject. 
There are farmers who breed hunters and who ride their young horses to hounds, as a matter either of business or of pleasure. If they would try them unshod, they might be agreeably surprised at the result. Setting aside their superior performance, they would find, when they came to sell them, that the veterinary surgeon would always pass them as free from all suspicion of brittle hoof, sandcrack, seedy toe, thrushes, corns, pumice-foot, cutting or brushing, or navicular disease. No unshod horse ever suffers from any of these diseases or defects, no matter how hard his work or over what ground. This much is allowed, as we have seen, by veterinary surgeons. But besides these certain advantages, there are others. For instance, spavins, splints, ring-bones, side-bones, wind-galls, ' swollen' legs and ' filled' legs (which are different), quittor, curbs, stringhalt, overreach, bad action, thickened tendons, and stumbling, are all to be found with singularly less frequency in the unshod horse than in the shod one. The same remark applies also to those occult infirmities and defects of which mention has already been made, many of which constitute unsoundness by law. 


\section{CHAPTER XVIII.}

THE LADY'S HORSE-MUST NOT BE EXPOSED TO STUMBLINGWGHT TIPS WILL WEAR AS LONG AS HEAVY SHOESHORSES AS HACKS FOR ELDERLY GENTLEMEN-PARK HACKS - CARRIAGE HORSES-ABNORMAL ACTION AND GRACEFUL ACTION-CONCUSSION THROUGH THE IRON SHOE-BEARING REIN FOR 'SCREWS'-IT ' PULLS THEM TOGETHER'-CRUELTY THEREOF-'DOCKING' A HORSE'S TAIL IS VIVISECTION' CUTTING' CAUSED BY SHOEING-CRUEL MODE OF CURE AT PRESENT EMPLOYED-COACHMEN.

EQUaL to the hunter in value is the lady's horse. In the 'Book of the Horse,' we find it said of him: 'He should be free from the slightest suspicion of unsoundness in feet and forelegs, or those tricks of stumbling which lead to falls.' In an editorial article, the 'Morning Advertiser' has said : 'There can be no doubt that to encase the foot of either man or beast in a hard, heavy, unyielding case or cincture is against every law of Nature. It is equally true that by so doing the delicacy of the foot is impaired, the sensitiveness injured, and, accordingly, the liability of the animal-let us say the horse-to stumble much increased.' This being so, as it undeniably is, a lady's horse should evidently be unshod. He would then possess further 
advantages as being lighter in hand-no trifling one-and all his gaits would become more elastic and airy, rendering him much easier to sit and ride, and give his rider a more graceful seat, while at the same time she would experience less fatigue, and be in greater safety.

Should these lines attract the notice of any fair reader, it is to be hoped that she may give their substance due consideration. Let her reflect that the present prevailing mode of shoeing is an unscientific and old-fashioned affair, and that it is now high time there should be a change of fashion, for ladies, at least. Let her consider that the hoof grows from above downwards; and thus, when the bottom part gets fair play, diseases and defects of the hoof will gradually disappear to a great extent, if not entirely. Any lady may improve her present favourite, both in comfort to him and in safety as well as comfort to herself, by having him shod all round with tips. The Charlier is much the best system, but where it cannot easily be put in practice, the common tip, made as narrow and thin as the Charlier, will be found very effective, and a very great improvement on the broad, heavy, 'full' shoe now in almost universal use.

Charlier did not invent the narrow, thin shoe or tip; he only made better use of such a piece of iron by imbedding it in the crust, on a level with the outer edge of the sole-and this was certainly an improvement. Mayhew says:- 'All idea of the breadth of shoe affording the slightest protection 
should be at once abolished, because the broad web has been proved by the general employment of the picker rather to afford harbour to hurtful particles than to protect the sole from injury. The shoe should be made only just wide enough to afford bearing to the wall of the hoof, and to allow sufficient room for the nails to pierce the substance of the iron. . . . . There can be no doubt as to the safety of tips. . . . . Were tips more generally employed, this form of shoe would be more highly valued.' So we see that Mayhew was only short of the idea of imbedding his narrow strip of iron, which idea occurred to M. Charlier shortly after Mayhew wrote.

It may not be out of place to repeat here that such a narrow, weak strip of iron is not found to answer when applied in the shape of a full-sized shoe, as it will then either twist or break; but in the short length required for a tip, it is found that it will do neither.

Impulsive or superficial thought may suggest the idea that such light tips may soon wear out. This is not the case, for Mr. Douglas found by practical experiment that light shoes wear the longest; and a little reflection would account for this.

The proper width of a tip for a lady's horse would be from $\frac{3}{8}$ in. to $\frac{1}{2}$ in., and the thickness $\frac{1}{4}$ in. only. Light iron, as has been observed, only requires light nails, and few of them, to hold it on; and as the narrowness of the web of the tip would bring the nail-holes nearer to the edge of the hoof, 
the danger of pricking the sensitive parts would be almost entirely done away with; and thus there would be much less of mutilation of the hoof.

Perhaps, after a time, some ladies may find their horses improved through the wearing of tips, and then some of them might be found willing to do away with them on the hind feet of their horses; and, if this were found a success, something more might suggest itself to them. But those who employ tips, even should they get no farther, will find their advantage in a week or two. They must not expect that those diseases of the bones, cartilages, or tendons which have been brought about by shoeing, if they are firmly established, can be entirely cured by the change; but their progress may be arrested; and, what is equally consoling, they will find by the 'going' of their horses under them, that the absence of inconvenience and pain in their feet and legs makes them more 'springy,' and, consequently, safer and easier to ride. Let them notice also the difference in the weight they throw on the bit after a while.

A horse adapted to carry a lady safely and with ease would be well suited for an elderly gentleman, or a timid or inexperienced rider of the plain sex.

Park hacks, it has already been conceded by authority, 'would go more safely without shoes than with them, because shoes accumulate the soil.' Evidently, it must also be unpleasant to have a compound of tan and manure thrown in one's teeth by 
horses in front. Unshod horses cannot pick it up or even scatter it knee-high.

Although it may be rather out of place here, we will remark en passant that 'circus' horses do not appear to labour under any very pressing necessity of being cursed with shoes, yet they are; and they continually favour spectators in the front seats with showers of filth that often finds a resting-place in the eye, and thus deprives its receiver of the enjoyment of the remainder of the 'spectacle.'

But, anyhow, breeders of park hacks, seeing the concession made by authority in favour of these animals, would be going out of their road, and incurring extra risks, if they shod them even to break them. Let them break them unshod, and in the same state offer them for sale. They would thus pass their examination as to soundness without difficulty; and then if their buyers thought proper to shoe them their sin would be upon their own heads. By so doing, they would simply follow up the purchase of a valuable article by deliberate efforts to depreciate its intrinsic worth. Of course, there should be fair play over the transaction, and it should be understood that the horse had his feet inured to hard roads, and not have been broken-in upon grass. Horses broken-in upon grass do not acquire showy action. It would not, therefore, pay to shirk the thing; and this would be a safeguard for the buyer, in case he wanted the horse for immediate work; it would regulate the price. 'A thing (of any kind) is worth what it will fetch,' and so 
fancy prices are continually being paid for horses, especially ladies' horses and park hacks.

Another class of horse that often commands a long price is the carriage-horse of the ' upper ten.' As a rule, the accusation that they get early worn out by hard work would hardly lie; yet at what a comparatively early age they become 'screws,' through the bearing-rein and their shoeing. Their work lies largely over stone paving, the evils of which, to shod horses, Mr. Fearnley and others so justly denounce. One purpose of the bearing-rein is avowedly to give lofty action, not graceful action, which, on the contrary, it prevents. Horses with their heads rigidly attached to their tails are continually tossing up their heads, in which no doubt they find a passing relief alternately for their various excruciating pains, which must extend from the tail to the teeth. The throwing up of the head necessarily tends to raise their fore feet higher, but not with regularity, as may be seen by observation. This abnormal high action causes so much the greater shock on the feet when they come down on the stone, and this brings their shod hoofs to grief. Mr. Douglas says :- 'The evil effects of concussion, of the firm, hard blows from the ground, striking through the iron up a horse's leg that is being driven fast along the road, cannot be over-estimated. Such common results as splints, spavins, and ringbones, I have already referred to elsewhere, as well as to another and more fatal disease, known as foundered feet, due to the same cause-concussion. 
It is allowed that the cause of this disease proceeds from the violent exercise over hard roads, and that young horses are most liable to it: of course, all combined with heavy wide-webbed shoes, fastened on to mutilated feet.'

As a remedy or a prevention of concussion, Mr. Douglas proposed to let guttapercha into a dovetailed groove on the face of the shoe. At the best, this would have been only a partial remedy, but the shoe never came into use. No innovations find easy acceptance; and why? Mayhew solves this conundrum, when he tells us that 'it is in their own interests that farriers make no improvements!'

The crippled screws of which we are now speaking would always be wanting to rest one fore-foot and one hind one at one and the same time, and alternating them frequently, besides drooping their heads in despondency, when they were at a stand. Here comes in another purpose of the bearing-rein, which is that of 'pulling them together,' and thus hiding from the ignorant the infirmities and sufferings in their feet, by the application of counterirritation. Thus they are supposed to make a better show when drawn up in Regent Street, or at Lancaster Gate, or, say, even at the door of Willis's Rooms, when an anti-vivisection congress is sitting. If only for the sake of decency, we should show a little consistency. Let it be understood that we are not arguing either pro or con. on the question of vivisection of the lower animals; we have our own opinion on the subject, but we prefer to stand in 
the present instance upon neutral ground, and so talk to both sides. Those who are against it can find no excuse for docking the tails of horses, which custom cannot be considered other than vivisection; whilst those who argue that science can be advanced by investigating the interior organs of a guinea-pig, cannot argue that docking a horse's tail proves anything more than that we are still little more than half-reclaimed savages, with a remnant of idolatry which obliges us to offer up as sacrifice the ends of our horses' vertebral columns to that idol which we worship under the name of 'fashion.' The whole system is rotten.

To drive a horse that cuts himself is cruelty to animals, and at some future time it will be punished as such. To rasp away, and thus weaken, the inside of the shell of the foot, in a futile endeavour to avoid cutting, is also cruelty, and some day this practice will also be prohibited on that account. The prevailing idea of cruelty seems to be that blood must be flowing, or sores visible under the harness; but a sore that gets hit with the foot is quite as bad.

The operation of rasping away the hoof, to cure cutting, is as unscientific as it is unsuccessful. The idea that suggests it is one of those that ' $\mathrm{Im}$ pecuniosus' says ' has sprung from wrong roots altogether.' He cured his horses of this misfortune by shoeing them with Charlier tips. The cause of cutting is the shoeing. It is not meant by this that it is the shoe or nails that cut -as anyone may see 
that. What is meant is that an unshod horse, or even one wearing tips, never hits his leg with the opposing foot; one reason for this being because he wears away his heels in their proper economical ratio and form, and thus gets a natural 'tread.' Nature never meant him to knock himself about so awkwardly at every step. Cutting is always accompanied by deterioration of action, and diminution of speed, and then all his defection is reckoned up together, and the unfortunate horse (instead of his master) is put down as a ' rip,' although he may perhaps be only a victim of routine.

The eye of 'fashion' too often looks through that of its coachman when estimating action, and thus it has become callous, so to speak, and insensible to the elegance of the natural action of such a graceful animal. Mayhew says that 'pride has no brains, and but a very limited amount of intellect.' Let pride, or 'fashion,' just stoop to the use of tips, and then their coachmen would gradually come round. Coachmen are not all fools, any more than they are all sages, although they are all prejudiced; and few of them nowadays are as interested as their class formerly was in bolstering up trade interests. We find that they mostly acquire an affection for their horses-as they look upon them, and they should not be altogether discouraged from so doing-barring some unfortunate animal that is obliged to become a crib-biter, \&c., but in favour of which they are generally willing to admit either pluck or something else. They cannot under- 
stand that he is being driven into such vices; they believe them to be inherent in the individual. This affection for, and interest in, their horses, which has been developing itself of late years in coachmen (not so much in stable-helpers), would soon reconcile them to any innovation which might be found beneficial to horses, however much they may be averse to them when first introduced to their notice or approval.

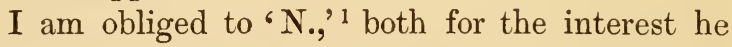
has taken in what I have written and for the case he mentions of impending lockjaw (which it would appear to have been) through ill-grown teeth. I have not met with a parallel case, but I once knew a cart-horse that cost $£ 100$ to die of lockjaw from getting ' pricked'in shoeing. The nail was withdrawn, but the veterinary surgeon stated that there had been a scale on the inside of it which had been forced off in the withdrawal 'against the grain,' and had made its way into the sensitive parts, to remain there.

To 'J. F. K. S.' ${ }^{2}$ I am equally indebted. He may rest assured that no fair trial has ever been given to the artillery horses at Woolwich, but it has been given to such horses at the Cape, and with the greatest success. They were found to go better, when unshod all round, over the roughest description of hilly roads, and for years together.

What has happened at Woolwich has been that shoes are removed from all horses before shipping

1 See Appendix F.

2 See Appendix G. 
REMOVING SHOES FOR A SEA VOYAGE. 175

them for a long royage, both to hinder them from slipping about and prevent them from getting foundered, which it is well known to veterinary surgeons they are particularly liable to when at sea, if shod. 


\section{CHAPTER XIX.}

'THE 'RIDE AND DRIVE' HORSE-OMNIBUS, VAN, TRAMWAT, AND CAB HORSES-TRAMWAY MULES-MR. FEARNLEY ON CALKS -UNSCIENTIFIC SHOEING OF MULES-MR. FEARNLEY ON THE CHARLIER SHOE-BRACY CLARK-MAYHEW ON THE VARIOUS KINDS OF SHOES.

A CLASS of horse that is extensively kept is le cheval à deux fins, the one that is ridden on one day, and driven, perhaps, the next, and so on. This horse could but gain in both his capacities by going unshod, and it would be an error on the part of his owner to argue within himself that it might answer under saddle, but would not do for harness work, or vice versû. People are strangely given to shirk innovations by laying hold of every excuse they can put their hands upon.

Omnibus, van, tramway, cab, and such-like horses, busily employed in cities, will perhaps be the last (although not the least requiring) to receive full benefit of a change in the order of things; but get it some day they must, as they have obtained relief from the bearing-rein, for which they are indebted to the energetic agitation of Mr. Flower. A careful inspection of their legs and feet would convince anyone endowed with perception that the present 
system of shoeing is simply ruining them. As we have seen, there is, at least, one intelligent firm who have stuck to the Charlier system for more than seven years, and have made their success with it public through the Press. To all appearance they might almost as well have remained silent on the subject. Who is there that can boast of having put their enterprise and experience to profit? Echo answers, Who? May we be allowed to ask, whence arises such indifference on a question of millions annually? If submitted to Lord Dundreary, he would probably say: "It is one of those things no fellow can understand;' and this is the only solution the writer can propose as a corollary to that of 'Impecuniosus,' which is, ' because everyone does it, I suppose ;' and to that of 'Santa Fé,' who says: 'Fortunately our ancestors did not shoe their dogs and cats, or, in all probability, most of us would do so in the present day.' The enterprising London firm in question liberally offered their horses for inspection, and no one went to see them! One gentleman said: 'I have got along for the last thirty-five years, and I shall not change now.' He had something of either the Mede or Persian about him, and there are too many like him. We may say, en passant, that his horses were about as badly shod as any that can be found nowadays, and were, every one of them, unsound from this very cause; but he did not want to know any better.

A propos of horses, we will look at the lightlybuilt and lightly-limbed mules, with hoofs scarcely 
bigger than those of donkeys-those that run on some tramways. Light as they are, they are strong and powerful; and the only advantage which could ever be expected from them lay in the lightness of their frame, legs, and feet, which would give them a pull over heavy horses, if we may assume that they would not batter their feet and legs to pieces on the hard stone pavement-since they run upon nothing else. For a mule requires more feed than a horse, taking him hands for hands, and equal mileage, load, and speed; and this the tramway companies will find out ere long, if they keep satisfactory records of each and all.

These mules have no weight or load to keep back. They cannot have any, as it is done for them by a brake on the car, which is powerful enough to stop the whole concern, mules and all, in the traject of a few feet; neither have they any weight to carry, beyond that of the collar, traces, and bridle; there is not even a pole to the cars, so they have nothing to do but to pull. Yet they are shod, especially behind, in an outrageous manner, with shoes that are extra long, and are, besides, calked! What ghost of a reason is there for calks on animals thus employed? Calks are only a clumsy, ignorant, and utterly unsuccessful substitution for a brake on the wheels. The tramcars have the brake, and even if they had not, calks will not help an animal to pull up upon pavement. They may do so upon country roads, but only with prejudice to the animal's limbs. Hear Mr. Fearnley upon this subject; and lay 
what he says to heart:- ' There could be no better service rendered to the horse universe than the passing of an Act of Parliament rendering it a misdemeanour for any one shoeing a horse to reduce the thickness of his soles or frog'-he omits to state the evils of cutting out the bars-' or to put under his heels or quarters iron exceeding a defined thickness, except under the certificate of a qualified veterinary surgeon, who should, after examining the horse, explain the need for the same. Horses, like every other property, are national property, and a man owning them mediately has no more right to deface them than he has to deface the coin of the realm, which he also owns only mediately. "What is mine is my own' is still the creed, not only of the vulgar, but of those who ought, at least, to know the rudiments of political economy.'

The writer thinks with Mr. Fearnley, that the question should be one for the Government; but then there is that awful red tape, which, slight as it is to look at, holds progress in bonds. So there is no hope from that quarter for the present. It is only two years ago that Mr. Fearnley expressed himself thus, and it is possible that no member of either the late or the present Government, even if they read his book, bestowed any attention upon it, although there is, perhaps, not a single member of either that has not been at loss and inconvenience through a horse being badly shod. That makes no difference to them. They have their political squabbles to keep up over aliens, and we and our 
horses may go to the crows, because they fail to see the importance of an immense national economy. Luckily, we may do without their interference if we like, and show them 'how it is done.'

But we must not get away from those mules just yet. Without knowing positively, we cannot be far from the mark if we suppose that stables which contain hundreds of them must be daily visited by a veterinary surgeon; and, if such be the case, why should he not have direction over the farriers? If he had such, we should soon see the calk, as well as a big piece of superfluous length of iron, cut off from each side of the heel. Here is another opportunity for asking "What ghost of a reason there is' for leaving iron to protrude behind the heels? What is it meant to protect-the tails? The mules have them close shaven; so they are not in reach of anything below the hocks. What purpose, then, is it meant to serve? One result of the practice is to make their heels come to the ground sooner than they were intended to do, and so give them a false 'tread,' thus using them up early, by making their legs perform unnatural functions which lead to fatigue and diseases. What is to hinder them from wearing tips, to begin with? The heavy shoeing, and the generally indefensible manner in which they are now shod, cause these hapless, light-limbed, and small-footed creatures, when at their trot, to swing their feet backwards and then upwards, in a manner that is most ridiculous to a person accustomed to mules; but their Cockney half-brothers, who have 
been hitherto unacquainted with them, seem to consider this as correct action. This forced and unnatural amount of play upon the articulations can but cause serious injury, especially to the tendons and synovially lubricated surfaces generally. In fact, it is undue wear and tear all round, even on the muscles, which carry us up to the heart, and on the nerves, which carry us up to the brain.

What chance, then, have these poor animals of showing what they may be worth? They are only an experiment as yet, and are all young; and, through a very unfair treatment, it will be presently discovered that they have not answered expectations. This will not be the fault of the mules, but their misfortune. They are already a partial failure, as may be seen from the fact that in many cases three of them are employed on a two-horse car, and two of them on a one-horse car; but a good deal of this is to be accounted for from the fact that people of the gobe-mouche fraternity fancy that a mule consumes less provender than a horse. It is true that a mule can, upon an emergency and for a short time, make a shift upon shorter and lower quality rations than a horse can; but, take him all the year round, he not only cannot do so, but requires more than the horse. On this account mules are useful in foreign countries where privations may be expected on journeys; but, put them to regular work and regular feed, and then the writer has always found them, during a very extensive experience, to require more sustenance than a horse doing the same work. 
People get statistics (not always correct) that a mule consumes so many pounds of barley and chopped straw per diem, and then they substitute (on paper) the same weight of oats, putting nothing down for hay for fodder and straw for litter, neither of which Spanish mules get in their own country, and forgetting that barley goes further than oats in the shape of nutrition; and thus they arrive at a false conclusion.

A mule, when doing the same work as a horse of his power, over stages with accommodation, must eat more than the horse to be able to do it ; it is, therefore, doubtful whether he can ever compete with the horse in England. Abroad, he is undoubtedly useful in many parts, because he can stretch a point where a horse sometimes could not, through his being able to subsist for a few days on what would not maintain the horse; although, of course, he has to make up for it afterwards, which he will not forget to do. In the Spanish army, the mules get the ration-anda-half of a horse's barley. There are many more horses than mules in this service in Spain. We shall see presently how mules pay on tramways in England; but in the meantime it is certain that the companies are throwing away their best chance, which was that of finding out whether through being lighter in their feet, legs, and superstructure, they could stand battering about on pavements. To investigate this, they have shod them worse, in proportion to their build, than they have shod their horses.

So much for companies, societies, and all corpo- 
rate bodies; clear-headed individuals have to be depended upon for putting the thing to the test. Board meetings are amongst the slowest and most obtuse of all institutions ; they always demand precedents, and when they receive them, they shake their heads, and do as they meant to do. However, some of them have rushed into mules, and it would look as if they now had to rush about for more stable accommodation, more helpers, and more farriers. The farriers will be striking against them soon for more wages and less work-everything is worth what it will fetch in the market; and they are creating a demand for farriers by multiplying the number of their animals-but is this making things good for trade? The farriers probably think it is, but then they are interested parties; how about the shareholders? This is not only a question of humanity, which we will put first (for the sake of form for such people), but also of largely vested interests. We will ask again, what is the reason for such extensive shoeing? We have seen that the mules have no load to keep back; does it help them to pull, or prevent them from slipping when so doing? Let anyone take the trouble to go and look at them. If he should happen to be a shareholder, all the better, and he will be persuaded that their hardest task is to gain a foothold for a start. They run only on flat ground, or ground with searcely appreciable ascents; but see how they strain every muscle, and how they make the sparks fly out of the stones. Of course, the larger the surface of 
slippery iron opposed to the smooth stones, the more they slip. It is only through encountering resistance in the joints between the paving-stones that they are able to start at all. As the mules have discovered this, they knowingly start on the tips of their toes, in order to let them catch these irregularities : they have found out that by putting their feet down flat they slip over them. The full use of the frog is what they are in want of. They would not start on their toes if this were put at their disposition; but no shoe can give it, except the Charlier tip.

Mr. Fearnley says :- 'People will watch a horse drawing a heavy load up a hill, violently digging his toes into the ground, or backing a load down a hill, digging his heels into the ground, and then go home and invent a shoe!'

What oceans of misdirected ingenuity have been wasted over this bugbear-an article that is entirely unnecessary. It is true that Mr. Fearnley does not go quite so far as to say this-he has no experience in working unshod horses; but he does say that the simplest and smallest of all, the Charlier, 'is at once the most scientific, as it is the most commonsense, shoe.' He is about as late an authority on the subject as can be found; but all advice in this direction seems to be cast to the winds. People rely more on the knowledge of their stable-helpers and farriers, and ask their opinion on the subject, which is, of course, that they know more about it than all the professors yet born, and they know that all parts 
of a horse's foot must be kept off the ground, 'or else why does he limp when he loses a shoe?' This settles the thing at once with the master, and he shuts up, instead of giving the thing fair consideration and investigation, and talking it over with other owners to obtain an interchange of ideas. People do not like to do this, because, as Bracy Clark said: ' No man likes to make inquiries about horses, for that would imply a want of knowledge.' This nail got another blow on the head lately from 'Caractacus,' when he said in the 'Farm Journal': 'Unfortunately it forms too prominent a feature of the average Englishman's vanity to affect to know much more about the horse than he really does.' As a general rule, that is what is the matter with them; but in the affair of treatment of the foot they tacitly acknowledge that stable-helpers and farriers understand it better than themselves, and so they leave these two lumps of ignorance to make arrangements between them over such a small affair, heedless of the not time-honoured maxim, 'No foot, no horse.' Thus, these worthies have become authorities on shoeing, to the prejudice of professors who were almost at their wit's end to grapple with the question.

Mayhew says: 'No shoe can give that which is dependent upon motion'-expansion is motion. ' There are many more pieces of iron curved, hollowed, raised, and indented than I have cared to enumerate. All, however, have failed to restore health to the hoof. Some, by enforcing a change of position, may, for a time, appear to mitigate 
the evil; but none can, in the long-run, cure the disorder under which the hoof evidently suffers. Anointing the hoofs, or using various stoppings, are equally fruitless.' You cannot get the present race of stablemen to believe a single word of this; therefore their present sway must be wrested from them. 


\section{CHAPTER XX.}

QUESTION IN THE 'FIELD' AS TO AN UNSHOD HORSE WORKING IN LONDON-NO ROADS TOO HARD FOR AN UNSHOD HORSE - XENOPHON ON HARD, ROUGH STABIE FLOORS, ETC.-ERRONEOUS IDEA OF 'SOMETHING NICE AND SOFT' TO STAND UPON-FLINT ROADS OF HERTFORDSH RE- ' YOU CANNOT TREAT AN ORGANIC BODY AS IF IT WERE AN INORGANIC ONE '-BRACY CLARK, 'THE MISERABLE, COERCED, SHOD FOOT' - BRACY CLARK ON DIFFERENCE OF GROWTH OF HORN IN THE SHOD AND THE UNSHOD HORSE-FAILURE OF BRACY CLARK AND MILES TO PRODUCE A PERFECT HORSESHOE.

THE 'Field,' in its issue of May 1, 1880, contains the following:- 'Last week I saw in the City a brown horse without shoes drawing a full-sized brougham: his feet scemed particularly sound and well-shaped. It would be interesting to learn the method of treatment, and the length of time necessary to fit a horse for use unshod on the London stones. If the owner should see these lines, perhaps he will give your readers the benefit of his experience.'

This communication proves that there is at least one more unshod horse going sound in our midst, and that he has excited the interest of at least one observer. Although this gentleman does not directly express it, he seems to imply his wonder how the 
horse could do his work over the paved streets of London, which are the cause of so much injury to shod horses through their slipping about upon them so continually, and the 'concussion striking through the iron up the leg' (Douglas).

This brings us back again to the question of roads-there are no bad ones for an unshod horse; but neither the hardest nor the roughest are the worst.

We have before cited Xenophon, but now we will do so more fully. He says: 'Damp and smooth stable-floors injure even naturally good hoofs; to prevent damp, they should slope backwards.' The damp of acrid excrement is evidently implied. 'To prevent them from being smooth, they should have irregular-shaped stones inserted in the ground, and close to one another, similar to a horse's hoof in size; for such stable-floors give firmness to the feet of horses that stand upon them. The ground outside the stable-door, upon which the horse is groomed, may be put into excellent condition, and serve to strengthen the horse's feet, if a person throws down upon it here and there four or five measures full of round stones, large enough to fill the two hands, and each about a pound in weight, surrounding such spaces with an iron rim, so that the stones may not get scattered; for as the horse stands on these, he will be in much the same condition as if he were made to travel part of every day on a stony road. A horse must also move his hoof when he is being rubbed down, or when he is 
annoyed with flies, as much as when he is walking; and the stones which are thus spread about will strengthen the frogs of his feet. He that gives trial to this suggestion will give credit to others which I shall offer, and will see the feet of his horse become firm.'

Paul Louis Courier translated Xenophon's treatise, and was so impressed with its inculcations that he put them to the proof by riding unshod horses in the Calabrian campaign of 1807 , and he found them right. Does not this look as if we have been striving to know better than our masters, and hunting to heel, or peering through the wrong end of the telescope? 'The 'Cavalry Officer' before quoted had got hold of the right end of the thing, and so have a few others who have given their experience to empty air from time to time.

The unshod horse can successfully deal with all roads. Those that are soft, and have to be travelled over continually, are the worst for him ; but Xenophon shows us how to meet even this difficulty, by making him stand at every opportune moment upon the roughest material we can find for paving. How opposed is it to the opinions and ideas of the present age, that a horse could be benefited by dancing about upon loose shingle of the size of an orange, whilst he was being groomed outside a stable that was intentionally roughly paved for the purpose of giving as much attrition as possible, in even waste time.

Xenophon did not write upon theory, but gave 
the result of his practice and experience, which does not seem to have taught any one very much, for we find modern writers who quote him shifting out of the question by stating that he had not our modern artificial hard roads to deal with. From his style of writing we may infer that he would have been glad to shake hands with Macadam, or even with a pavior that would extend his stable floors out-ofdoors as far as possible. He would not have asked for a steam-roller to smooth down loose stones, because he knew that his horses would prefer them to the soft mire encountered continually when in campaign, at which times they could not always get the benefit of the hard floors, on the use of which in barracks he laid so great stress.

The universal idea nowadays is that horses must have something ' nice and soft to stand upon' when they are not at work, and that this something should have smoothness also connected with it; some people even argue that a stable without straw spread over it in the daytime looks naked and comfortless. This is conventionality. In Spain the best-appointed stables are clean swept by day, and the presence of an odd straw knocking about would be considered slovenliness. Tastes differ according to established customs or prevailing fashions; but the hygiene of the horse should never be sacrificed to such empty and variable things as fashions or appearances of any kind.

'Herts' seems unwilling to believe that unshod horses could trot for miles together over roads con- 
structed and repaired with flints. They can do so, however, and with more ease and comfort than shod ones. If they could not, there would be an end of the thing, for evidently the horse should be able to go anywhere and everywhere, and at a moment's notice. This is just what shod horses cannot do, as they are continually being sent to the forge to have alterations made when a frost sets in, or for some other reason. His statement that his horses are found very much lamed and cut when they go only half a journey over such roads, after losing a shoe, everyone (including the writer) will most readily accept. As regards the deer that could not stand upon its feet for three weeks after a run, we have no evidence that he ran upon macadamised roads, or even that he suffered in his feet. He most likely had too much of either the pace or the distance, and so had given out, as many a good horse has frequently had to do, and even die in the field upon occasions, notwithstanding his being blessed with shoes. This accident to a solitary deer does nat seem to have led to the practice of shoeing deer that have to be hunted. It is generally accepted amongst sportsmen (those who ride, at least) that their chase should have fair play. The deer which we hunt in England are captive animals (except those on Exmoor), and if shoeing would give them fairer play they certainly ought to get the benefit of it; not only on account of the fair play, but also on the score of speed, activity, confidence, and staying powers, of which they might (theoretically) take 
advantage, and which should make their chase all the more exciting. Perhaps people are afraid that then they would never be run down at all, or even viewed. Foxes run stoutly, and some of them manage to outrun both hounds and huntsmen without the aid of so much as a sock or slipper, and so do the deer on Exmoor that have rougher ground to deal with than most people imagine; yet we do not hear much about their going into hospital. The deer that got so knocked up on the occasion cited could not have been in condition, or ' fit' for a hard run, and must have been prostrated by simple overexertion. Should he be brought forward after many years as evidence that horses require shoeing? Fair argument and common sense do not appear to be entirely necessary to everyone who is determined not to be convinced.

However, as regards those sharp flints, Mr. Douglas has informed us that the frog does not fear them. Colonel Burdett says that the natural sole is almost impenetrable, and so hard and strong that it protects the sensible sole from all harm; and Osmer tells us that all feet exposed to hard objects become more obdurate thereby if the sole be never pared. Now, has 'Herts' considered that our shoe does not cover either the frog or more than the edge of the sole, and, mutilated as they are by the knife, that the sharp stones must continually be reaching them, and that still horses do not get cut by flints in these parts? Where they get cut and crippled is on the brittle crust, and sometimes on the outer rim 
of the sole, precisely those parts which have always been covered and protected with iron, or, in fact, deprived of all attrition, whilst the frog and sole get some occasionally from inequalities to be met with on almost every road. Both of these must, therefore, be exposed to the sharp points of the broken flints in question to a very great degree, although they do not hurt them unless a stone gets fixed between the shoe and the sole. People ought not to want to have such simple facts pointed out to them; they see them daily, and they are patent enough. But no; people close the doors of their minds, and when they have incapacitated the outer rim of the foot from performing its natural functions, they point triumphantly to it, as if the mischief were not their own bringing about. Certainly, no one must expect to tear off the shoes and be able to put the animal to full work in five minutes afterwards. Not only has no one been invited to act thus unreasonably, but they have been warned against it. For hardworking horses, that cannot be suspended from labour, the use of tips has been recommended. Keep on with the tips if you are satisfied with the results they give you, for months if you choose, or even altogether, if you are afraid to go farther. You will, anyhow, have made a vast improvement.

Here is another argument in favour of tips. You may have an ordinary full-sized shoe put on in the best manner possible, even inspected by the best veterinary surgeon to be found, and one who will. 
forbid all carving away of the frog bars and sole, and will see that the frog comes down to the ground (even if it has to go over the Hertfordshire flints, for which the veterinary surgeon will have no fear), and then you will get frog pressure, which is already something, and your horse will then be one of the best shod in England, but if you will just lift up his foot and examine the frog, you will see that it is semicloven. Now, as you will hardly regard the cleft as the result of a careless construction, you should reason out for yourself what it is there for, and then you could hardly help arriving at the conclusion that it was to allow the heels to spread. Why then do you lock them together with a full shoe? You have obtained some pressure and attrition for the frog by abstaining from mutilation, but its third necessity-expansion-you do away with altogether. This has been expounded by Bracy Clark. Mayhew says:- 'You cannot treat an organic body as if it were an inorganic one,' but this is just what you are doing when you turn a flexible foot into a rigid one. Hope was also aware of this, and he recommended that, after a journey, the two hindermost nails on each side of the shoe should be drawn, to give the horse relief. All kinds of dodges have been proposed with the same view, but the tip is the only one that has answered; so you are earnestly. advised to try it. You risk absolutely nothing, as has been proven over and over again. Keep up its use as long as you feel nervous about leaving it off; but when you determine on getting rid entirely of 
what Bracy Clark calls ' the miserable, coerced, shod foot,' and entering that seventh heaven of a horseman, where the bother, anxiety, and expense of shoes are unknown, you must bear in mind that the horn at the toe will still be somewhat brittle, and may chip away until the nail-holes have grown down to the ground. This is to be prevented or remedied by following Osmer's advice to 'keep them rasped round and short at the toe.' The nail-holes will grow out much sooner than may be expected.

Hear Bracy Clark on the difference of the rate of growth of horn in the shod and unshod horse :'To consider all the beauty and purposes of the singular construction of the foot, we must dismiss from our views the miserable, coerced, shod foot entirely, and consider the animal in a pure state of nature, using his foot without any defence. . . The wall, or crust, of the hoof, where there is a demand for its wear, grows rapidly, as when in a state of nature and exposed to the ground; but, shod, it loses this power in so great a degree that in many horses a few thin slices only can be removed at each shoeing, after the interval of four or five weeks, in which time twenty times as much horn would have been produced had there been a demand for it.' It may be doubted by some that horn can grow so fast when allowed to do so, and it may be asked where it is tc be seen. On the heels and quarters attrition uses it up as fast as it grows, and so these parts never require rasping -in fact, they

$$
02
$$


must be let alone altogether. But in the case of the toe it is different, for attrition will not suffice to keep down an exuberant growth, and the rasp is, therefore, needed to remove it. All that have had the experience are agreed upon that point.

Bracy Clark dedicated the best part of his life to the task of producing a perfect horseshoe. He did not succeed in this task, any more than he succeeded in seeing the full force of his own arguments. In this he was rivalled later on by Miles, who wrote:- The principal argument upon which the uninformed ground their objection to bringing in the heels of the shoe is the necessity which they affirm to exist for affording the horse more support at the heels than Nature has given him, and which they say my plan entirely deprives him of. Now, what does this argument amount to? Neither more nor less than a declaration that the Almighty Creator of the Universe has failed in imparting to the horse's foot the form best suited to its requirements, and has delegated to the puny intellect of man the task of devising a remedy. Surely the stoutest sticklers for the infallibility of old plans and old prejudices will shrink from subscribing to such a doctrine as this.' Mayhew wrote :- 'A return to perfect freedom could alone cure the evils caused by unnatural restraint.' Still, after expressing himself thus, Mayhew 'went home and invented another shoe,' as Mr. Fearnley says, but one which never came into use, and never will. 
PREJUdICE AMONGST GIFTED MEN.

It is lamentable to find writers of such calibre holding forth such arguments, afflicted with shoes on the brain up to the very last, and unable either to get over or break through the low, flimsy fence which stood between them and the field which contained perfection. 


\section{CHAPTER XXI.}

ASPHALTE PATING, AND DIFFERENT OPINIONS CONCERTIKG IT

-DISSATISFACTION THAT REIGXS WITH REGARD TO THE ORDINARY METHOD OF SHOEING-TRANSMISSION BY PARENTS OF DISEASES PRODUCED BY SHOEING-FREXCH STATISTICS AS TO DISEASES OF THF FEET AND LEGS OF THE HORSES IN THE ARMY-SHOEING, A NATIONAL QUESTIOX.

ASPHALTE is a class of road surface that has caused a great deal of controversy. At certain times, and on certain days, such as when fog and mist prevail, it gets greasy (as this state is called). In some other weathers the same state of greasiness is produced during the beginning of rain; but when sufficient rain has fallen to reduce the consistency of this so-called grease, the slipperiness disappears, and then asphalte becomes a better holding surface, for even shod horses, than either the wood or granite which are contiguous to it; supposing them each and all to have received the same amount of rain. In fine summer weather, watering with carts will make wood and granite slippery, when it will not so affect the asphalte. But in any weather the unshod horse can deal with it more successfully than the shod one. The Almighty defies 'the puny intellect. of man' to produce a road of any kind that can 
harm the foot which He has designed with his omniscience and omnipotence to grapple with everything that can possibly spring up on the surface of the earth.

Modern writers on the horse (asphalte is only a modern introduction) have been for some time, and significantly enough, much at variance as to the virtues or defects of this material, according to the different lights under which they looked at it; even when all of them were ignorant that the unshod foot was the proper one to deal with it successfully under all circumstances.

In June 1878, in one contemporary we read:'Asphalte pavement appears to be on its trial. As we briefly mentioned last week, the R. S. P. C. A. has volunteered to assist those who do not approve of these pavements, and to "unite with any respectable agency for the purpose of mitigating the evil complained of." Respecting this voluntary effort, Mr. Gerard F. Cobb, of Trinity College, Cambridge, requests the society "to carry out its own acknowledged objects, and to regard the question entirely from the horse's point of view, but in all its bearings. I know, if I were a horse, what I should say, viz., that I would gladly incur the risk of an occasional downfall (which, after all, is less than what I am exposed to on the granite) for the sake of the unparalleled ease and comfort with which it enables me to perform my daily tasks." Mr. Cobb also suggests that "If the Society meddles at all in this matter, I would venture to suggest that its efforts 
would exert a more extended beneficence if it induced owners to adopt the Charlier system of shoeing suggested by Mr. Stevens." Eight days later on, another contemporary published a communication on the same subject, from which we give the following extract:- ' All the cab proprietors, all the omnibus proprietors, all railway van proprietors have protested against the dangers and cruelties created by asphalte pavement. Falls on asphalte are not only more frequent but of a graver character than on any other kind of pavement. Veterinary surgeons meet with fractures of the pelvis and ribs, which were before almost unknown. Strains of a serious kind are created in starting loads on a surface almost as smooth as ice. It is a mistake to appeal to the climate of Paris. The climate of Paris is not the climate of London, where in five minutes a greasy fog makes Cheapside one long chapter of accidents. Unfortunately, asphalte has on its side the vested interests of the City legislators. It is the least noisy, the least dirty, the most easily cleaned of pavements, and although it tortures the horses, it suits the respectable tradesmen who pay the City rates. It is to be hoped that public opinion will shortly be too strong for natural but selfish legislation, and that the Society for the Prevention of Cruelty to Animals will find some subjects for their righteous zeal of a higher class than costermongers.'

With the last part of the last paragraph we heartily agree. But the Society in question, after being invited to investigate the question of shoeing, 
on the one hand, and that of roads on the otherboth of them being within its scope-has moved in neither direction. Feeling itself incompetent to treat the question at all, it has maintained a 'masterly inactivity.' The last of the two exponents who thus invoke in such opposite ways the aid of the Society in favour of an animal over which it watches in other matters, sets forth that asphalte makes the best road of all, except for the horses. Yet we are asked to abandon the economies and comforts of this production of modern intelligence, because it would render another improvement necessary, which would bring about as much or more economy and comfort on its part. This is to offer a two-fold opposition to progress.

Asphalte, however, is not yet suppressed; nor does it appear likely to be, since we read within the last fortnight that 'the carriage-ways of London Wall, Bucklersbury, Cannon Street, Abchurch Lane, Castle Street (Cripplegate), Trump Street, the north side of St. Paul's Churchyard, Long Lane, Broadway (Blackfriars), and Philpot Lane, are to be forthwith asphalted'-the contracts being signed.

Science and progress cannot be put down by 'old-fogyism,' however much the latter may retard them. Asphalte will ultimately supersede, in towns, both wood and granite; and the asphalting companies could forward this end to their immense commercial benefit if they had the intelligence to demonstrate that unshod horses would not slip on their productions, by using unshod horses them- 
selves. Will this ' tip' be thrown away upon them? We have heard that they have held out encouragement to inventors who could remedy the only defect of their pavements; here they get all they want, and without any charge for it. All inventions to avoid slipping upon asphalte have been applied to the wrong surface. Let them turn their attention to the other one, and so do what other societies are unable to do, because they get muddled with conflicting advice, and are unable to discern for themselves.

We have now, we believe, treated of all roads; and the upshot is that people are most afraid of the best-which are the hardest. Loose, broken flints, freshly spread, no man in his right senses would select as a trial for a horse that had just had his shoes pulled off; although judicious treatment would in a few days enable him to travel over them with more comfort than if he were shod. On the other hand, to try to harden his feet by working him upon grass or soft roads would be almost as great a mistake. It is well known that horses at pasture will become tender-footed in dry summer weather, if the ground becomes dry and hard, and that often they have to get tips put on on this account. 'Santa Fé' has advised that horses should be worked in the fields at first, and then be gradually used to hard roads. In this we are at variance with him, and must uphold that from the first day they should daily get some exercise on hard roads. The distance cannot be laid down, as it depends so much on the 
state of brittleness of the hoof: intelligence alone can decide the degrees. Ni tanto, ni tan poco. The advice offered by a 'Cavalry Officer' is about as good as any, and the excellent remark of 'Impecuniosus,' that ' it is the shoe, and not the road that hurts, the horse,' contains the gist of the whole thing in fewer words than any other writer has been able to put it. Unfortunately, he did not arrive at the point of doing away with iron altogether; but he went on cutting it down in every dimension, until he found that the less of it there was the better he got on; and then he imparted the result of his experience to a public that had not sufficient capacity to take it in.

The more simple the means offered, the less reliance a horsey public is inclined to place in them. There is always existing a latent hope that some extra-scientific invention may spring up, which will conquer all difficulties. There is no use in waiting for it. Nature cannot, and will not, be superseded by the puny intellect of man, when it is a question of treating a living structure, which is so admirably constructed as to make the very idea of improving its construction ludicrous. Everyone may give up all hopes on this score; and the best thing to be done is to travel on the 'back-track', and meet Mother Nature at the point where they failed to detect her finger-post. The travel on the backtrack necessitates only the inversion of weeks to unfold the errors of centuries; and thrift is always on the right side. What more can be asked for? 
It may, perhaps, appear to some to be too cheap to be of any use. The writer, however, has had proofs in the correspondence which his remarks have called forth in the 'Farm Journal,' that the horsey world is still as uneasy on the subject of shoeing as it ever has been, and that a certain portion of it is open to receive new ideas, and, at least, give them consideration. Another proof that the system of shoeing followed at the present day is not universally satisfactory, is to be deduced from the fact that at a council meeting of the Royal Agricultural Society of England, held May 5 of the present year (go back for a century, or bring it down to present date, it always resolves itself into the same thing at last), it is reported that 'a letter from Mr. Robert Mynors, suggesting the republication of "Miles on the Shoeing of the Horse" as a sixpenny pamphlet, was read and referred to the "Journal" committee, on the motion of Sir Brandreth Gibbs, seconded by Mr. Bowley.'

Miles, as has before been stated, was seeking only to secure the benefits resulting from expansion. He did not fully grasp the question, because he was, like all others, blinded, or semi-blinded with iron; but he tried to reduce the excessive number of nails then, as now, used in fastening on the shoe. He failed in establishing his system, because it was not even as much as a half-measure; and the society in question will do no better with it on this very account. The sixpenny pamphlet of Mr. Stevens, which is ready-made, and at hand, is far more worthy of their attention and patronage, especially when we 
see the system it explains so highly advocated by an authority like Mr. Fearnley. Why should societies feel so inclined to revert to anything they can lay hold of that carries them back to what we may call the infancy of the art of shoeing? The reason is that they are disgusted with the results of the present system, and so they are always on the lookout for ' any port in a storm.' There is a haven open for them at an easy distance, and with wind and tide in their favour. Although they still prefer beating to windward, they will tire out in time. They are evidently in want of smooth water at the present moment. Let them therefore put back. There is no cowardice in so doing when they find that they really cannot weather the storm.

Before concluding, there is yet another question which demands a high consideration in many points of view. It has been long maintained that many diseases are transmissible by sires and dams (either or both) to their progeny. Not to go farther back than the last month or two, the columns of contemporaries have teemed with opinions on this subject, many of them emanating from acknowledged authorities, amongst whom are to be found managers and secretaries of horse shows, in which progenitors have their special classes. It has been urged that if all those who were not free from those physical. defects which are considered as hereditary were objected to, there would scarcely be a competition, on account of the number of disqualifications. It appears right, however, that only perfect animals 
should be chosen for the purpose of reproducing other perfect ones. If there is anything wanting or anything superfluous, we must be aware that it will show itself in some way or other in the foal, and generally in the spot where either the sire or the dam exhibited a like defect. Spavins, \&c., are justly ascribed to shoeing as their principal cause; leave off shoeing and you reduce the prevalence of such kinds of ossification. 'Like produces like.' The tailless breed of Manx cats was produced only by persistently amputating the tails of all kittens, until there was not left upon the island a tail to reproduce another one. Within the memory of the writer a good sheep dog was supposed to be obtainable only if he had been pupped without a tail, or a curt apology for one. All those who dared to bring tails into the world with them were condemned to the horse-pond. Within his memory, the same law held good in France with regard to the poodle. Now-a-days a good tail is an important point in both the colley and the poodle; so much so, that neither colley nor poodle possessing a 'stump' would be admitted to a show or fetch three halfpence anywhere.

\section{'Men change with travel, \\ Manners change with climes, \\ Tenets with books, \\ And principles with times.'}

Entire horses mostly save their tails in their entirety ; strictly speaking, they would not be entire unless they did. So also do many mares; but if we were 
to fall into the habit of docking those of both parents, we should soon get a breed of horses with a diminished number of vertebræ. If the minus reappears in the offspring, it is presumable that the plus will reappear likewise. The plus is often to be ascribed to shoeing.

Where our horses most fail is in their feet and legs. It was lately stated at a meeting in England that French statistics have shown that in their army two-fifths of all cast horses were so cast for 'worn out feet and legs.' Let us take a common-sense (which will turn out to be the most scientific) care of our horses' feet by the use of the brake on wheels, and not a clumsy substitution in the shape of a calked shoe on the horse's foot. The frog is a natural calk, but it must have fair play. It is pointed in front like a ploughshare to offer resistance in one direction. To offer resistance in the contrary direction it is semi-cloven, and thus it offers a double resistance, for the very evident reason that a horse needs more aid to go ahead than he does to stop himself. Yet the two ends have been rightly balanced by Nature, if we could only see the thing as such.

We have the authority of previous writers that the shoeing question is a national one, and that much economy is in store for the nation if any improvement can be introduced. The real fact is that millions annually hang upon this very hinge, because we are obliged, through the short lives of our horses, to import weekly a large number of hideous foreignbred brutes, many of which are mares, which, when 
they have had enough of London stone pavements, are sold in foal by transport companies. See recent advertisements in the daily press, and then give us the lie.

At the Northern Horse Repository go and see every Friday a sale of foreign horses that always are unshod, at least on the hind feet. The sellers are evidently wide enough awake to have perceived that there is some advantage in showing them off in this state, or else they would clap shoes on to them, to give them a fictitious value. Horse-dealers suppose themselves to be up to every dodge, and this is one, amongst others, that they are keeping as 'dark' as they can. The innocent (or ignorant) acquirers of these animals (as we have found out by frequent attendance at these sales) never dream of putting them to work until the farrier has been allowed to exercise those brutalities, in which he is such an adept, upon their feet.

These writings could be prolonged by pushing arguments and quotations; but we are inclined to think that enough has been said on the present occasion, which we regard strictly as a first stage upon the road. We are not sanguine enough to believe for a moment that we can bring about a sudden revulsion, although we may, perhaps, bave helped on a movement which will not be arrested. We have vouchers that some readers have been able to keep their attention sufficiently alive to go through a course of nearly seven months' weekly reading on the subject in the 'Farm Journal,' and this is en- 
EXISTING DESIRE FOR SOMETHING NEW. 209

couraging. It seems to prove that 'Impecuniosus,' practical and enterprising as he was, was not far wrong when he still craved for some writing out of the 'ordinary follow-my-leader style,' which might 'throw some light on a subject hitherto veiled in obscurity, viz., the horse's foot.' We should only be too glad to learn that this active-minded gentleman is still in the land of the living, and that writing containing the 'original ideas' which he, being so far ahead of the 'ruck,' was still open to receive, may fall under his criticism. He is chargeable to a great extent for its having appeared. 


\section{APPENDICES.}

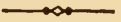

Appendix A.

\section{Horse-Shoeing.}

\section{(LETTER OF ABERLORNA.)}

I HAVE read with great interest the letters of 'Free Lance' upon the subject of horse-shoeing. Seeing he so strongly advised using tips in place of entire shoes, I resolved to try them, and, accordingly, rode down to the smith's shop (ten miles off) to get them put on, and see he did it properly. When I arrived I told him what I wished; he laughed, and said they never would do on the roads, but would put them on if I wished, and so put on they were. I rode home again, ten miles, over a road covered with new metal in a simply abominable state, and he arrived all safe. Two days after I rode down again to convince the smith there was something in the system, and he was quite surprised the horse had not broken down on the way home after he was shod. I must say, however, he certainly went tender, but this appears to be wearing away in a great degree, and it is surprising how hard and firm the soles of his feet have got. He has naturally rather flat and tender feet. I am so far convinced that this is the correct way of shoeing horses that, if all goes well, I shall have all the 
rest done the same way. 'Free Lance' objects very strongly to applying a hot shoe, and I will just give one or two extracts from a prize essay by George Armitage, M.R.C.V.S.

'As a result of cold shoeing-i.e. fitting the shoes cold, which means rather fitting the foot to the shoe, much inconvenience is engendered. No man can alter cold shoes. If they are applied the foot must be altered, and that is accomplished by tearing it away. When the shoe is heated, it can be caused to " bed" itself to the foot, and no injury is found to result when due care is exercised. Good feet are never injured by it, and bad feet might frequently be benefited by its adoption, as the shoe always remains on more securely. Two surfaces are caused to correspond, friction is set up between them, and their separation not so easy. When, on the contrary, those surfaces do not bear any relation to each other, they are easily separated, as all inequalities act as so many levers against their position In practice, the number of lost shoes under the cold method of fitting exceeds those executed while hot more than fifty times, and that number can be supported by all who have gone into the matter carefully.' 'If a little calm investigation were made, it would become evident that the objection to the use of hot shoes in fitting is only injurious to weak and tender feet when carried too far-the foot fitted to the shoe, in other words.'

The above extracts appear to me very sensible, and I believe no ill effects ever result from hot shoeing, except when done by ignorant men, who should be anywhere but in a shoeing-forge.

Aberlorina. 


\section{A ppendix B.}

\section{Horse-Shoeing.}

Sir,-I have read with the greatest interest the letter's of 'Free Lance' on Horse Management, and am inclined, from my own observations in other countries where horses and mules are not shod, to try the experiment, and have no doubt many of my brother farmers would like to do the same; but will 'Free Lance,' or other' equally good authority, tell us how to make a right beginning?

My horses have, of course, all undergone the 'burning on' and 'laceration' consequent on this barbarous custom, and farming operations are too backward to admit of the apparently necessary ' rest' being given to allow the injuries to the hoof to 'grow out' and harden.

Our local farrier does not, and probably would not care to, know much about the 'Charlier' shoe, and could throw every impediment in the way of a gradual change being successful.

All my horses have been bred on the farm, and, with the exception of the sire and another, are young and fresh; they are in perfect health; neither they nor their predecessors, during the last quarter of a century, having ever taken a drop of 'medicine,' or 'horse balls,' save the leaden ones to cure them of 'crippled' old age.

My carter thinks it might ' do' on the land, but shows a disposition to kick over the traces if the experiment is tried on the road. However, I am prepared to face ignorant prejudice by anointing the outraged feelings of my man by giving him half the saving in the blacksmith's bill, which success will entail, to carry out the instructions necessary to perfect the change.

Will Watcif. 


\section{Appendix C.}

\section{Horse-Shoeing.}

Sir,-I was rather amused with the letter of 'Free Lance" on Saturday. No doubt I did give my poor nag rather a severe trial at first, but I believe it has set a good many people thinking, which is a good thing, and it has not injured the horse. I thought myself the trial was too severe, and determined to be more cautious next time. On Friday last I took another to be shod on the same principle. This horse has first-rate feet, but has had shoes put on reaching nearly to his heels, allowing the frog to come well to the ground, and I shall shorten them each time he goes to the smith until they are of the required size. I will not say any more about hot shoeing; this will become unnecessary if all people use tips, which any person ought, I think, to be able to put on with very little practice and thus save the time and trouble of having to send their horses away to be shod.

I have ridden horses hundreds of miles in South America which never had a shoe on. Their feet grew fast, and often I had to cut the toes, which was done with some difficulty with a chisel and mallet by placing the foot on a block of wood. I do not remember seeing any lame horses except in the towns, and those were generally, if not always, I observed, shod. The roads were, for the most part, sand, full of rough stones, and in some places causewayed for miles. Anyhow, they were pretty rough going. People in this country seem to have no idea what a horse's foot is ; they have always seen horses shod, and think they always must be shod, and never will alter the method if they are let alone. As to the farriers, it is useless talking to them. Take 
your horses to them, and make them follow out your directions through thick and thin; it is the only way.

A Berloria.

\section{Appexdix D.}

\section{Horse-Shoeing.}

SIR,-In answer to 'Free Lance,' my reply is that I used a chisel and mallet in preference to a knife, because with the latter it would have been a laborious job, owing to the extreme toughness of the horn. I never saw an ordinary horse's hoof in this country so hard, because I suppose they are all shod. I regret I never compared the hoof of a shod horse with that of an unshod one in South America, as it would have been interesting to note what difference there was in the toughness.

Regarding the causeways, these were as rough as could be-stones of all descriptions and sizes laid up endways, as one sees in this country, but very roughly done and full of hollows, \&c. I often wondered at the work these little horses went through, living almost entirely on grass and a little molasses mixed with their water, which they would refuse to drink without. These horses journey 400 miles or so with heavy bags of cotton and sugar slung on their backs to the coast, and make the return journey home laden as heavily with salt codfish and other provisions; yet how rare it is to see them either lame or footsore!

I am not quite sure that in this climate of ours a horse's foot will become as hard, owing to the damp; but this I hope soon to find out to my satisfaction. All I have to say now is, let any one who has taken the trouble 
to read all this discussion give the system adrocated by 'Free Lance' a fair trial ; don't be too hard at first, but work on gradually, and don't be disheartened the first two months or so, while the horse's feet are hardening.

Aberlorna.

\section{Appendix E.}

\section{Horse-Shoeing.}

Having lived for a considerable portion of my life in the Argentine Republic, allow me to say a few words about the shoeing of horses. In the camp, as the country is termed there, horses are never shod, but town horses are. As you are aware, there are no stones on the plains of the Argentine Republic. The soil is a rich black mould of a considerable depth. Horses, if their hoofs have not been accustomed by degrees to paved streets, will naturally go tender at first; therefore, the owners immediately clap shoes on them. It would be as absurd to expect a horse not reared in a stony country to go sound when first brought on to pavement, as it would to be surprised at a person who has never gone barefoot feeling uncomfortable when walking over gravel without shoes or stockings. Yet it only needs practice, and Nature will soon put a hard covering on the sole of the foot.

We could tell in an instant if a horse had come from the Sierras of Cordova or other stony mountain ranges. The hoofs are smaller than those of a Pampas horse; in fact, more mule-shaped and worn down by the hard ground, and not by artificial means ; the horn is, moreover, very dense and free from cracks. Depend upon it 
Nature will adapt herself to circumstances. Horses bred in Cañadas or low swampy grounds have broad, flat feet. The dampness of the soil keeps the horn soft, and the weight of the horse expands it. Besides, there is nothing hard to wear down the hoof-all the better for the horse as long as he has to go on wet, soft ground; the extensive surface of his foot gives him more support; but these kinds of hoofs need a good deal of dressing. We generally used a chisel and mallet, making the horse stand on a hard bit of ground, and cutting the hoof, sometimes only at the toe, but more frequently at the sides also. In the northern provinces the natives often cut them square at the toe. Our favourite horses generally got a finishing touch with rasp and draw knife. The hind feet seldom required much doing to them. In dry weather the hoofs get very hard, and the mallet must be used with considerable force. White hoofs are much softer than black ones. With a moderately tame horse there is very little trouble connected with keeping his feet in good order. The rasp and draw knife are all that is needed, and hard ground will keep them in good shape without much labour expended on them. Although I have not tried the experiment in this country, I have little doubt of its success. Keep a young horse's feet trim, and use him in the fields at first, and then by degrees on the hard road, and his hoofs will soon suit themselves to the nature of the ground. Fortunately our ancestors did not shoe their dogs and cats, or, in all probability, most of us would do so in the present day.

Of course the veterinaries and smiths will, in selfdefence, predict utter ruination to the feet of unshod horses, and 80 per cent. of horse owners will refuse to give up shoeing because it was never done in the old days, and they cannot be bothered with trying anything 
new. A.'s lease is nearly out, and it is not worth while making a change; $B$. is just entering a new farm, and does not wish to risk his horses being laid off work by lameness; C. thinks he may be taken up and fined for cruelty to animals; D. thinks there may be some truth in it, but he will wait till some one else tries it; and E. says his horses do their work well enough as they are, and so on.

I think tips will be necessary for draught horses, for some time, at any rate, especially in a hilly country, where so much weight is thrown on the toes in going up hill.

I may not remain long enough in England to try Nature $v$. The Blacksmith, but I wish every success to those who have pluck enough to give the non-shoeing system a fair trial.

Santa Fé.

Appendix F.

The Teeth affecting other Organs.

Sir,-In reference to 'Free Lance's' excellent articles on horses, particularly as to the teeth of that animal affecting its other members, the following case is, perhaps, worthy of his knowledge. Twenty-six years ago, a valuable horse, the property of Blantyre Mill Co., became rigid in all its members, and showed symptoms of lockjaw. The veterinary surgeon ordered it to be shot. At this point Dr. Miller, of Hamilton, appeared on the scene, and disbelieving lock.jaw to be the case, orlered its mouth to be examined, particularly as to overgrown beaks, which was instantly done, and after the needed relief was given the horse became well, as if by magic. 
Appendix G.

Unshod Artillery Horses.

Sir,-When defending the arguments of 'Free Lance' upon the 'Bare Foot' system, I was met with the reply that a fair trial had been given to the system some time ago upon the artillery horses at Woolwich, and that it proved an entire failure, so that they were obliged to return to the old system of shoeing.

This I cannot believe, but my present information will not warrant me in contradicting it. I should, therefore, be glad if any of your readers could inform me whether such a trial was made, and how it was conducted.

\section{J. F. K. S.}

\section{Appendix H.}

\section{Unshod Artillery Horses.}

Sir,-I am able to contradict the statement "that a fair trial had been given to the system some time ago, upon the Artillery horses at Woolwich, and that it proved an entire failure, so that they were obliged to return to the old system of shoeing,' and to inform J. F. K. S. that the Royal Artillery have never tried their horses in England without shoes.

R. C. R., Major-General. 


\section{A pPendix I.}

Horse-Shoeing.

Sir,-I cannot thank 'Free Lance' too much for his ' tip,' and I strongly advise every one who owns a horse to folluw the advice he has given. I have done so sooner, perhaps, than most others, because some years ago, in South America, I had the benefit of seeing and using unshod horses, and therefore knew what a horse's foot could do. If people could only be got to know the amount of trouble and expense which they would dispense with by following out this system, they would be surprised. But no, my ancestors nailed lumps of metal on to their horses' feet, and were never pleased with the result, and therefore I do likewise.

The farriers must not be consulted on the subject at all : turn a deaf ear to all they say. One gravely informed my groom that he thought the frog would wear through ! and this after he had seen the horse running ten weeks on his own soles. My concluding advice is, follow out exactly what 'Free Lance' says about getting the foot ready, and persevere steadily, and you will find, like me, that perfect success will follow. Never again will I shoe a horse on the old plan, and am just rather doubtful if I put anything on some.

May 24.

Aberlorna.

\section{A Ppendix K. \\ Horse-Shoeing.}

SiR,-Allow me to thank 'Free Lance' for laying before us the absurdities of the present system of horse-shoeing; 
and for, at the same time, giving us his excellent remedy by not shoeing at all, or to use only a 'tip.' I have the management of thirty draught horses, whose work is entirely on stone paved roads. They run about eighteen miles a day, and at the rate of six miles an hour, including stoppages. So that you can imagine what a severe shaking their legs and feet would get with an ordinary shoe (which weighs about thirty-two ounces) attached to each foot. The horses would continually brush and cut the fetlock with the shoe of the opposite foot, and very soon go over at the knees; and how was I to prevent it? Rest would often check it, as regards cutting and brushing the fetlock, for a day or two; but I have to study economy, and cannot, in consequence, keep a sufficient number of horses to rest them every third or fourth day. They have to be satisfied with one day's rest per week. Some of your readers may say, why do I drive them so fast? Well, because it is a kind of business which will not allow of driving slowly.

On visiting a railway book-stall, I saw on the front page of the 'Farm Journal,' 'Horses-Their Management and Mismangement.' I naturally wanted to know if I was numbered with those who mismanaged, and, on reading the paper, I very soon found out that I must consider myself as one of such. I also found that 'Free Lance' was writing from practical experience when be recommended that the horse should be driven barefoot, or with only a short piece of iron 'curled round the toe,' therefore I lost no time in sending sixpence to Mr. Stevens for his pamphlet advocating the use of the Charlier shoe-a shoe which I had not heard of before to my knowledge.

After reading the pamphlet, and seeing that a horse could go with the frog on the ground, I at once sent 7 s. $6 \mathrm{~d}$. 
for Flemings' improved drawing-knife, with guide, the only special tool required, and as soon as it arrived I began shoeing my horses on the Charlier principle by letting a narrow piece of iron into the outside crust and allowing the frog, sole, bars, and heels to come well to the ground.

I began very cautiously (although my horses' feet had never been cut away, by way of trimming) for fear of a failure, and a laugh from my farrier and others. I ventured on a shorter shoe than the Charlier. My first measured, before turning, ten inches. It had six nail holes. This was for a horse $15 \frac{1}{2}$ hands. I put them on one of my old 'screws,' and I am pleased to say that he ran his eighteen miles splendidly and without any signs of lameness. I allowed him to run, with his usual rest, until he had gone a distance of 228 miles, as a trial. This was done without wearing the frog through to the quick, as my farrier was so much afraid of. The hoof was now in splendid condition. I then gave orders for all my horses to be shod on this principle, beginning with my best to prevent further unnecessary injury.

With each successive horse I have shortened the iron. Now I begin shoeing with four inches of iron let well into the toe. I have not had one case of lameness from tender feet, and every horse so shod has been able to do his ordinary work without any extra rest. I find that the shorter the iron the better it answers. I buy the $\frac{1}{2}$-inch round iron and flatten it to $\frac{3}{8}$ by $\frac{1}{2}$ inch; cut off four inches, which weighs four ounces, let it well into the toe, and nail on with No. 6 counter-sunk nails. This I find wears quite as long, after the first shoeing, as the ordinary shoe did. My drivers are continually having their attention called, by 'good meaning persons,' to the fact that 'the 'oss 'as lost 'is shoe.' They have got so used to 
it that they merely answer, 'And a good job too.' The frog does not become hard, as the crust, sole, and bars do. It feels like a firm piece of inciarubber, and answers its purpose well by preventing concussion to the whole limbs, an office which it is debarred from fulfilling when the foot is shod in the old-fashioned style. My farrier asked me if he should use up the old-fashioned shoes which he had on hand, as it was a pity to keep them. I said it would be a $\sin$ to use them.

As will be seen in the commencement of this letter, horses when running on stone paved roads slip very much when shod on the old-fashioned system. Now, sir, if the only advautage to be gained by using 'tips' would be to prevent horses from slipping, I would use them in preference to the old shoe. But as 'Free Lance' has so ably pointed out, this is only one of the many advantages. Horses shod with tips can pull a much heavier load, and with less exertion than a horse with a full shoe. This I have repeatedly proved. They trot carelessly along without fear of a fall. I have several horses with that hideous and incurable blemish-capped elbow-which is brought about, so veterinaries say, by the heel of the full shoe; this cannot happen when using tips; cutting and brushing also cease with the use of 'tips.'

June 15.

Humane.

\section{A ppendix L.}

\section{Unshod Horses.}

SIR, - I wish to say a few words to your readers in favour of the theory propounded by 'Free Lance'-a theory, 
by-the-way, never heard of in this part of this very verdant isle-that horses not only could walk, but ru, and work, without shoes.

Having read the letters of 'Free Lance,' and thinking there might be some truth in the plan, I determined, when I got as far as the 14th chapter, that 1 would make a trial. Accordingly, I took the shoes off a three-year-old colt in daily farm work.

My farrier prophesied that I would not only ruin the feet, but the horse; but the horse is now, at the end of eight weeks, in the full enjoyment of all his faculties, and has four good, sound feet, although I have driven him daily from four to fourteen miles (Irish measure) regularly.

I would have done as 'Free Lance' advised, and put on three-quarter shoes, and come gradually to the bare foot, only I could not get a farrier either able or willing to put them on. This I believe to be the right plan, but in a backward country place it is hard to get the work rightly done.

In the hope that many will be tempted to try as I have done, I am, \&c.,

Co. Armagh, June 18, 1880.

D. S.

\section{A ppendix M.}

\section{Unshod Horses.}

Sir,-Since I wrote my last letter, I have taken the shoes off a pony that I use for driving, churning, \&c. J begin to work very gradually, not more than two miles (Irish) for the first few days, increasing the length of the journey as the foot gets hard. 
I think this plan a very good one where the horse owner has not much work pressing, as is the case with most Irish farmers at this time of year.

Perhaps in the next generation people will begin to see that 'Nature beats Art.'

Co. Armagh, June 29.

D. S.

Three gentlemen, as will be seen, have given their experience of doing away with the ordinary full shoeone of them has used an ordinary tip, and another the Charlier tip, and both of these without losing any work from their horses: whilst the third has at once done away with all iron, with only the precaution of not overworking his horses from the outset. They have all succeeded, and are satisfied that they have conferred a great benefit upon their horses.

London, August 1880.

The Author. 


\section{INDEX.}

\section{$\mathrm{ABE}$ \\ $\mathrm{COG}$}

A BERLORNA, experience of, A $100,109,119,123,210$, 213,219

Action of horses, 148, 151, 169, $170,173,181$

Aloes, 25, 26

American farmers, $65,66,67$, $74,79,141$

- horseshoers (see Russell)

- trotters, 42

Anstruther Thompson, Colonel, 161

Antimony, 17

Apathy of horseowners, 15

Army, farriers in the, 84, 121

Arsenic, 17

Artillery horses, 174, 218

Asphalte pavement, $43,58,85$, $88,126,198,199,200,201$, 202

Astley, Philip, 60

Attrition, 94, 95, 112, 114, 183, $193,194,195$

Australia, 113

BACKING a load, 78, 142, B 184

Bare feet, $82,83,84,88,94$, $113,114,117,121,123,124$, $125,130,143,154,187,189$, $199,208,215,223$

Bare floors, 22, 24, 32, 65, 82, $83,92,115,116,154,163$, 189
Bars of the foot, $38,55,56$, $100,137,139,177,221$

Bearing rein, the, 26, 134, 170, $171,176,194$

Blistering, 6, 25, 26, 27, 36, 91, $92,97,151$

Bracy Clark, 185, 194, 195, 196

Brakes on wheels, 2, 7, 9, 11, $12,24,60,86,178,207$

Brittle hoof, 20, 46, 76, 91, 92, $93,97,104,135,139,151$, 154,157

Broken wind, 147.

Brushing (see Cutting)

Burdett, Colonel, 91, 103, 104

' CARACTACUS,' 185

Cape, horses at the, 83 , 141,174

Calks, $34,35,37,38,66,77,78$, $87,105,107,178,207$

Carriage horses, 170

Carts and cart horses, $\bar{\tau}, 2 \overline{7}, 35$

Cavalry officer, a, 154

Centennial shoe, the, 74

Charlier shoe, the, $54,55,5 \varepsilon$, $60,61,62,63,65,67,69$, $74,77,78,140,157,17 \%$, $184,200,220$

Cleft of frog, 194, 207

Climate, $81,115,117,130$

Clips, 43, 76, 87, 105, 107

Coffin bone, the, 34,71 , 95

Cogs, 86, 87 
Cold shoeing, $36,37,66,102$, $105,106,107$

Concussion, 57, 65, 72, 74, 170, 188,222

Corns, 5, 31, 37, 61, 63, 90, 115, 151,157

Coronet, the, $72,90,91,92,93$, 94

Cowdung, 19, 31, 46, 56, 58, 92

Crib-biting, 150

Crust, or wall of hoof, 31,33 , $36,44,55,58,71,73,75$, $78,98,136,140,195,221$

Cutting and brushing, 5, 39, $61,151,157,172,220,222$ 'DAILY NEWS,' the, ex-

' Daily Telegraph,' the, extract from, $86,154,161$

Dalziel on corns, 90

Dentist, veterinary, 147

Docking the tail, 132, 172, 207

Donkey, the, $80,81,88,129$, 130

Douglas, Mr., on slippery shoes, 10

- the frog, $11,72,98$

- hoof ointments, 19

- stride, 34

- hot shoeing, 36

- weight of shoes, 43,167

- structure of the crust, 44 , 136

- average life of the horse, 60

- structure of the sole, $72,9 \mathrm{~S}$

- military farriers, 84, 121

- thrush, 89

- water, litter, grease, tar, 91

- grass and roads, 94, 98

- horseshoers, 117

- navicular disease, 150

- concussion and founder, 170

- gutta percha, 171
Down hill, 2, 3, 7, 8, 11, 66, 86

Drugs, $17,18,19$

D. S.'s letters, 223

TXPANSION, 46, 48, 50 61, $72,95,144,158,160,185$, 194

ALSE quarter, $31,36,151$

Fashion, 41, 87, 88, 134, $166,172,173,190$

Fearnley, Mr., on blistering, 92

- the horse's head, 131

- the Charlier shoe, 140

- wood pavement, 140

- the larynx, 147

- the hunter, 156

— mutilation of foot, 179

- calks, 179

- shoes, 184

'Field,' the, newspaper, 40, 55, 72,187

Fitting foot to shoe, $34,35,39$, 106

Flints, 98, 191, 202

Flower, Mr. E. F., 26, 133, 134, 176

Foreign horses, 24, 88, 207

Founder (see Laminitis)

French army, 82, 207

Frog, the, 11, 37, 55, 56, 61, 66, $72,74,75,89,98,137,139$, $144,184,189,192,194,207$, 221

Frost, 85, 86, 161, 191

CAUCHOS, 113

U Granite pavement, 58, 85 , $88,178,182,187,198,220$

Grass, 56, 94, 101, 113, 114, 154. $159,169,202$ 
GRE

Greasing the hoof, 91, 92, 104

Groggy lameness (see Navicular disease)

Gutta percha, 161, 171

UEAD, the, 28, 131

H Hoof ointments, 19, 31, $46,91,186$

Hope, Sir W., 194

Horn, growth of, 33, 58, 61, \$0, $109,112,124,195$

Hot shoeing, 35, 36, 44, 65, 66, $76,87,102,107,120$

Human skin, the, 95, 98

' Humane,' letter of, 220

Hunter, the, 156-164

TCE, 64, 85, 127

1 Impecuniosus on tips, 49

- mutilation of hoof, $\tilde{5} 1$

- shoeing reform, 52

- the Charlier shoe 54

— india-rubber, 57

— three-quarter shoe, 61,110

- ideas sprung from wrong roots, 138

- hind feet, 141

- his horses, 156

- it is the shoe that hurts the horse, 203

Improved principles, 32, 37, 38

India, cavalry in, 83

India-rubber, 57

JENNINGS, H., trainer, 143, 145,153

$\mathrm{K}^{\text {IDNEYS, irritation of, 2o }}$

T ARYNX, the, 147

$L$ Laceration of horn, 73,87 , 136
MAY

Lady's horse, the, 165-168

Lafosse, $44,45,46$

Laminitis (founder), 34, 65, 66, $157,170,175$

' Lancet,' the, on shoeing, 125

Lawrence, Mr., 13

Life, average of, in the horse, 62

Litter, 22, 23, 24, 31, 91, 154, 182

Lock jaw, 174, 217

Ludgate Hill, 10, 12, 126, 127, 128,129

Lunette shoe, or tip, 45, 109

Lupton, Mr., 30, 136, 137

]AYHEW on springs, 1

11 - sprain of tendon, 11

- servants, 14, 15

- masters, 14

- prejudices of ignorance, 25

- aloes, physicking, 26

- seedy toe and false quarter, $31,97,149$

- tips, 49,167

- expansion, 50, 96

- veterinary surgeons, 51,82 , 96

- nature a strict economist, 59

- foot of donkey, 80

- conceit of mankind, 81

-- spavin, splint, and ringbone, 90

- the necessity of being 'practical,' 94

- the necessity of attrition, 95

- selfishness, ignorance, and prejudice, 117

— evil results, 134

- different aspects of disease, 149

- navicular disease, 150

- the folly of obstinacy, 152

- transpiration in the foot, 162 
Mayhew on farriers, 171

- pride has no brains, 173

- the multiformity of shoes, 185

- grease and stopping, 186

- organism of the foot, 194

- unnatural restraint, 196

Mexico, 88, 130

Miles, on the horse's foot, 46, $114,159,196,204$

' Morning Advertiser,' the, extracts from, 83, 165

Moscow, retreat from, 82

Mules, 88, 177, 180, 181, 182, 183,184

Mutilation of hoof, $32,33,35$, $37,43,52,58,59,66,100$, $104,171,179$

NAVICULAR disease (grog1 giness), 5, 37, 62, 150

Nitre, 17

Nostrums, 17

\section{CULIST, 146,149 \\ Oils, 92,97}

Osmer, 77, 116, 192, 195

Overreach, 90

Overshot fetlock, 151

DARENTS, 205, 208

1 Park hacks, 168

Pembroke, Lord, 14, 22, 29, 35

Percival, Professor, on tips, 49

Physic, 25

Poisoning, 18, 64

Pumice foot (drop sole), 5,57 , $58,62,97$

$Q^{\text {UITTOR, 5, 89, 90, } 151}$

RACE horses, 34, 144, 153

R Rasping the toe, 79, 80, $112,117,122,172,195$
Rest, 6, 25, 26, 97, 103

Ride and drive horse, the, 176

Ringbone, 5, 89, 90

Roads (see also Asphalte, Gra. nite and Wood ), 49, 55, 63, $66,70,79,80,81,86,89,99$, $101,122,144,145,165,169$, $180,188,190,191,192,194$, 202,215

Roaring, 147

Royal Agricultural Society, 204 Roman horses, 45

Roughing, 58, 59, 86

Routine, $26,67,81,82,85,153$

Russell, American horse-shoer, $73,75,76,147$

Runaway horses, 2, 12

SAND, 85, 126, 127

S Sandcrack, $5,34,36,89$, 90,97

Santa Fé (correspondent), 153, $177,202,215$

Sawdust, 23

Scoop-toed rolling-motion shoe, 74

Seedy toe, $5,23,31,34,36,89$, $90,97,147,149,151$

Seeley shoe, the, 105, 107

Servants, 7, 14, 15, 29, 30, 39, 61

Sidebones, 5, 39, 61, 89, 157

Sires and dams, 205, 208

Slipping, 5, 10, 31, 35, 45, 48, $58,63,70,72,85,86,126$, $127,135,175,184,202,222$

Smither, Messrs., $43,62,63,68$, 88

Snow, $61,85,87,161$

Sole, the, $33,35,37,55,56,57$, $58,61,62,70,72,75,76$, $77,98,101,103,104,117$, $137,167,192,210$

Spain, shoeing in, $36,37,106$, 190 
ZUL

Spain, mules in, 182

- stables in, 190

Spavin, 5, 89, 90

Splint, 5, 39, 89, 90, 94, 104, 151

'Sporting Gazette,' the newspaper, 161

'Sportsman,' the, newspaper, 143

Springs on vehicles, 1

'Standard,' the, extract from, 145

Stanley, Mr., on navicular disease, 62

St. Bell, on shoeing, 58

Stevens, Mr., on the Charlier shoe, $62,63,78,163,200$, 204,220

Stone pavement, (see Granite)

Stopping the feet, $19,31,58$, $91,92,186$

Straw, 22, 24, 182, 190

Stride, 28,34

Swollen legs, 22, 157

TIAR, 19, 91

1 Teeth, 148, 174, 217

Tendons, $5,11,27,39$

Three-quarter shoe, $61,78,119$, $163,213,221$

Thrush, 5, 89, 90

Tight shoeing, 106

Tips, 44, 45, 49, 55, 58, 61, 65, $66,67,77,78,102,109$, $110,112,120,140,144,154$, $166,193,210-221$

Toe, $34,49,55,79,80,87,109$, $112,121,196,213,221$
Trainers of racehorses, $3 t, 143$, 145,153

Tramways, 105,178

Transmission of disease, $20 \check{5}$

Transpiration in the hoof, 162

Tread, on, 34, 39, 40, 61, 80, $137,173,180$

TRUGUAY, horses in, 88

VEGETIUS on wood paving, 116

Veterinary dentist, 148

WATER-CURE, the, 91, 92 Weaving, 150

Weight of dirt, 158

- shoe, 35, 42, 77, 105, 158, $167,171,220$

Wind, broken, 147

Windsucking, 150

Wood pavement, 85, 88, 126, 140, 198, 199

$\mathrm{X}^{\text {ENOPHON, 22, 116, } 188}$

YOUATT, $26,42,77,95,158$

$Z^{\mathrm{ULU} \text { war, the, } 83,84}$

LONDON : PRINTED BY

SPOTTISWOODE AND CO., NEW-STREET SQUARE

AND PARLIAMENT STREET 



\section{RURAL SPORTS, HORSE AND CATTLE MANAGEMENT, \&C}

ANNALS OF THE ROAD; or Notes on Mail and Stage-Coaching in Great Britain. By Captain MALET. With 3 Woodcuts and 10 Coloured Illustrations. Medium 8vo. 21s.

DOWN THE ROAD; or Reminiscences of a Gentleman Coachman. By C. T. S. Birch Reysardson. Second Edition, with 12 Coloured Illustrations. MIedium 8ro. 21 s.

\section{BLAINE'S ENCYCLOP EDIA OF RURAL SPORTS;}

Complete Accounts, Historical, Practical, and Descriptire, of Hunting, Shooting, Fishing, Racing, \&c. With 600 Woodcuts. 8ro. $21 s$.

A BOOK ON ANGLING; or, Treatise on the Art of Fishing in every branch; including full Illustrated Lists of Salmon Flies. By Francis Fraxcis. Post 8vo. Portrait and Plates, $15 s$.

WILCOCKS'S SEA-FISHERMAN; comprising the Chief Methods of Hook and Line Fishing, a glance at Nets, and remarks on Boats and Boating. Post 8ro. Woodcuts, 12s, $6 d$.

THE FLY-FISHER'S ENTOMOLOGY. By Alfred Rosacds. With 20 Coloured Plates. 8vo. $14 s$.

horses AND RIDINGA. By George Neville, M.A. With 31 Illustrations. Crown 8ro. $\epsilon$ s.

London, LONGMANS \& CU. 
2 Rural Sports, Horse and Cattle Management, \&c.

YOUATT ON THE HORSE. Revised and enlarged by W. WATSON, M.R.C.V.S. 8ro. Woodeuts, $7 s .6 d$.

YOUATT'S WORK ON THE DOG. Revised and enlarged. 8 ro. Woodcuts, $6 s$.

THE DOG IN HEALTH AND DISEASE. By Stonehenge. Third Edition. With 78 Wood Engravings. Square crown 8 ro. $7 s .6 d$.

THE GReyhound. By Stonehenge. Revised Edition, with 25 Portraits of Greyhounds, \&c. Square crown 8 ro. $15 s$.

STABLES AND STABLE FITTINGS. By .W. Miles. Imp. 8vo. with 13 Plates, $15 s$.

THE HORSE'S FOOT, AND HOW TO KEEP IT SOUND. By W. Miles. Imp. 8ro. Woodcuts, $12 s .6 d$.

A PLAIN TREATISE ON HORSE-SHOEING. By W. Miles. Post 8 ro. Woodcuts, $2 s .6 d$.

REMARKS ON HORSES' TEETH, addressed to Purchasers. By W. Mures. Post 8ro. 1s, $6 d$.

THE OX, his Diseases and their Treatment; with an Essay on Parturition in the Cow. By J. R. Dobson, M.R.C.V.S. Crown 8ro. Illustrations, $7 s .6 d$.

London, LONGMANS \& CO. 
Websion y Medicine

Cumm: $20 \quad+\ldots$ yedicine at

Tuits:

200 Wos: 31 Jav

North Grafton, NA 01536 


